University of Louisville

ThinkIR: The University of Louisville's Institutional Repository

Electronic Theses and Dissertations

7-2018

\title{
Tooling for injection molding using laser-powder bed fusion.
}

\author{
Mohith Ram Buxani
}

University of Louisville

Follow this and additional works at: https://ir.library.louisville.edu/etd

Part of the Industrial Engineering Commons, Mechanical Engineering Commons, and the Other Engineering Commons

\section{Recommended Citation}

Buxani, Mohith Ram, "Tooling for injection molding using laser-powder bed fusion." (2018). Electronic Theses and Dissertations. Paper 3001.

https://doi.org/10.18297/etd/3001

This Master's Thesis is brought to you for free and open access by ThinkIR: The University of Louisville's Institutional Repository. It has been accepted for inclusion in Electronic Theses and Dissertations by an authorized administrator of ThinkIR: The University of Louisville's Institutional Repository. This title appears here courtesy of the author, who has retained all other copyrights. For more information, please contact thinkir@louisville.edu. 
TOOLING FOR INJECTION MOLDING USING LASER-POWDER BED FUSION

By

Mohith Ram Buxani

A Thesis

Submitted to the Faculty of the

J. B. Speed School of Engineering of University of Louisville

In Partial Fulfillment of the Requirements

for the Degree of

Master of Engineering

in Industrial Engineering

Department of Industrial Engineering

University of Louisville

Louisville, Kentucky

July 2018 
Copyright 2018 by Mohith Ram Buxani

All Rights Reserved 

TOOLING FOR INJECTION MOLDING USING LASER-POWDER BED FUSION

\author{
By
}

Mohith Ram Buxani

A Thesis Approved on

July 20, 2018

By the following Thesis Committee:

Thesis Director

Sundar V. Atre

John Usher

Erin Gerber 


\section{DEDICATION}

This thesis or dissertation is dedicated to my family

To my father, Ram Mohanlal Buxani

To my mother, Sonam Ram Buxani

To my sister, Jasmina Ram Buxani

who have provided me with all the support to strive for continuous improvement 


\section{ACKNOWLEDGMENTS}

Firstly, I would like to thank my mentor, Dr. Sundar V. Atre, for providing me with an uncountable number of opportunities that have allowed me to grow personally, as well as professionally. His guidance, perseverance, and motivation pushed me to strive for continuous improvement. Without him, this study would have not been possible.

I would like to thank the Materials Innovation Guild (MIG) group, for all the time and support they have invested in this study. I would like to thank Harish Irrinki, who has been a lab colleague and a friend guiding me throughout the journey of this project. Furthermore, his experience and lessons have taught me a lot. I would like to thank Dr. Kunal Kate, Bushan Bandiwadekar, Subrata Deb Nath, and Abdullah Abdulmogith, for the support and technical knowledge provided during this study.

I would like to thank Max Gatsche and John Ballaro from Amaray Plastics, Michael Rodenberg and Ron Sherman from Murakami, and Donnie Brockman from Plastic Products Co for providing various hours of machining and testing of the molds in this study. I would like to thank Srikar Vallury and Alex Baker for the technical support in using the Moldex3D software. I would like to thank Joyce Yeung from GE Concept Laser for the fabrication of the molds in this study. I would like to thank other collaborators that enabled this study, such as Walmart Foundation for the funding, MTI Albany for mold fabrication, and North American Hoganas for providing the powders. 


\begin{abstract}
TOOLING FOR INJECTION MOLDING USING LASER-POWDER BED FUSION
\end{abstract}

\author{
Mohith R. Buxani
}

July 20, 2018

Laser-Powder Bed Fusion (L-PBF) has been considered for some time by the injection molding industry for the fabrication of tooling for injection molding in order to address large lead times and costs for tool-making. Computer-aided simulations are also routinely used to evaluate new part and mold designs as well as understanding the effects of material compositions and processing conditions on part quality and overall productivity. However, there remains a significant need to integrate the perspectives from injection molding, 3D printing, metal powders, and component design and process simulation to better utilize LPBF for fabricating tooling required for injection molding. The present research addressed this need and built a supply-chain collaboration that used a combination of experiments and modeling to evaluate the performance of L-PBF fabricated molds as a function of machining, part design, simulation tools, material composition and conformal cooling channels. The results helped advance the understanding on the opportunities and barriers in the design and fabrication of tooling for injection molding using L-PBF. 


\section{TABLE OF CONTENTS}

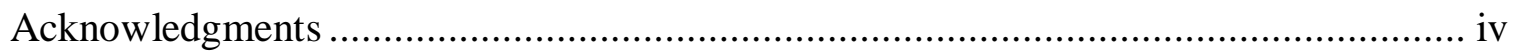

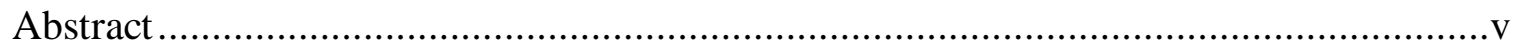

List Of Figures ...................................................................................... vii

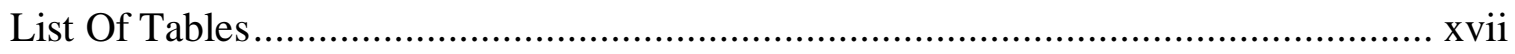

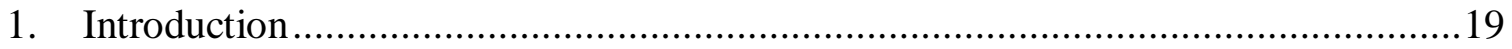

2. Evaluation Of Laser-Powder Bed Fusion (L-PBF) Fabricated Molds For Plastic

Injection Molding And Mold-Filling Simulations ...........................................28

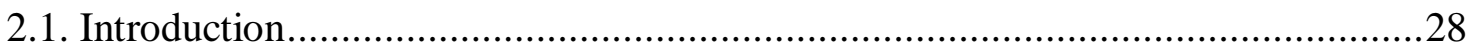

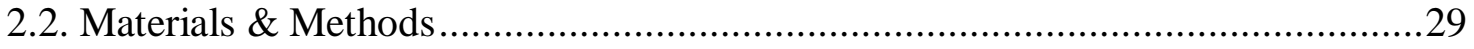

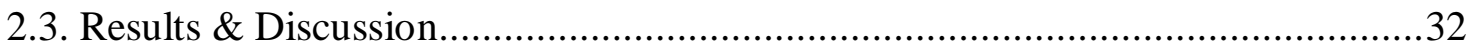

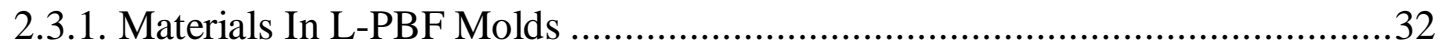

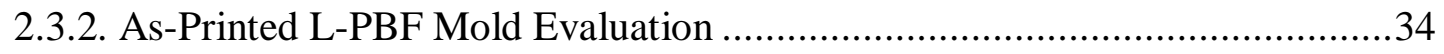

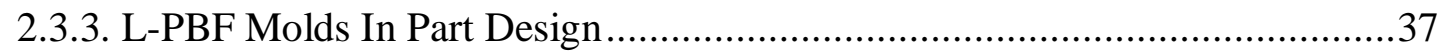

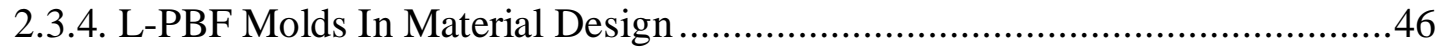

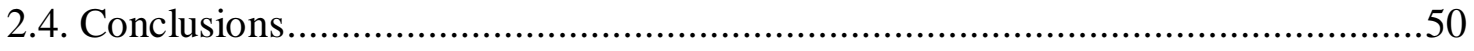


3. Laser-Powder Bed Fusion Fabricated Tooling For Plastic Injection Molding With

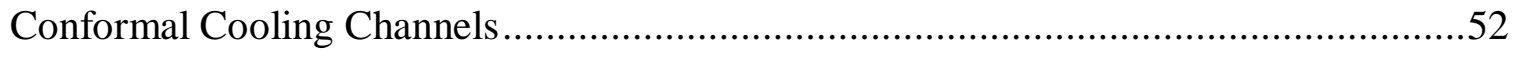

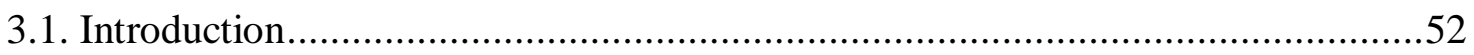

3.2. Materials \& Methods ....................................................................................53

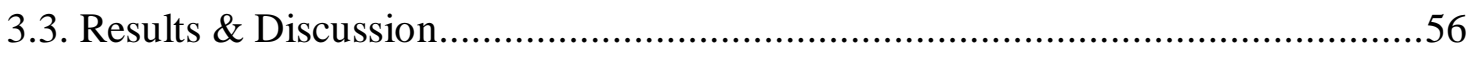

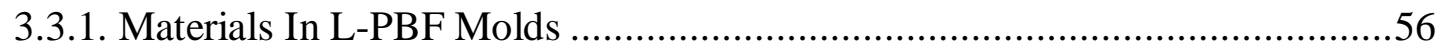

3.3.2. As-Printed L-PBF Mold Evaluation ...................................................57

3.3.3. Laser-Powder Bed Fusion Fabricated Molds In Machining Operations .........59

3.3.4. Laser-Powder Bed Fusion Fabricated Molds In Part Design ........................63

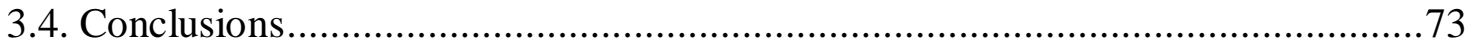

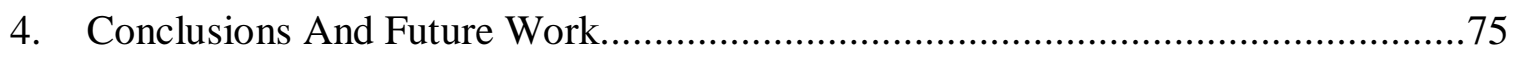

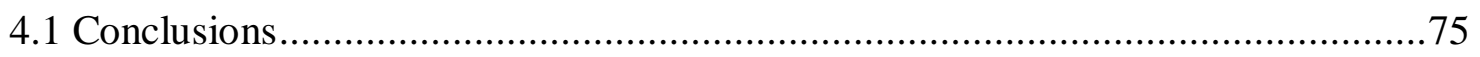

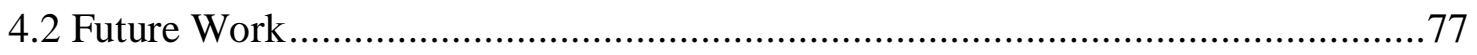

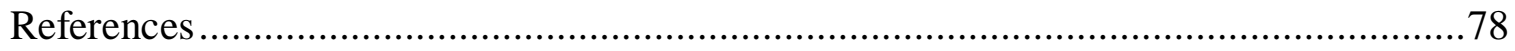

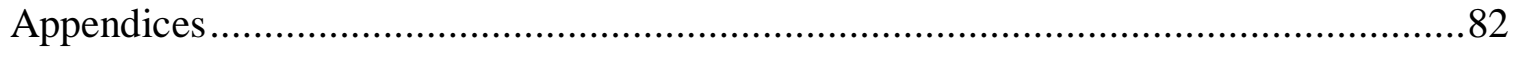

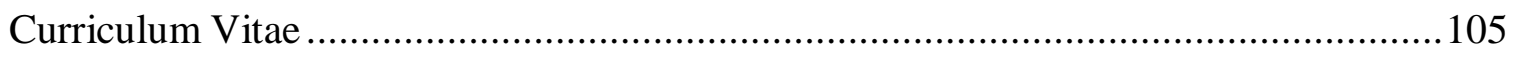




\section{LIST OF FIGURES}

Figure 1.1.1 Processing cycle for plastic injection molding [4] ...............................19

Figure 1.2 Proessing cycle fo Laser-Powder Bed Fusion (L-PBF) [12] .......................20

Figure 1.3 Supply chain for the fabrication of tooling for injection molding .................22

Figure 1.4 Materials for L-PBF fabricated mold as a tooling materials review, L-PBF parts

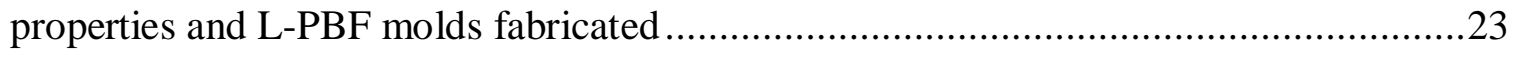

Figure 1.5 Material development studies by Materials Innovation Guild (MIG)[29]......23

Figure 1.6 Tooling for injection molding using L-PBF with multiple materials [30-33].24

Figure 1.7 Mold evaluation for L-PBF fabricated molds using experiments and simulations to examine part design, material design, machining and conformal cooling channels .....25

Figure 2.1 (a) Mold design, (b) As-printed mold using L-PBF process, (c) post-machined mold with 5mm mold depth, (d) Post-machined mold with laser scanning microscopy...34 Figure 2.2 (a) Injection molded part using the as-printed mold (top-view), (b) Injection molded part using the post-machined mold (top-view)

Figure 2.3 (a) Deformation analysis for molded part with $5 \mathrm{~mm}$ part thickness (Keyence microscope), (b) Deformation analysis for experiments with $3 \mathrm{~mm}$ part thickness (Keyence microscope) 37

Figure 2.4 (a) Injection molded part using the machined mold with $5 \mathrm{~mm}$ mold depth (sideview), (b) Injection molded part using the machined mold with $3 \mathrm{~mm}$ mold depth (sideview) .38 
Figure 2.5 Mold-filling simulations for sink mark using: (a) mold with $5 \mathrm{~mm}$ cavity depth (rear-view), (b) mold with 3 mm cavity depth (rear-view). .38

Figure 2.6 (a) Injection molded part using the machined mold with $5 \mathrm{~mm}$ mold depth (rearview), (b) Injection molded part using the machined mold with $3 \mathrm{~mm}$ mold depth (rearview) 39

Figure 2.7 (a) Simulation plot of sink marks using the $5 \mathrm{~mm}$ mold cavity with cooling times: 12, 40, and $60 \mathrm{~s}$, (b) Experimental plot of sink marks for the $5 \mathrm{~mm}$ mold cavity with cooling times: 12,40 , and $60 \mathrm{~s}$

Figure 2.8 (a) Simulation plot of sink marks for the $3 \mathrm{~mm}$ mold cavity with cooling times: 12,20, and $40 \mathrm{~s}$, (b) Experimental plot of sink marks for the $3 \mathrm{~mm}$ mold cavity with cooling times: 12,20 , and $40 \mathrm{~s}$. .40 Figure 2.9 Mold-filling simulations for warpage using: (a) mold with $5 \mathrm{~mm}$ cavity depth (side-view), (b) mold with 3 mm cavity depth (side-view)

Figure 2.10 (a) Injection molded part using the machined mold with $5 \mathrm{~mm}$ mold depth (side-view), (b) Injection molded part using the machined mold with $3 \mathrm{~mm}$ mold depth (side-view)

Figure 2.11 (a) Simulation plot of warpage for the $5 \mathrm{~mm}$ mold cavity with cooling times: 12, 40, and $60 \mathrm{~s}$, (b) Experimental plot of warpage for the $5 \mathrm{~mm}$ mold cavity with cooling times: 12,40 , and $60 \mathrm{~s}$ .43 Figure 2.12 (a) Simulation plot of warpage for the $3 \mathrm{~mm}$ mold cavity with cooling times: 12, 20, and $40 \mathrm{~s}$, (b) Experimental plot of warpage for the $3 \mathrm{~mm}$ mold cavity with cooling times: 12,20 , and $40 \mathrm{~s}$. .43 
Figure 2.13 (a) Deformation analysis for experiments with $5 \mathrm{~mm}$ part thickness (Keyence microscope), (b) Warpage analysis for experiments with $3 \mathrm{~mm}$ part thickness (Keyence microscope) .44

Figure 2.14 Mold-filling simulations for frozen layer ratio using: (a) mold with $5 \mathrm{~mm}$ cavity depth (back-view), (b) mold with 3 mm cavity depth (back-view).....

Figure 2.15 Mold-filling simulations for melt regions using: (a) mold with $5 \mathrm{~mm}$ cavity depth (back-view), (b) mold with 3 mm cavity depth (back-view) .46

Figure 2.16 Injection molded parts using the machined mold with $3 \mathrm{~mm}$ mold depth (sideview): (a) 0 wt. \% BA, (b) 1 wt. \% BA, (c) 2 wt. \% BA .47

Figure 2.17 (a) Simulation plot of sink depth using the $3 \mathrm{~mm}$ mold cavity with: 0,1 , and 2 wt. \% BA, (b) Experimental plot of sink depth using the $3 \mathrm{~mm}$ mold cavity with: 0, 1, and 2 wt. $\%$ BA.

Figure 2.18 Sink mark and warpage analysis using a laser scanning microscope for experiments with $3 \mathrm{~mm}$ mold cavity at: (a) 0 wt. \% BA, (b) 1 wt. $\%$ BA, (c) 2 wt. \% BA

Figure 2.19 Main effects plot for means of sink marks with 3 replicates at (a) Location 1,

(b) Location 2, (c) Location 3.

Figure 2.20 Simulation plot of warpage using the $3 \mathrm{~mm}$ mold cavity with: 0,1 , and 2 wt.

$\%$ BA .50

Figure 3.1 (a) Core-side mold design, (b) Cavity-side mold design, (c) Cavity-side mold design with conformal cooling at $8 \mathrm{~mm}$ depth, (d) Cavity-side mold design with conformal cooling channels at $4 \mathrm{~mm}$ depth .57 
Figure 3.2 (a) As-printed core-side mold with conformal cooling channels at $8 \mathrm{~mm}$ depth, (b) As-printed cavity-side mold design with conformal cooling channels at $8 \mathrm{~mm}$ depth, (c) As-printed cavity-side mold design with conformal cooling channels at $4 \mathrm{~mm}$ depth 58 Figure 3.3 Print defects (a) Porosity in L-PBF fabricated molds, (b) Delamination ........59 Figure 3.4 (a) Machined core-side mold with conformal cooling channels at $8 \mathrm{~mm}$ depth, (b) Machined cavity-side mold design with conformal cooling channels at $8 \mathrm{~mm}$ depth, (c) Machined cavity-side mold design with conformal cooling channels at $4 \mathrm{~mm}$ depth ......60

Figure 3.5 (a) Part drawing, (b) Injection molded parts ..........................................61 Figure 3.6 (a) Core-side mold design with 3 ejector pin design, (b) Injection molded part using the 3 ejector pin mold design, (c) Core-side mold design with 6 ejector pin design, (d) Injection molded part using the 6 ejector pin mold design 62 Figure 3.7 (a) Core-side mold with draft angle issues, (b) Injection molded part with defects caused by draft angle issues, (c) Injection molded part with improved draft angles

Figure 3.8 Simulation mesh of the part with: (a) No conformal cooling channels, (b) Conformal cooling channels, (c) Conformal cooling channels at $8 \mathrm{~mm}$ depth, (d) Conformal cooling channels at $4 \mathrm{~mm}$ depth 64

Figure 3.9 (a) Simulation mold-filling behavior, (b) Experimental mold-filling behavior .64

Figure 3.10 Simulations with sink mark results at condition 1 using (a) No conformal cooling channels, (b) Conformal cooling channels at $8 \mathrm{~mm}$ from the mold cavity, (c) Conformal cooling channels at $4 \mathrm{~mm}$ from the mold cavity .65 
Figure 3.11 Sink mark locations on experimental parts using L-PBF fabricated mold with conformal cooling channels at $4 \mathrm{~mm}$ depth, conformal cooling channels at $8 \mathrm{~mm}$ depth, and no conformal cooling channels: (a) Location 1, (b) Location 2, (c) Location 3 crosssection .66

Figure 3.12 Simulation plot with sink mark defects using (a) No conformal cooling channels, (b) Conformal cooling channels at $8 \mathrm{~mm}$ from the mold cavity, (c) Conformal cooling channels at $4 \mathrm{~mm}$ from the mold cavity

Figure 3.13 Simulations with frozen layer results at Run 1 using (a) No conformal cooling channels, (b) Conformal cooling channels at $8 \mathrm{~mm}$ from the mold cavity, (c) Conformal cooling channels at $4 \mathrm{~mm}$ from the mold cavity . .68 Figure 3.14 Simulations with surface temperature results at Run 1 using (a) No conformal cooling channels, (b) Conformal cooling channels at $8 \mathrm{~mm}$ from the mold cavity, (c) Conformal cooling channels at $4 \mathrm{~mm}$ from the mold cavity 69 Figure 3.15 (a) Simulation results of surface temperature and internal temperature at run 1 (b) Simulations plot with difference in temperature at all conditions using no conformal cooling channels, conformal cooling channels at $8 \mathrm{~mm}$ depth, and $4 \mathrm{~mm}$ depth .70 Figure 3.16 Simulations with cooling temperature results after a cooling time of $10 \mathrm{~s}$ using (a) No conformal cooling channels, (b) Conformal cooling channels at $8 \mathrm{~mm}$ from the mold cavity, (c) Conformal cooling channels at $4 \mathrm{~mm}$ from the mold cavity .71 Figure 3.17 Simulations with cooling temperature results after a cooling time of $25 \mathrm{~s}$ using (a) No conformal cooling channels, (b) Conformal cooling channels at $8 \mathrm{~mm}$ from the mold cavity, (c) Conformal cooling channels at $4 \mathrm{~mm}$ from the mold cavity..... 71 
Figure 3.18 Simulations with heat flux results at Run 1 using (a) No conformal cooling channels, (b) Conformal cooling channels at $8 \mathrm{~mm}$ from the mold cavity, (c) Conformal cooling channels at $4 \mathrm{~mm}$ from the mold cavity . .72

Figure 3.19 In-stress on experimental parts using L-PBF fabricated mold with (a) conformal cooling channels at $4 \mathrm{~mm}$ depth, (b) conformal cooling channels at $8 \mathrm{~mm}$ depth, (c) No conformal cooling channels .73 Figure A. 1 (a) PVT graph for thermoplastic polypropylene, (b) PVT graph for high-impact polystyrene .82 Figure A. 2 (a) Viscosity graph for thermoplastic polystyrene, (b) Viscosity graph for highimpact polystyrene. .83 Figure C. 1 (a) Density plot for experimental parts from the as-printed mold, (b) Weight plot for experimental parts from the as-printed mold . .86 Figure C. 2 (a) Density plot for experimental parts from the machined mold with $5 \mathrm{~mm}$ cavity thickness, (b) Weight plot for experimental parts from the machined mold with 5 mm cavity thickness .87 Figure C. 3 (a) Density plot for experimental parts from the machined mold with $3 \mathrm{~mm}$ cavity thickness, (b) Weight plot for experimental parts from the machined mold with 3 mm cavity thickness .87

Figure C. 4 (a) Density plot for experimental parts with blowing agents from the machined mold with $3 \mathrm{~mm}$ cavity thickness, (b) Weight plot for experimental parts with blowing agents from the machined mold with $3 \mathrm{~mm}$ cavity thickness .88

Figure D.1 3D mesh using Moldex3D designer platform for (a) part with $5 \mathrm{~mm}$ wall thickness, (b) part with 3 mm wall thickness. .89 
Figure D.2 (a) Simulation plot of sink marks using the $5 \mathrm{~mm}$ mold cavity with Melt Temperatures $\left({ }^{\circ} \mathrm{C}\right): 185,204,226$, (b) Experimental plot of sink marks for the $5 \mathrm{~mm}$ mold cavity with Melt Temperatures $\left({ }^{\circ} \mathrm{C}\right): 185,204,226$....... .89

Figure D.3 (a) Simulation plot of sink marks using the $3 \mathrm{~mm}$ mold cavity with Injection Velocity (mm/s): 12.7, 25.4, 50.4, (b) Experimental plot of warpage for the $3 \mathrm{~mm}$ mold

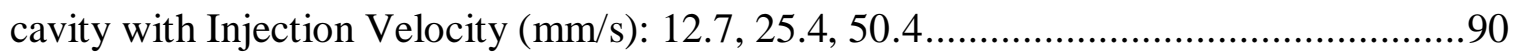
Figure D.4 (a) Simulation plot of warpage using the $5 \mathrm{~mm}$ mold cavity with Melt Temperatures $\left({ }^{\circ} \mathrm{C}\right): 185,204,226$, (b) Experimental plot of warpage for the $5 \mathrm{~mm}$ mold cavity with Melt Temperatures $\left({ }^{\circ} \mathrm{C}\right): 185,204,226$. .90 Figure D.5 (a) Simulation plot of warpage using the $3 \mathrm{~mm}$ mold cavity with Injection Velocity (mm/s): 12.7, 25.4, 50.4, (b) Experimental plot of warpage for the $3 \mathrm{~mm}$ mold cavity with Injection Velocity $(\mathrm{mm} / \mathrm{s}): 12.7,25.4,50.4$ 91 Figure D.6 Mold-filling simulation results for cooling time to reach eject temperature using: (a) mold with $5 \mathrm{~mm}$ cavity depth (front-view), (b) mold with $3 \mathrm{~mm}$ cavity depth (front-view) . .91

Figure D.7 Mold-filling simulation results for volumetric shrinkage using: (a) mold with 5 mm cavity depth (front-view), (b) mold with $3 \mathrm{~mm}$ cavity depth (front-view)..... .92 Figure D.8 Mold-filling simulation results for air trap using: (a) mold with $5 \mathrm{~mm}$ cavity depth (front-view), (b) mold with $3 \mathrm{~mm}$ cavity depth (front-view) ............................92 Figure D.9 Analysis of variance for means of sink marks at sink Location 1 ...........93 Figure D.10 Analysis of variance for means of sink marks at sink Location 2 ...........93 Figure D.11 Analysis of variance for means of sink marks at sink Location 3 ...........93 
Figure F.1 (a) Simulation setup of part design, (b) Simulation of part design with conformal cooling channels at $8 \mathrm{~mm}$ depth, (c) Simulation part design with conformal cooling channels at $4 \mathrm{~mm}$ depth, (d) Simulation part design with none. .95 Figure F.2 (a) Simulation process interface setup for mold material, (b) Simulation process interface setup for molded part material .95 Figure F.3 (a) Simulation process interface setup for filling/packing settings, (b) Simulation process interface setup for flow rate profile, (c) Simulation process interface setup for injection pressure, (d) Simulation process interface setup for packing pressure .96 Figure F.4 (a) Simulation process interface setup for cooling settings, (b) Simulation process interface setup for conformal cooling channels . .96 Figure G.1 Part design for the L-PBF cavity-side and core-side molds in Chapter 3 (a) Front-view, (b) Side-view, (c) Back view

Figure G.2 (a) Density plot for experimental parts from the machined mold with no conformal cooling channels, (b) Weight plot for experimental parts from the machined mold with no conformal cooling channels .98 Figure G.3 (a) Density plot for experimental parts from the machined mold with conformal cooling channels at $8 \mathrm{~mm}$ depth, (b) Weight plot for experimental parts from the machined mold with conformal cooling channels at $8 \mathrm{~mm}$ depth .99 Figure G.4 (a) Density plot for experimental parts from the machined mold with conformal cooling channels at $4 \mathrm{~mm}$ depth, (b) Weight plot for experimental parts from the machined mold with conformal cooling channels at $4 \mathrm{~mm}$ depth

Figure H. 1 (a) 3D Printed core-side mold, (b) 3D Printed cavity-side mold .100 
Figure H. 2 (a) 3D Printed molds for design evaluation, (b) 3D Printed molds with

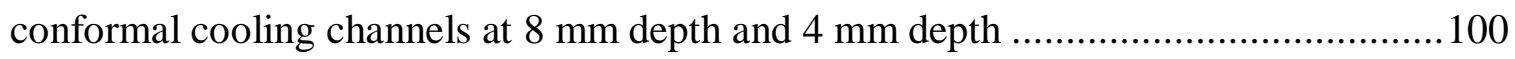

Figure H. 3 (a) Die-lock condition, (b) Cavity and core interface testing ...................... 101

Figure H. 4 Injection molding press for experimental trials: Cincinnati Milacron (CML)

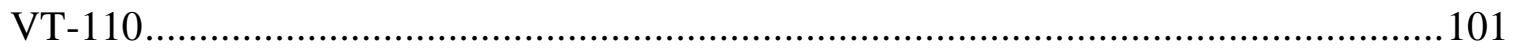

Figure H. 5 (a) Simulation part design with warpage defects (b) Simulation plot with warpage defects for all 3 runs with no conformal cooling channels, conformal cooling channels at $8 \mathrm{~mm}$ depth and conformal cooling channels at $4 \mathrm{~mm}$ depth 102

Figure H. 6 Simulations with surface temperature results at run 1 using (a) No conformal cooling channels, (b) Conformal cooling channels at $8 \mathrm{~mm}$ from the mold cavity, (c) Conformal cooling channels at $4 \mathrm{~mm}$ from the mold cavity 102

Figure H. 7 Simulations with surface temperature results at run 1 using (a) No conformal cooling channels, (b) Conformal cooling channels at $8 \mathrm{~mm}$ from the mold cavity, (c) Conformal cooling channels at $4 \mathrm{~mm}$ from the mold cavity 103

Figure H. 8 Simulations with packing volumetric shrinkage results at run 1 using (a) No conformal cooling channels, (b) Conformal cooling channels at $8 \mathrm{~mm}$ from the mold cavity, (c) Conformal cooling channels at $4 \mathrm{~mm}$ from the mold cavity 103

Figure H. 9 Simulations with cooling channel efficiency results at run 1 using (a) Conformal cooling channels at $8 \mathrm{~mm}$ from the mold cavity, (b) Conformal cooling channels at $4 \mathrm{~mm}$ from the mold cavity 104

Figure H. 10 Simulations with coolant Reynolds number results at run 1 using (a) Conformal cooling channels at $8 \mathrm{~mm}$ from the mold cavity, (b) Conformal cooling channels at $4 \mathrm{~mm}$ from the mold cavity. 104 


\section{LIST OF TABLES}

Table 2.1 Process conditions for injection molding using as-printed and machined mold 31

Table 2. 2 Taguchi matrix for injection molding using machined mold with $3 \mathrm{~mm}$ cavity depth 32

Table 2. 3 Physical and mechanical properties of 17-4 PH stainless steel fabricated by L$\mathrm{PBF}$ 33

Table 2. 4 Surface roughness measurements of the as-printed mold and machined mold.

Table 2. 5 P-values from the Analysis Of Variance (ANOVA) for sink marks at Location 1, Location 2, and Location 3.

Table 3. 1 Process conditions for injection molding using the core and cavity-side molds .55

Table 3. 2 Properties of 17-4 PH stainless steel fabricated by L-PBF .56

Table 3. 3 Surface roughness measurements $(\mu \mathrm{m})$ of the as-printed mold and machined mold .61

Table A. 1 Physical and mechanical properties for part material used for injection molding trials in Chapter 2 .82

Table A. 2 Physical and mechanical properties for part material used for injection molding trials in Chapter 3 
Table B. 1 Constant process parameters for all experimental trials

Table B. 2 Processing conditions using the as-printed mold

Table B. 3 Processing conditions using the machined mold with $5 \mathrm{~mm}$ cavity depth ......84

Table B. 4 Processing conditions using the machined mold with $3 \mathrm{~mm}$ cavity depth ......85

Table C. 1 Dimensions of the injection molded parts with $5 \mathrm{~mm}$ part thickness, $3 \mathrm{~mm}$ part thickness, and $3 \mathrm{~mm}$ part thickness with blowing agent ............................. 86

Table E. 1 Constant process parameters for all experimental trials.....................94

Table E. 2 Processing conditions using the machined mold with conformal cooling

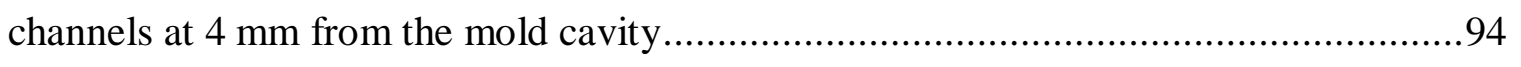

Table E. 3 Processing conditions using the machined mold with conformal cooling channels at $8 \mathrm{~mm}$ from the mold cavity and no conformal cooling channels.................94 Table G. 1 As-printed and machined mold density and dimensions for the core-side, cavityside 1 and cavity-side 2 molds............................................... 97

Table G. 2 Dimensions of the injection molded parts from using the cavity side mold with no conformal cooling channels, conformal cooling channels at $8 \mathrm{~mm}$ depth and conformal

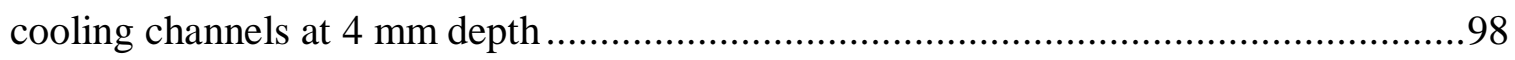




\section{CHAPTER 1}

\section{INTRODUCTION}

Plastic injection molding is a $\$ 284$ billion dollar global industry for the manufacturing of consumer plastic products [1]. Injection molding is one of the most exploited manufacturing processes for the mass-production of plastic parts [2]. In a typical injection molding cycle, polymeric material is inserted into a heated barrel, which melts the material and injects it into the mold. The mold is clamped under pressure with a temperature under the thermoplastic melt point, allowing the part to solidify and eject after cooling, as shown in Figure 1.1 [3].
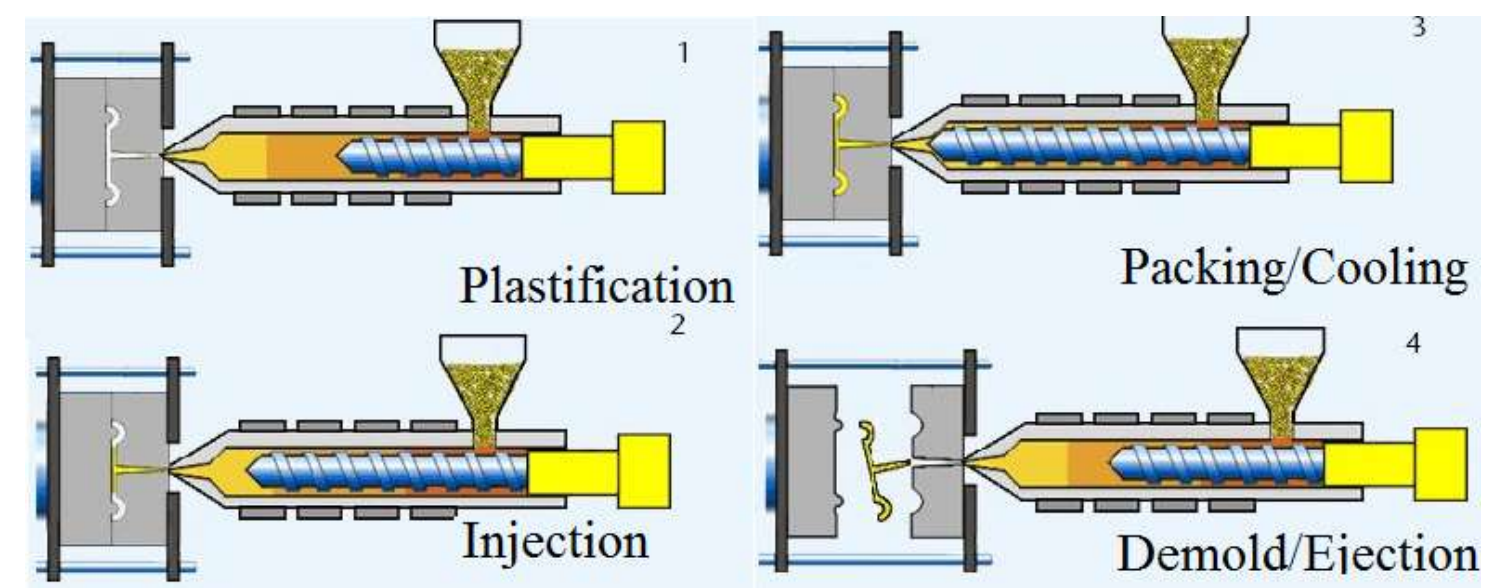

Figure 1.1.1 Processing cycle for plastic injection molding [4]

There is an increasing demand in various consumer industries for plastic products, mainly packaging, automotive, electrical and electronics, home appliances, and medical devices 
[5]. This forces the industry to accelerate their tool-making process to satisfy customerneeds. The tooling for the injection molding industry is commonly fabricated using conventional methods, such as Computer Numeric Control (CNC), high-speed milling, or lathe $[6,7]$. However, major bottlenecks in the injection molding industry have always been high tooling costs and large lead times for tool-making [8]. The injection molding industry is beginning to acquire other routes for tool-making [9-11]. Additive Manufacturing (AM) processes, such as Laser-Powder Bed Fusion (L-PBF) have the potential to approach some of these bottlenecks. In L-PBF, a high-energy laser melts fine layers of powder, which is then cooled. This process repeats for all layers until the part is created, as shown in Figure 1.2.

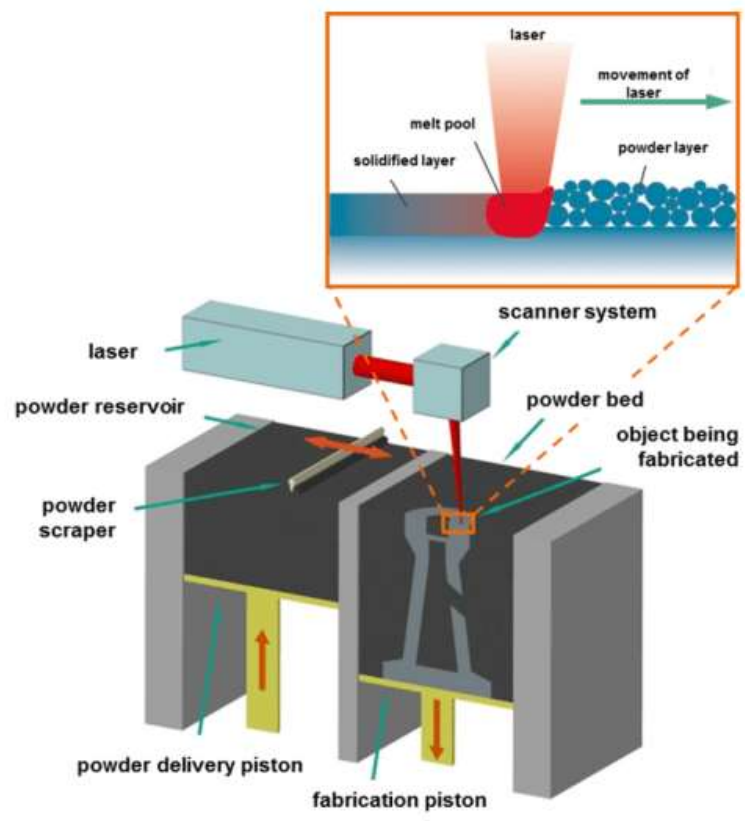

Figure 1.2 Processing cycle for Laser-Powder Bed Fusion (L-PBF) [12]

Additive manufacturing is a disruptive technology with annual sales expected to reach $\$ 12.1$ billion with a growth of 35\% during 2018 [13]. The fabrication of tooling for 
injection molding using L-PBF provides design freedom, while decreasing build times and cost [14-16]. Additionally, 3D printing manufacturers could fabricate tooling for injection molding with a variety of materials, such as stainless steels, tool steels, and aluminum alloys [17].

Mold CAE services provide platforms to run simulations for the injection molding industry. Simulations allow the evaluation of molding uncertainties and part design for the fabrication of tooling using L-PBF process. Additionally, simulation platforms allow the verification of processing conditions for injection molding trials using the L-PBF fabricated molds. There are multiple previous studies that used computer-aided simulations to evaluate their part design and processing conditions for injection molding [2, 18-25].

3D printing manufacturers, injection molding companies, and CAE simulation companies tool-makers hold a complementary set of expertise in the fabrication of tooling for injection molding. There are various studies that approach the 3D printing route for the fabrication of tooling for injection molding [15, 26, 27]. Additionally, there are studies that involve the use of simulations for the evaluation of part-design [25] [28] [23]. However, there were minimal studies found that integrated these perspectives together and evaluated the performance of L-PBF fabricated molds. Therefore, this study has taken on the challenge of integrating the individual expertise of each industry to create a supply chain collaboration, as shown on Figure 1.3. The supply chain collaboration enabled the evaluation of the performance of L-PBF fabricated tooling used in this study. 


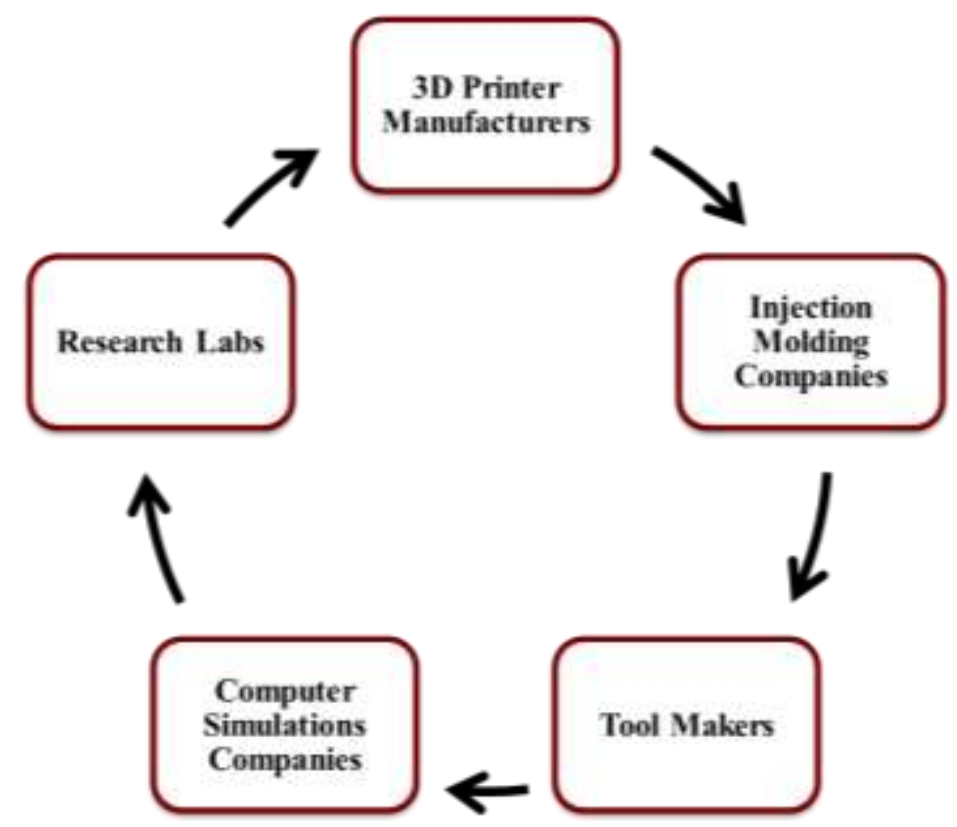

Figure 1.3 Supply chain for the fabrication of tooling for injection molding

The focus of this study is the evaluation of L-PBF fabricated molds. However, the evaluation of the molds was enabled by the research conducted by this group to study the materials for L-PBF molds. The materials section in this project was categorized as follows: materials used to fabricate L-PBF molds, mechanical properties achieved from LPBF molds, and fabrication of L-PBF molds, as shown in Figure 1.4. 


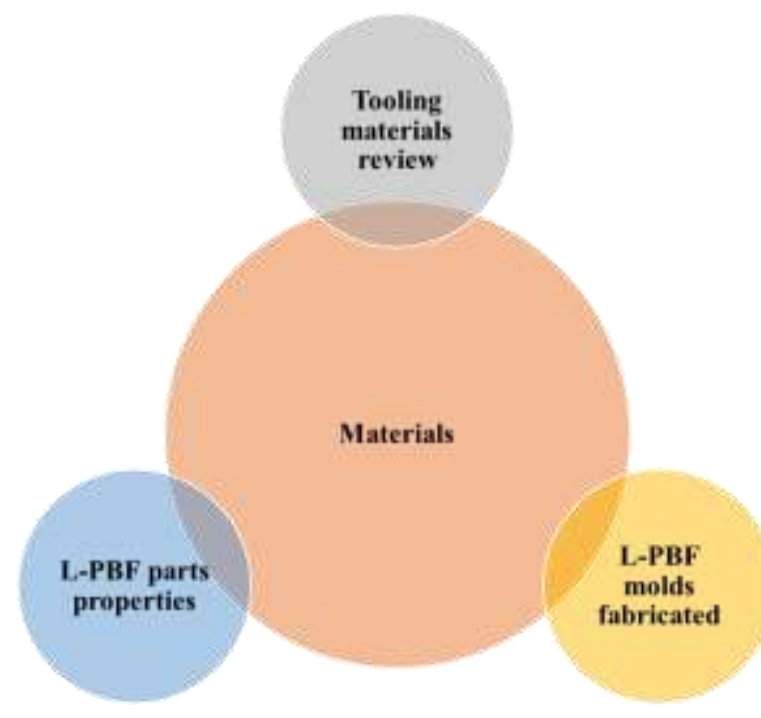

Figure 1.4 Materials for L-PBF fabricated mold as a tooling materials review, L-PBF parts properties and L-PBF molds fabricated

Several research papers have been studied by this group related to material development, as shown on Figure 1.5. The materials studied include P20 tool steel, T15 tool steel, A6 tool steel, 316L stainless steel, 17-4 PH stainless steel, H13 tool steel, M2 tool steel, 420 stainless steel, H10 tool steel and P20 tool steel. This study prioritized 17-4 PH stainless steel.

\section{Total: 120 papers}

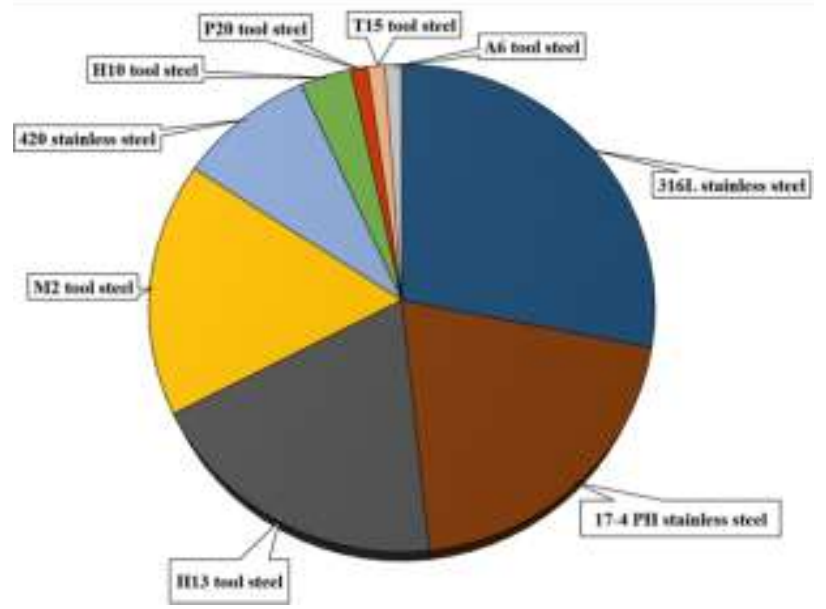

Figure 1.5 Material development studies by Materials Innovation Guild (MIG) [29] 
This research group fabricated multiple tools for injection molding using L-PBF process with different materials achieving good mechanical properties, shown in Figure 1.6. The tools were fabricated using different 3D printing machines, which include 3D Systems Pro X 300, Mlab Cusing R, M2 Dual Laser and EOS M290. The build time for the L-PBF fabricated molds ranged from 12 to 26 hours for tooling with different part-designs. The materials used to fabricate tooling using L-PBF process were 17-4 PH stainless steel gasatomized powder, 17-4 PH stainless steel water-atomized powder, 420 stainless steel gasatomized powder, bronze powder, bronze +420 stainless steel powders. The L-PBF fabricated molds were characterized for surface roughness as a function of material properties and processing conditions. For this study, the tooling for injection molding were fabricated with 17-4 PH stainless steel.

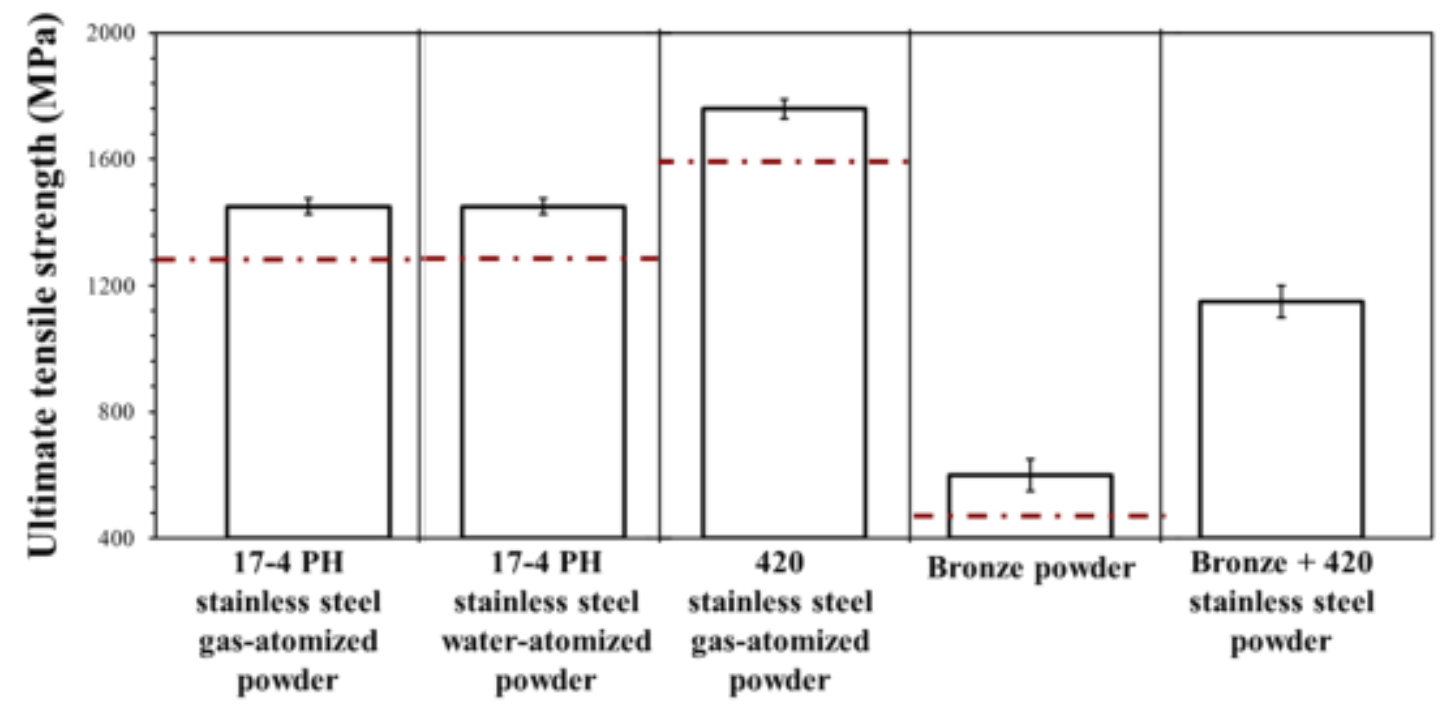

Figure 1.6 Tooling for injection molding using L-PBF with multiple materials [30-33]

As shown in Figure 1.7, this study focuses on evaluating L-PBF fabricated molds using experiments and simulations examining the following categories: post-machining, part- 
design, material design and conformal cooling channels. The results demonstrate the opportunities and barriers in the design and fabrication of tooling for injection molding using L-PBF.

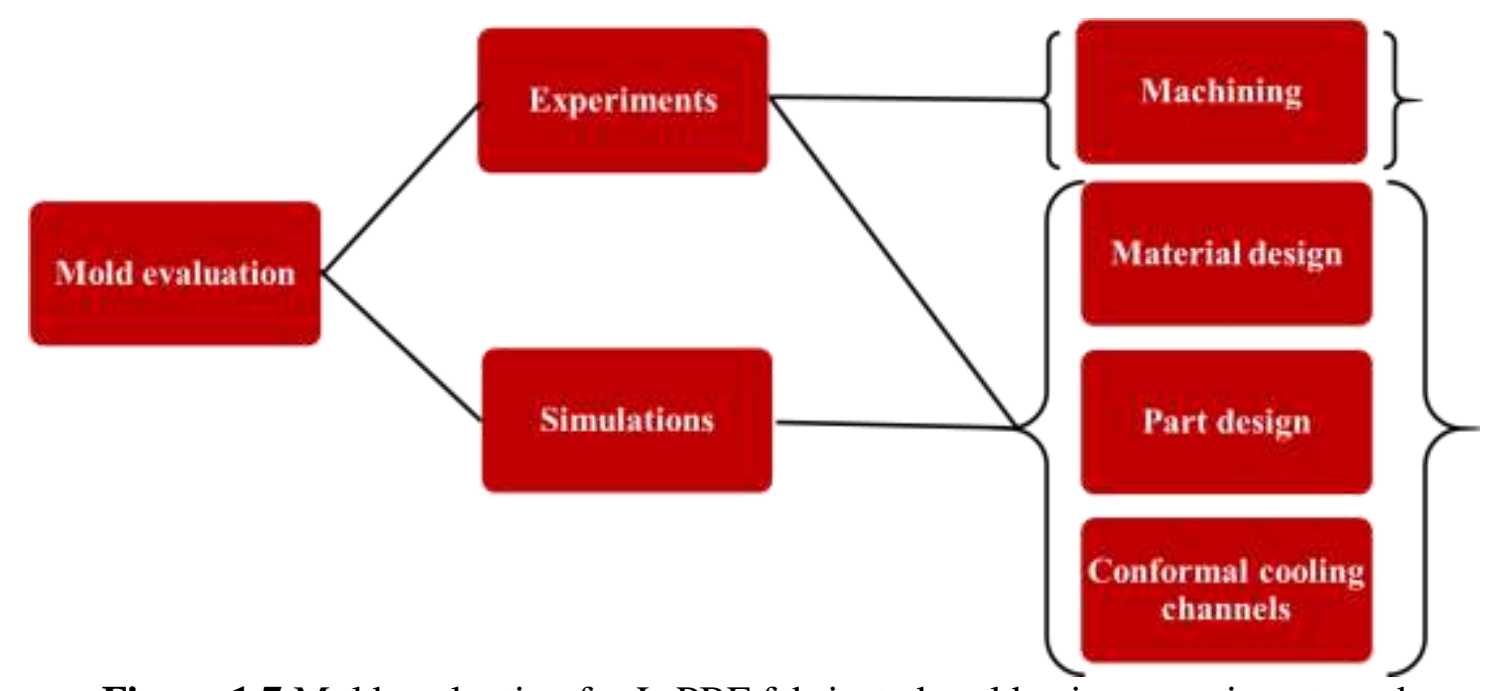

Figure 1.7 Mold evaluation for L-PBF fabricated mold using experiments and simulations to examine material design, simulation tools, machining and conformal cooling channels

Chapter 2 of the thesis presents a study using injection molding experiments and computer-aided simulations to understand the effects of single-sided L-PBF fabricated mold cavities on injection molded part quality and molding material composition. This study also provided a better understanding of the use of L-PBF fabricated molds in evaluating and refining mold-filling simulation platforms and refining material selection. The research study in Chapter 2 was presented at the International Conference on Metal Injection Molding (MIM) in 2017 and 2018 as well as the Additive Manufacturing with Powder Metallurgy (AMPM) Conference in 2017 and 2018. Chapter 2 will be submitted to Materials and Manufacturing Processes journal. 
Chapter 3 presents a study using experiments and computer-aided simulations to evaluate L-PBF fabricated core-and-cavity tooling with conformal cooling channels. The cooling phase plays a vital role in production rate and part quality, consuming $50-80 \%$ of the molding cycle, apart from the filling and packing phases [34]. Hence, cooling channels are used to decrease cooling time by improving temperature uniformity throughout the part. Commonly used in conventional injection mold tooling, traditional cooling channels are straight lines machined into the injection mold tooling. Water flows through the channels at a certain temperature and pressure, improving cycle time and part quality. However, the straight paths cannot provide uniform cooling throughout the tool's cavity design, causing bad part quality and longer cycle times [35]. Conformal cooling channels provide an alternative route that can be fabricated using AM processes. In contrast to conventional channels, conformal cooling channels curve according to the part's geometry to provide better cooling [2], [36]. Due to this, part quality improves using reduced cooling time [27] [37]. In addition, Chapter 3 evaluates the influence of the conformal cooling channels' distance from the tool's cavity surface. The research shown in Chapter $\mathbf{3}$ was presented at the International Conference on Injection Molding (MIM) in 2018 and the Additive Manufacturing with Powder Metallurgy Conference (AMPM) in 2018. Chapter 3 is currently under preparation for submitting to the Materials and Design journal.

Appendix A reports material properties of the thermoplastic resins used to run injection molding trials in Chapter 2 and Chapter 3. Appendix B reports the processing conditions at which the experimental trials and simulations were ran for the part design in Chapter 2. Appendix $\mathbf{C}$ contains the dimensions, density and weights for the experiments and simulations using the as-printed and machined mold from Chapter 2. Appendix D consists 
of experimental and simulation results for the part design from Chapter 2. Appendix EH replicates the outline, but for the results using the part design of Chapter 3.

This research study was funded by Walmart Foundation, alongside with multiple collaborators providing equipment, services and materials: Amaray Plastics (injection molding), Murakami (machining core and cavities), Moldex3D (mold-filling simulation platforms), GE Concept Laser (mold fabrication), MTI Albany (mold fabrication), Plastic Products Co. (injection molding), North American Hoganas (metal powders), the UofL 3D Printing Business Incubator (mold design), and the Materials Innovation Guild at the University of Louisville (L-PBF materials research). 


\section{CHAPTER 2}

\section{EVALUATION OF LASER-POWDER BED FUSION (L-PBF) FABRICATED MOLDS FOR PLASTIC INJECTION MOLDING AND MOLD-FILLING SIMULATIONS}

\subsection{INTRODUCTION}

Plastic injection molding is a $\$ 284$ billion dollar global industry for the manufacturing of consumer plastic products [1]. There is a continuous increasing demand in many consumer industries for plastic products, mainly packaging, automotive, electrical and electronics, home appliances, and medical devices [5]. The tooling for the injection molding industry is commonly fabricated using conventional methods such as computer numeric control (CNC), high-speed milling, or lathe. These technologies fabricate molds with high standards, durability and precision [6, 7]. However, mold-making for injection molding using conventional manufacturing routes still face high tooling costs and large lead times [14].

Additive manufacturing (AM) processes, such as laser-powder bed fusion (L-PBF) have the potential to alleviate some of these drawbacks. L-PBF, also known as selective laser melting (SLM), is an additive manufacturing method that melts the metal powders layer by layer using a laser to form $3 \mathrm{D}$ structures depending on the CAD file $[17,38]$. The fabrication of tooling for injection molding using the L-PBF process could decrease geometric constraints, provide design freedom, while decreasing build times and cost [14- 
16]. In the past, various independent research studies have been reported on tooling for injection mold using the L-PBF process $[15,16,27,37]$. However, to the best of our knowledge, there are no reports in the open literature on the performance of the L-PBF fabricated tooling for injection molding that integrate experiments and mold-filling simulations with changes in injection molded part design and material.

In order to address this gap, the present study was performed to critically evaluate the performance of L-PBF fabricated tooling using experiments and mold-filling simulations as a function of tooling surface roughness, injection molded part design and injection molding material. The results from the mold-filling simulations and experiments presented in this paper clearly demonstrate the opportunities and challenges in the design and fabrication of tooling for injection using L-PBF.

\subsection{MATERIALS \& METHODS}

The mold cavity design selected for the study is an elliptical-shaped keychain with various features, as shown in Figure 2.1a. The diameters for the features on the surface of the part range from $2.87 \mathrm{~mm}$ for the smallest circles to $8.85 \mathrm{~mm}$ for the largest. The thickness of the part's features ranges from $1.92 \mathrm{~mm}$ shortest feature to $3.40 \mathrm{~mm}$ for the largest. The dimensions of the designed mold were $80 \mathrm{~mm}$ in length, $60 \mathrm{~mm}$ in width and $30 \mathrm{~mm}$ in height.

The starting material to fabricate the tooling for injection molding using L-PBF process was 17-4 PH stainless steel powder of median size $\left(D_{50}=13 \mu \mathrm{m}\right)$. Mechanical and corrosion properties in previous research studies performed by our group showed that 17$4 \mathrm{PH}$ stainless can be used as a starting material for the fabrication of injection mold tools 
[39]. The detailed information about the powder characterization can be found in our previous papers [39-42].

The tooling for injection molding, as shown in Figure 2.1b, was fabricated through LaserPowder Bed Fusion process using a 3D Systems ProX 320 machine in Ar atmosphere at Metal Technologies Inc., Albany, OR. The L-PBF fabrication process took 12 hours with the following processing parameters: laser powder of $195 \mathrm{~W}$, scan speed of $1250 \mathrm{~mm} / \mathrm{s}$, layer thickness of $30 \mu \mathrm{m}$, hatch spacing of $50 \mu \mathrm{m}$ and energy density of $104 \mathrm{~J} / \mathrm{mm} 3$ [39].The as-printed mold was subjected to stress relief at a temperature of $650^{\circ} \mathrm{C}$ for 1 hour in air and separated from the build plate using wire electrical discharge machining $(\mathrm{EDM})$.

Characterization for dimensional tolerance and surface roughness of the as-printed mold was performed using Vernier calipers and a surface profilometer, respectively. The asprinted mold was inserted into a master-unit die (MUD) to perform injection molding trials. Several machining operations were performed on the as-printed mold to evaluate its performance as a function of part design. Machining operations such as surface grinding, EDM, milling, drilling and tapping were performed on the as-printed mold to improve the surface finish, draft angles and reduce the cavity depth from $5 \mathrm{~mm}$ to $3 \mathrm{~mm}$. Furthermore, the injection molding tool's performance was evaluated as a function of the as-printed mold, machined mold with $5 \mathrm{~mm}$ cavity depth, machined mold with $3 \mathrm{~mm}$ cavity depth and machined mold with $3 \mathrm{~mm}$ cavity depth using a blowing agent.

The polymer material used for the injection molded trials was Celanese Celstran Polypropylene GF30-05CN01/10. A 45-ton Cincinnati Milacron D-Series 44 (B) injection mold press at Rapid Prototyping Center, University of Louisville was used to run initial 
injection molding trials with the as-printed mold followed by Sumitomo SE180 S at Amaray Plastics using machined molds. The injection molding trials with the as-printed and machined molds were run under the conditions mentioned in Table 2.1.

Table 2.1 Process conditions for injection molding using as-printed and machined mold

\begin{tabular}{|c|c|c|c|}
\hline Type & $\begin{array}{c}\text { Injection pressure } \\
(\mathbf{M P a})\end{array}$ & $\begin{array}{c}\text { Injection velocity } \\
(\mathbf{m m} / \mathbf{s})\end{array}$ & $\begin{array}{c}\text { Cooling time } \\
(\mathbf{s})\end{array}$ \\
\hline As-printed mold & 30,45 & 25 & 12,60 \\
\hline $\begin{array}{c}\text { Machined mold } \\
\text { with 5 mm cavity } \\
\text { depth }\end{array}$ & 30,45 & 25 & $12,40,60$ \\
\hline $\begin{array}{c}\text { Machined mold } \\
\text { with 3 mm cavity } \\
\text { depth }\end{array}$ & 10,14 & 25,13 & $12,15,20,60$ \\
\hline
\end{tabular}

Computer-aided simulations were performed using Moldex3D platform to evaluate the mold-filling behavior of injection molding as a function of cavity dimensions and process conditions. Moldex3D Designer platform was used to mesh the part design and transfer the meshed file to Moldex3D Simulation platform. Moldex3D Simulation platform was used to run simulations and evaluate part quality as a function of sink marks and warpage.

The final injection molding trial in this mold-evaluation study included the use of a chemical blowing agent (endothermic azodicarbonamide, FCX 128112). The chemical blowing agent was used to evaluate its efficacy in reducing sink marks and improving surface finish of injection-molded parts by releasing gas and creating foamed structures inside the part. Table 2.2 shows the process conditions for the injection molding trials with chemical blowing agents using an L-9 Taguchi matrix. Minitab statistical software was 
used to run an Analysis of Variance (ANOVA) to display the most significant factors in the design of experiment.

The weight of the injection molded parts, as shown in Figure 2.2, were characterized using a Mettler Toledo scale and the data was used to compute the part density using the Archimedes principle, at the Materials Innovation Guild, University of Louisville. Part dimensions were measured using Vernier calipers. Part quality, as a function of sink marks and warpage, was measured using a dial indicator and a 3D laser scanning microscope, Keyence VR-3200.

Table 2. 2 Taguchi matrix for injection molding with blowing agents using the machined mold with $3 \mathrm{~mm}$ cavity depth

\begin{tabular}{|c|c|c|c|}
\hline Condition,\# & $\begin{array}{c}\text { Blowing agent } \\
(\mathbf{w t} \text {. })\end{array}$ & $\begin{array}{c}\text { Injection Velocity } \\
(\mathbf{m m} / \mathbf{s})\end{array}$ & $\begin{array}{c}\text { Injection } \\
\text { Pressure (MPa) }\end{array}$ \\
\hline 1 & 0 & 50.8 & 13.8 \\
\hline 2 & 0 & 63.5 & 17.2 \\
\hline 3 & 0 & 76.2 & 20.7 \\
\hline 4 & 1 & 50.8 & 17.2 \\
\hline 5 & 1 & 63.5 & 20.7 \\
\hline 6 & 1 & 76.2 & 13.8 \\
\hline 7 & 2 & 50.8 & 20.7 \\
\hline 8 & 2 & 2.5 & 2.0 \\
\hline 9 & 2 & 3.0 & 2.5 \\
\hline
\end{tabular}

\subsection{RESULTS \& DISCUSSION}

\subsubsection{MATERIALS IN L-PBF MOLDS}

Table 2.3 summarizes the physical and mechanical properties of 17-4 PH stainless steel for injection mold tooling in three conditions: as-printed, heat-treated, and hot isostatic pressing (HIP). 
Table 2. 3 Physical and mechanical properties of 17-4 PH stainless steel used to fabricate tooling

\begin{tabular}{|c|c|c|c|}
\hline Property & $\begin{array}{c}\text { As-printed } \\
{[\mathbf{3 9}],[\mathbf{4 3}],}\end{array}$ & $\begin{array}{c}\text { Heat-treated } \\
{[\mathbf{4 2}]}\end{array}$ & $\begin{array}{c}\text { Hot Isostatic Pressing } \\
{[\mathbf{4 4}]}\end{array}$ \\
\hline $\begin{array}{c}\text { Density } \\
\text { (\% theoretical } \text { ( })^{*}\end{array}$ & $97.5 \pm 0.5$ & $98 \pm 0.5$ & $99.5 \pm 0.3$ \\
\hline $\begin{array}{c}\text { Ultimate tensile strength } \\
(\text { MPa) }\end{array}$ & $950 \pm 50$ & $1300 \pm 30$ & $1450 \pm 20$ \\
\hline $\begin{array}{c}\text { Hardness } \\
(\text { HRC) }\end{array}$ & $28 \pm 2$ & $45 \pm 1$ & $36 \pm 2$ \\
\hline $\begin{array}{c}\text { Elongation } \\
(\%)\end{array}$ & $16 \pm 1$ & $2 \pm 1$ & $11 \pm 1$ \\
\hline
\end{tabular}

* theoretical density: $7.87 \mathrm{~g} / \mathrm{cm}^{3}$ (cast part)

It can be observed that as-printed parts can achieve density values close to heat-treated and HIP-processed parts, ranging between 97-99\%. For parts processed with heat-treatment techniques, ultimate tensile strength ranges between 1430-1470 MPa for HIP parts and 1270-1330 MPa for heat-treated parts. However, as-printed parts achieve a lower ultimate tensile strength of 900-1000 MPa. Hardness is a common mechanical property characterized for steels. HIP and heat-treatment processes strengthens parts to increase the material's hardness. As observed, heat-treatment and HIP causes a decrease in elongation. The present study used the as-printed tooling for mold-evaluation studies, as the strengths and hardness were acceptable for injection molding trials. 


\subsubsection{AS-PRINTED L-PBF MOLD EVALUATION}

Figures 2.1b and 2.1c show the as-printed mold and the post-machined mold fabricated by L-PBF using 17-4 PH stainless steel. In Figure 2.1c, it was observed that the machined mold had a smoother surface finish, compared to the as-printed mold in Figure 2.1b. Additionally, the post-machined mold included extruded boxes around the letter of the cavity, allowing a decrease in feature thickness of the part. Draft angles were also increased to facilitate part ejection. Figure 2.1d shows a laser-scanned microscopic image of the post-machined mold. It can be shown that the design contains various features of multiple shapes and sizes
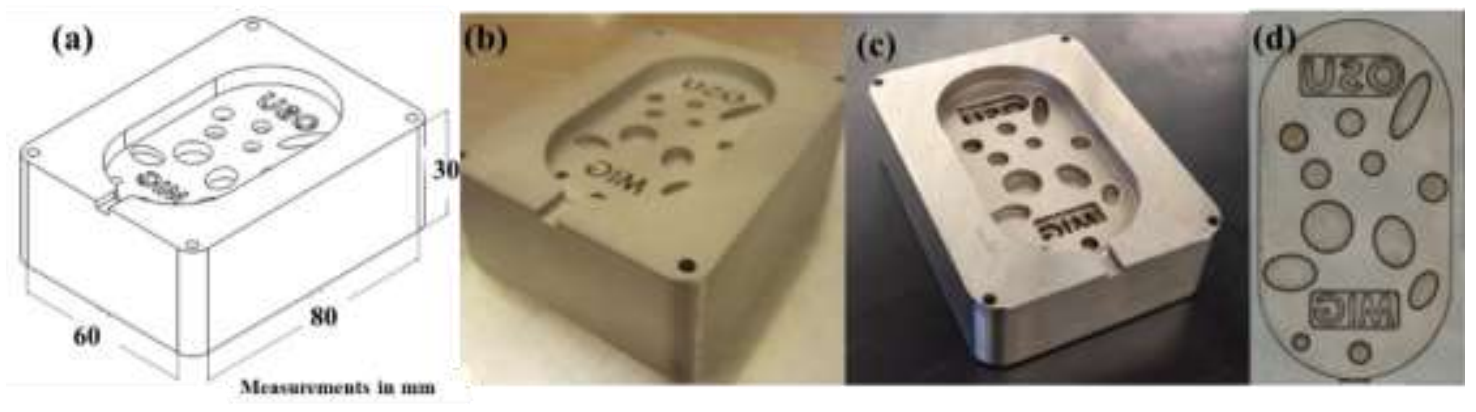

Figure 2.1 (a) Mold design, (b) As-printed mold using L-PBF process, (c) post-machined mold with 5mm mold depth, (d) Post-machined mold with laser scanning microscopy

Table 2.4 indicates the surface roughness measurements of the as-printed mold and the post-machined mold. On the cavity of the as-printed mold, the surface roughness was 5.1 $\pm 0.6 \mu \mathrm{m}$. On the cavity of the post-machined mold, the surface roughness decreased to 1.6 $\pm 0.1 \mu \mathrm{m}$. Due to this, there was a $\sim 70 \%$ reduction in surface roughness of the cavity following machining operations on the L-PBF fabricated mold. 
Table 2. 4 Surface roughness measurements of the as-printed mold and machined mold

\begin{tabular}{|c|c|c|c|}
\hline Mold & \multicolumn{2}{|c|}{ As-printed mold } & Post-machined mold \\
\hline Surface & $\begin{array}{c}\text { Parallel to surface } \\
(\boldsymbol{\mu m})\end{array}$ & $\begin{array}{c}\text { Perpendicular to } \\
\text { surface }(\boldsymbol{\mu m})\end{array}$ & $\begin{array}{c}\text { Parallel to surface } \\
(\boldsymbol{\mu m})\end{array}$ \\
\hline Top & $5.1 \pm 0.4$ & $4.6 \pm 0.7$ & 0.6 \\
\hline $\begin{array}{c}\text { Bottom } \\
\text { (Machined) }\end{array}$ & $0.9 \pm 0.2$ & $0.8 \pm 0.1$ & 0.2 \\
\hline Sides & $5.1 \pm 0.7$ & $6.3 \pm 1.0$ & $1.1 \pm 0.1$ \\
\hline Cavity & $5.1 \pm 0.6$ & - & $1.6 \pm 0.1$ \\
\hline
\end{tabular}

Figure 2.2 illustrates a comparison between injection-molded parts using the as-printed mold and the post-machined mold. The part using the as-printed mold was injection molded under an injection pressure of $30 \mathrm{MPa}$ and cooling time of $12 \mathrm{~s}$. The part using the postmachined mold was injection molded under an innjection pressure of $45 \mathrm{MPa}$ and cooling time of $40 \mathrm{~s}$. The injection-molded parts using the as-printed mold resulted in a noticeable warpage and distortion of features, as shown in Figure 2.2a. Part weight for injection molded parts using the as-printed mold was $8.52 \pm 0.02 \mathrm{~g}$. However, injection molded parts were tremendously improved using the post-machined mold, as shown in Figure 2.2b. Machining operations performed on the as-printed surface have improved warpage and features. The post-machined mold resulted in increased part weight to $10.95 \pm 0.01 \mathrm{~g}$. 


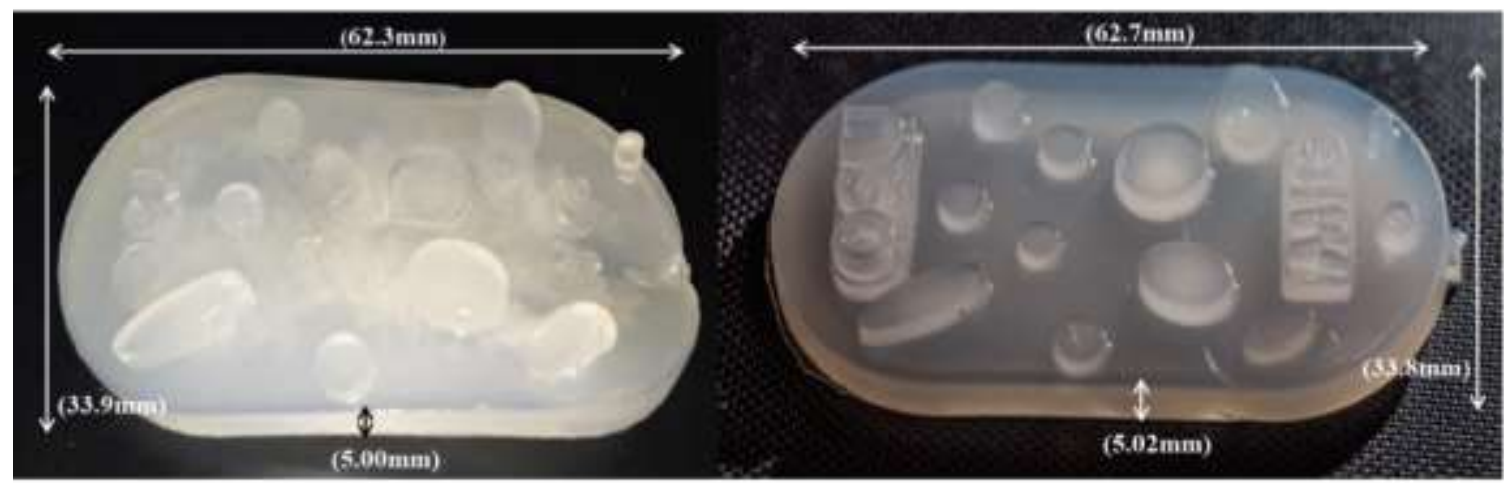

Figure 2.2 (a) Injection molded part using the as-printed mold (top-view), (b) Injection molded part using the post-machined mold (top-view)

Figure 2.3 shows warpage and sink mark results extracted from the laser scanning microscope of the experimental parts using the as-printed and post-machined mold. In Figure 2.3a, the scale bar's red section indicates that molded part using as-printed mold resulted with warpage of 0.4 to $2.23 \mathrm{~mm}$ on the opposite edges of the part. However, after additional experimentation, all experimental parts using the post-machined mold resulted in decreased warpage ranging from 0.4 to $1.05 \mathrm{~mm}$, when compared to parts molded from the as-printed mold. Based on the weight improvement, surface feature improvement, warpage and sink mark reduction, it can be concluded from the experimental measurements that machining operations on the as-printed mold improved part quality on the injection molded parts. 
(a)

Molded part with As-printed mold Molded part with post-machined mold

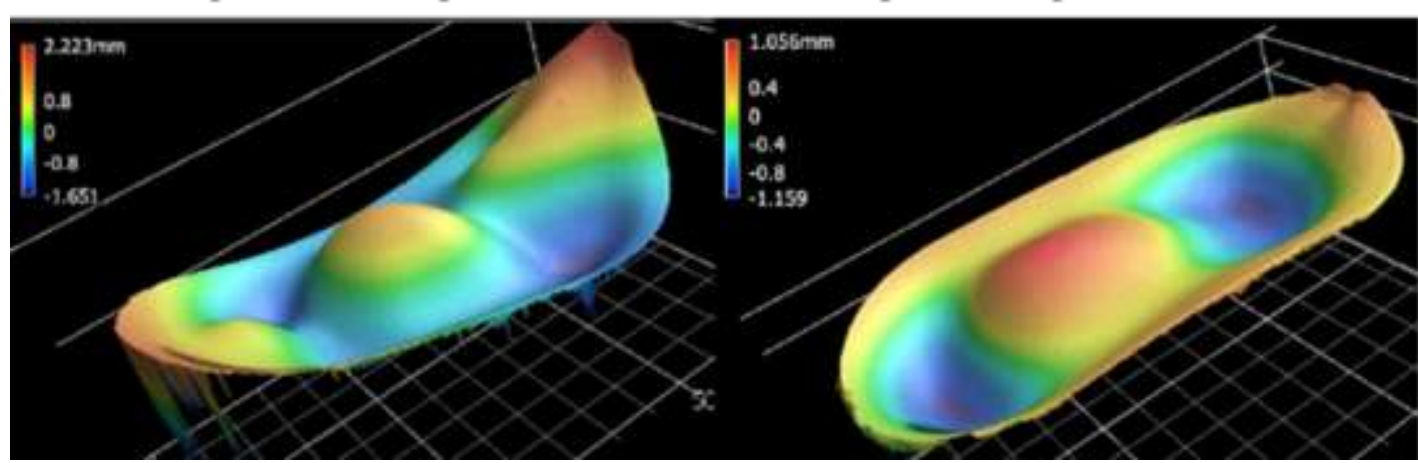

Figure 2.3 (a) Warpage and sink mark analysis for molded part with $5 \mathrm{~mm}$ part thickness, (b) Warpage analysis for experiments with $3 \mathrm{~mm}$ part thickness

\subsubsection{L-PBF MOLDS IN PART DESIGN}

Figure 2.4 illustrates a side-view comparison between injection molded parts using the post-machined mold with a $5 \mathrm{~mm}$ cavity depth and $3 \mathrm{~mm}$ cavity depth. The part using the post-machined mold with $5 \mathrm{~mm}$ cavity depth was injection molded under an injection pressure of $45 \mathrm{MPa}$, Melt Temperature of $226^{\circ} \mathrm{C}$ and cooling time of 40 seconds. The part using the post-machined mold with $3 \mathrm{~mm}$ cavity depth was injection molded under an injection pressure of $10 \mathrm{MPa}$, Melt Temperature of $226{ }^{\circ} \mathrm{C}$ and cooling time of 40 seconds. In Figure 2.4a, bent features can be noticed at Locations 1 and 2. In Figure 2.4b, the features at the indicated locations are more aligned. 
(a) $5 \mathrm{~mm}$ part thickness

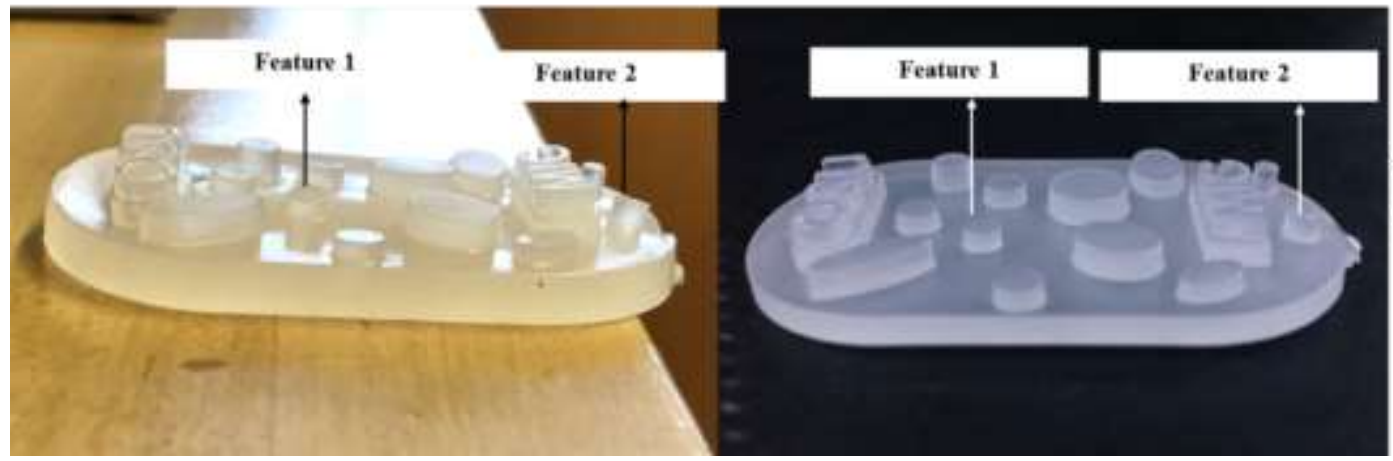

Figure 2.4 (a) Injection molded part using the machined mold with $5 \mathrm{~mm}$ mold depth (side-view), (b) Injection molded part using the machined mold with $3 \mathrm{~mm}$ mold depth (side-view)

Mold-fillings simulations of sink marks on the rear-view of the part are shown in Figure 2.5. Sink mark locations are indicated in green for the parts with $5 \mathrm{~mm}$ and $3 \mathrm{~mm}$ thickness. As shown in the scale bar of Figure 2.5a, the sink depths on the part with $5 \mathrm{~mm}$ thickness ranged between 0.08 to $0.14 \mathrm{~mm}$. However, sink depth decreased on the part with $3 \mathrm{~mm}$ thickness to 0.07 to $0.11 \mathrm{~mm}$, as shown on Figure $\mathbf{2 . 5}$.

(a) $5 \mathrm{~mm}$ part thickness

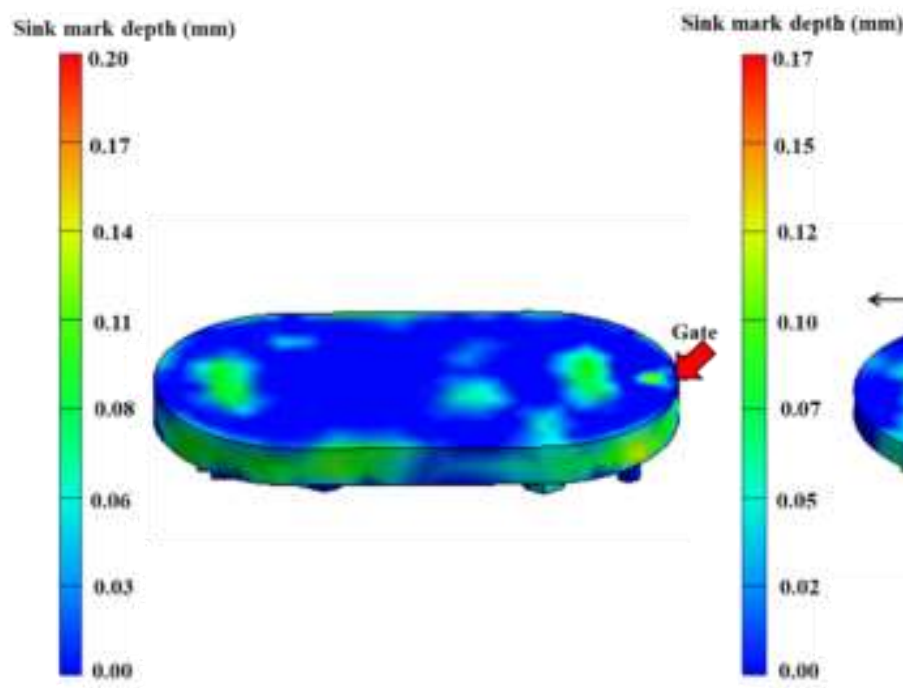

(b) $3 \mathrm{~mm}$ part thickness

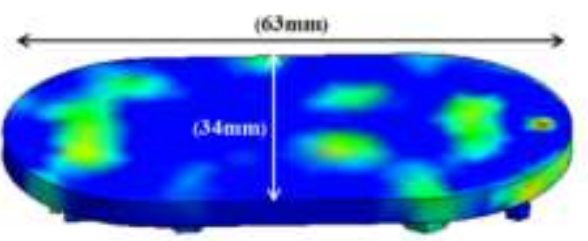

Figure 2.5 Mold-filling simulations for sink mark using: (a) mold with $5 \mathrm{~mm}$ cavity depth (rear-view), (b) mold with 3 mm cavity depth (rear-view) 
Figure 2.6 shows a rear-view of the injection molded parts using the machined molds with $5 \mathrm{~mm}$ cavity depth and $3 \mathrm{~mm}$ cavity depth. As shown on Figure 2.6a, the location of sink marks observated on the injection molded parts correlated well with sink locations indicated in mold-filling simulations, as seen in Figure 2.6a. Further, decreasing the cavity thickness from $5 \mathrm{~mm}$ to $3 \mathrm{~mm}$ resulted in a reduction in sink depth, as qualitatively seen in

Figure 2.6b.

(a) $5 \mathrm{~mm}$ part thickness

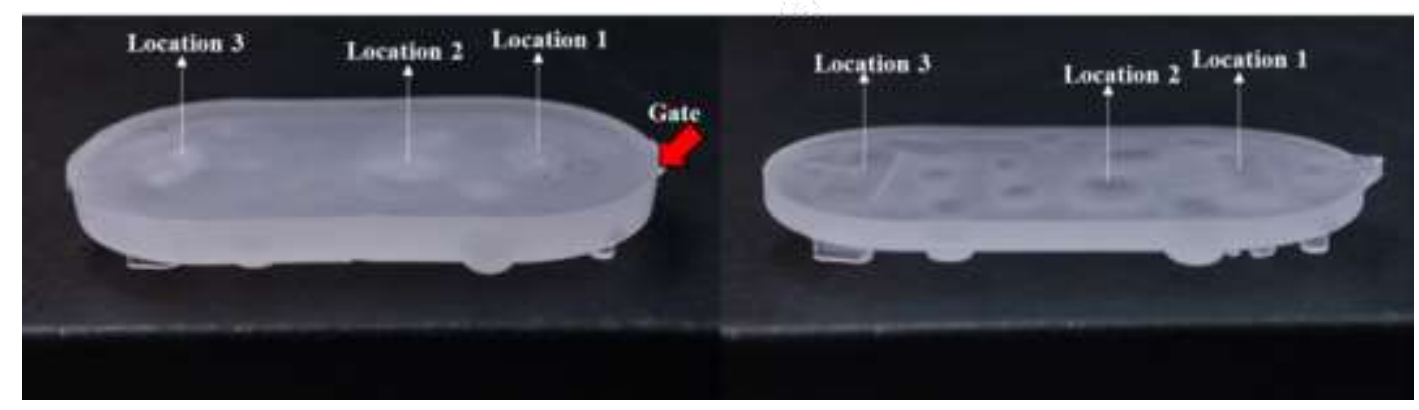

Figure 2.6 (a) Injection molded part using the machined mold with $5 \mathrm{~mm}$ mold depth (rear-view), (b) Injection molded part using the machined mold with $3 \mathrm{~mm}$ mold depth (rear-view)

Figures 2.7 and 2.8 plot a quantitative comparison between experimental and simulation results for sink depths of multiple molded parts with varying cooling times during the injection molding cycle $(12,20,40,60 \mathrm{~s})$. The plots represent three locations indicated in Figure 2.6 on the parts with 3 as well as $5 \mathrm{~mm}$ wall thickness. In Figures 2.7 and $\mathbf{2 . 8}$, differences in the magnitude of sink depth were noticed between the simulations and experiments. Further, differences in sink mark trends as a function of changing cooling time were also seen between simulations and experiments. In Figure 2.7, Locations 2 and 3 appeared to be the locations with severe sink depth, as shown in simulations and experiments. However, from Figures 2.7 and 2.8, it can be noticed that the overall trends 
on the effect of wall thickness on the depth of sink marks have reasonable correspondence between experiments and simulations at all locations.

(a)

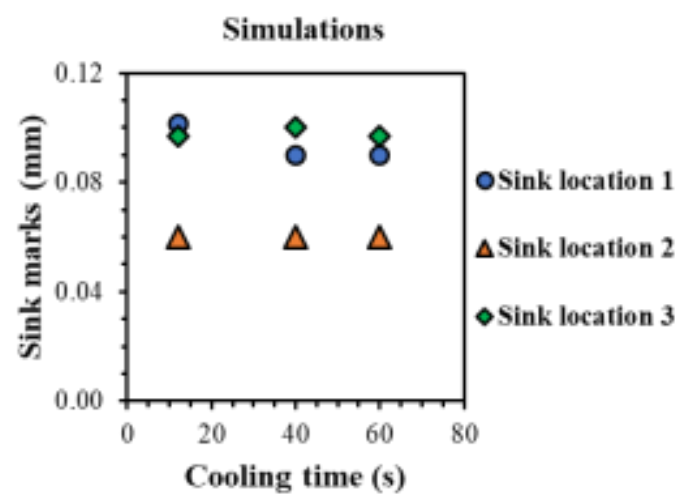

(b)

\section{$5 \mathrm{~mm}$ part thickness}

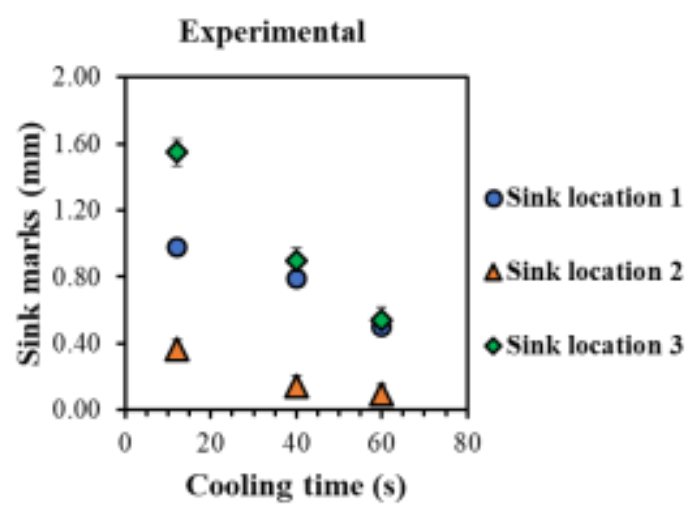

Figure 2.7 (a) Simulation plot of sink marks using the $5 \mathrm{~mm}$ mold cavity with cooling times: 12, 40, and $60 \mathrm{~s}$, (b) Experimental plot of sink marks for the $5 \mathrm{~mm}$ mold cavity with cooling times: 12,40 , and $60 \mathrm{~s}$.

(a)

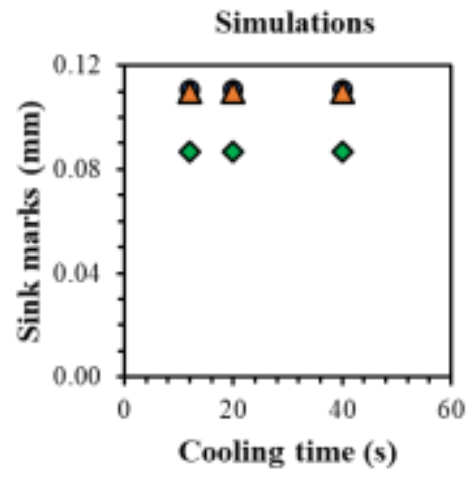

(b)

\section{$3 \mathrm{~mm}$ part thickness}

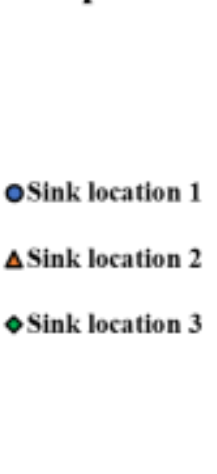

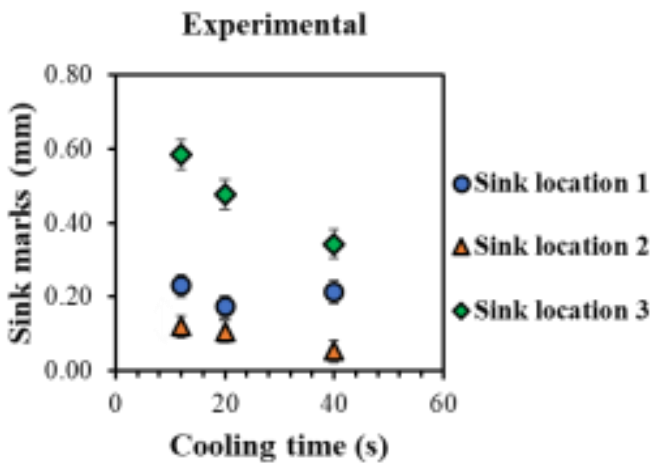

Figure 2.8 (a) Simulation plot of sink marks for the $3 \mathrm{~mm}$ mold cavity with cooling times: 12,20, and $40 \mathrm{~s}$, (b) Experimental plot of sink marks for the $3 \mathrm{~mm}$ mold cavity with cooling times: 12,20 , and $40 \mathrm{~s}$.

In addition to sink marks, the quality of injection-molded parts can be represented by warpage. Figure 2.9 represents mold-filling simulations of warpage using the side-view of the part. Affected areas by warpage are indicated in red and blue at the opposite ends of 
the part. Positive and negative values of warpage refer to deviation from a flat reference plane located at the bottom surface. As seen in the scale bar of Figure 2.9a, the warpage at Location 1 of the part with $5 \mathrm{~mm}$ wall thickness varied between -0.90 to $-1.45 \mathrm{~mm}$ and ranged between 0.22 to $0.50 \mathrm{~mm}$ at Location 2 . In comparison, the part with $3 \mathrm{~mm}$ wall thickness, shown in Figure 2.9b, had a reduction in warpage at Location 1 and was found to range from -0.77 to $-1.21 \mathrm{~mm}$ and from 0.11 to $0.33 \mathrm{~mm}$ at Location 2 . As noted, simulations predicted a reduction in warpage with a lower wall thickness.

(a) $5 \mathrm{~mm}$ part thickness

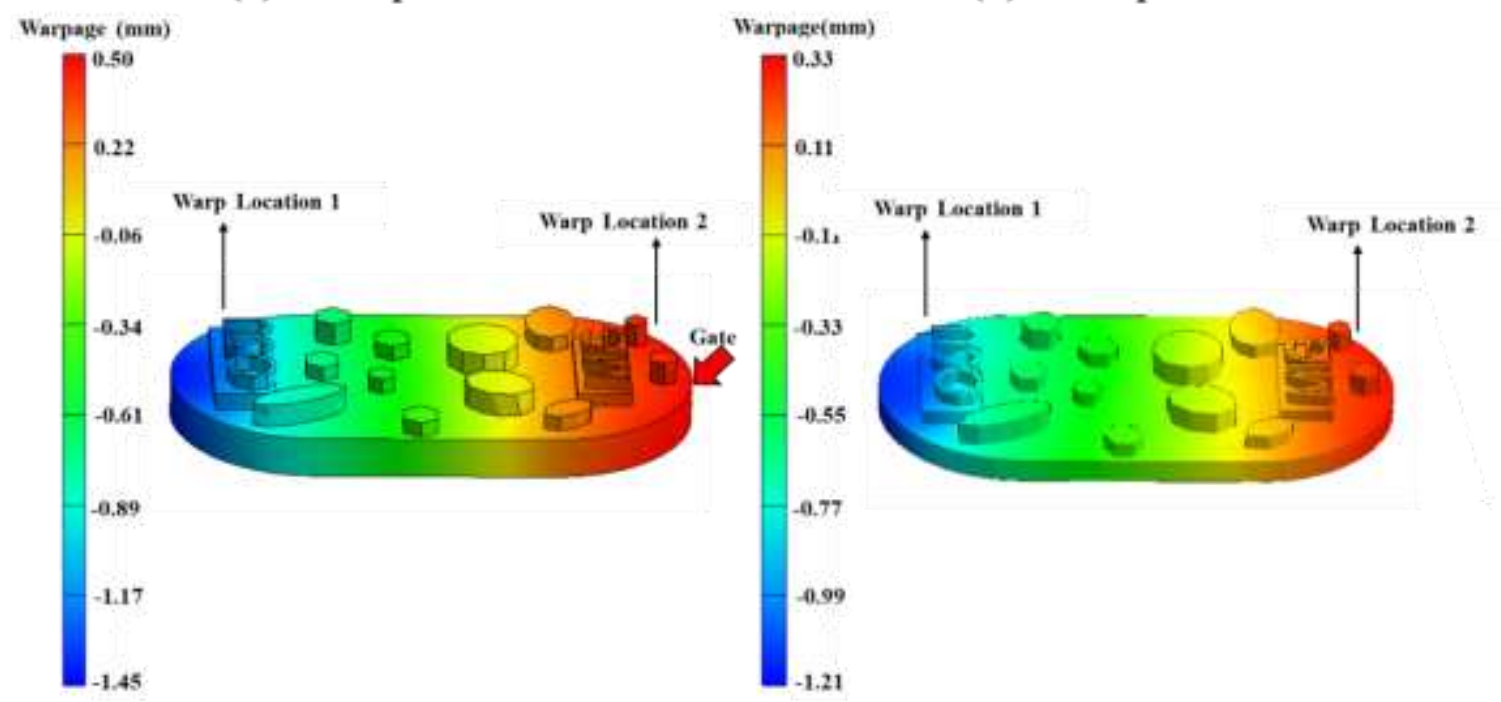

Figure 2.9 Mold-filling simulations for warpage using: (a) mold with $5 \mathrm{~mm}$ cavity depth (side-view), (b) mold with $3 \mathrm{~mm}$ cavity depth (side-view)

Figure 2.10 shows a side-view of the injection molded parts using the post-machined molds with $5 \mathrm{~mm}$ cavity depth and $3 \mathrm{~mm}$ cavity depth. The principal areas of warpage were visible on the same locations indicated by mold-filling simulations. Also, a lower wall thickness visually demonstrated improvements in warpage. 
(a) $5 \mathrm{~mm}$ part thickness

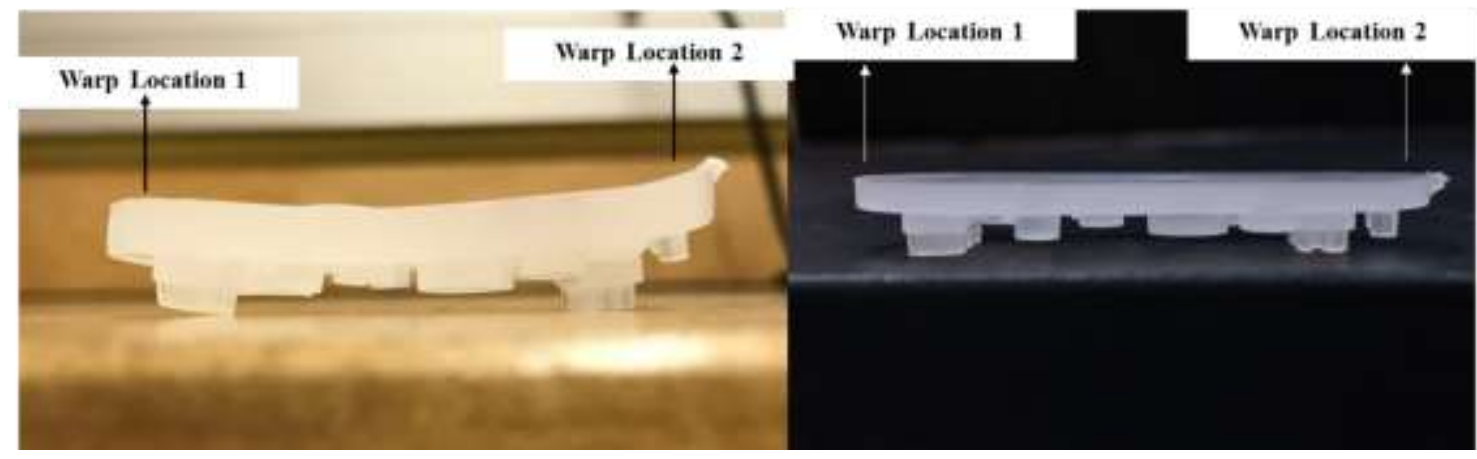

Figure 2.10 (a) Injection molded part using the machined mold with $5 \mathrm{~mm}$ mold depth (side-view), (b) Injection molded part using the machined mold with $3 \mathrm{~mm}$ mold depth (side-view)

Figures 2.11 and 2.12 plot a comparison between experimental and simulation warpage results of multiple molded parts with varying cooling times $(12,20,40,60 \mathrm{~s})$ on indicated locations in Figure 2.10 of the parts with $5 \mathrm{~mm}$ wall thickness and $3 \mathrm{~mm}$ wall thickness, respectively. A small difference in the magnitude of warpage can be noticed between simulations and experiments. As shown in Figures 2.11 and Figure 2.12, warpage decreases with increases in cooling time for experiments and simulations of parts with both wall thicknesses. Also, it can be noticed that Location 1 has more severe warpage than Location 2, for experiments and simulations of both part thicknesses. 
(a)

(b)
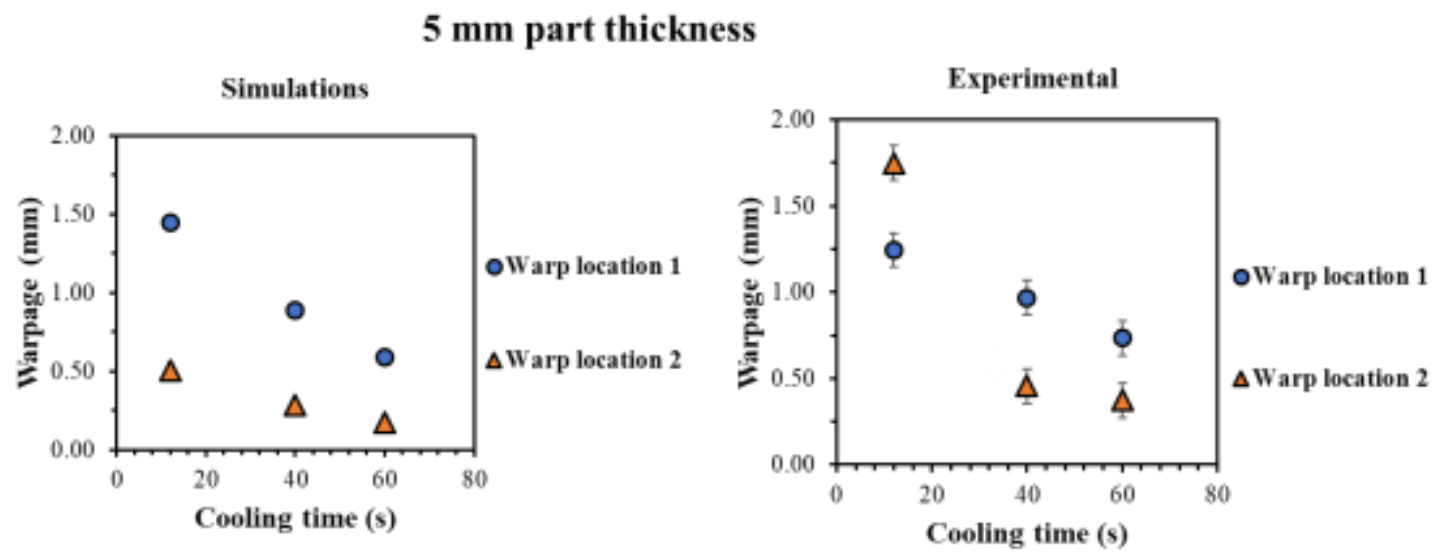

Figure 2.11 (a) Simulation plot of warpage for the $5 \mathrm{~mm}$ mold cavity with cooling times: 12,40 , and $60 \mathrm{~s}$, (b) Experimental plot of warpage for the $5 \mathrm{~mm}$ mold cavity with cooling times: 12,40 , and $60 \mathrm{~s}$

(a)

(b)

\section{$3 \mathrm{~mm}$ part thickness}
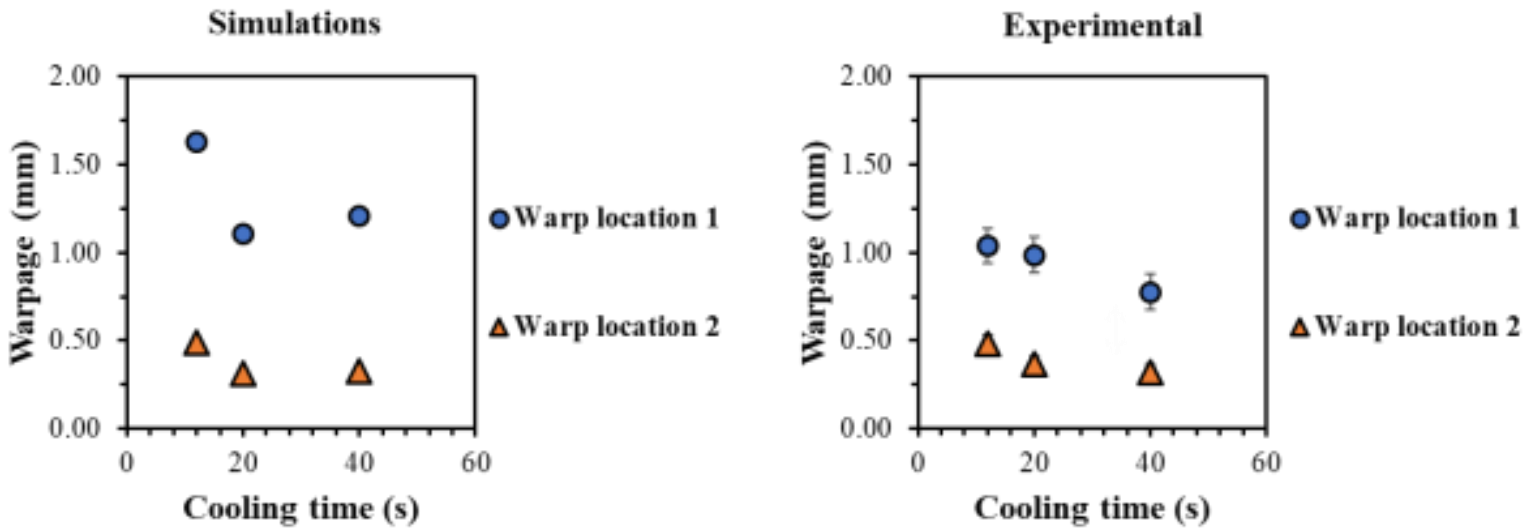

Figure 2.12 (a) Simulation plot of warpage for the $3 \mathrm{~mm}$ mold cavity with cooling times: 12, 20, and $40 \mathrm{~s}$, (b) Experimental plot of warpage for the $3 \mathrm{~mm}$ mold cavity with cooling times: 12,20 , and $40 \mathrm{~s}$.

Figure 2.13 shows part-deformation results extracted from the laser scanning microscope of an experimental parts with a thickness of $3 \mathrm{~mm}$ and $5 \mathrm{~mm}$. In Figure 2.13a, the scale bar's red section indicates that parts with $5 \mathrm{~mm}$ part thickness resulted with warpage of 
0.4-1.05 mm on Location 1, Location 2, and Location 3. However, experimental parts using the $3 \mathrm{~mm}$ mold cavity resulted with warpage of $0.4-0.69 \mathrm{~mm}$ on Location 1 and Location 2, as shown in Figure 2.13b. It can be seen that warpage in Location 3 have been eliminated due to part thickness decrease. Location 4 and Location 5 indicate locations where sink marks were seen. In Figure 2.13a, the scale bar's blue section indicates that the molded part with $5 \mathrm{~mm}$ part thickness resulted with a maximum sink depth of -0.4 to $-1.16 \mathrm{~mm}$ on Location 4 and Location 5. However, experimental parts using the $3 \mathrm{~mm}$ mold cavity resulted with a decrease in sink depth to 0 to $-0.27 \mathrm{~mm}$, as shown in Figure $\mathbf{2 . 1 3 b}$. Therefore, it can be concluded from the experimental measurements that sink marks and warpage have improved due to the reduction in part thickness.

(a) $5 \mathrm{~mm}$ part thickness

(b) $3 \mathrm{~mm}$ part thickness

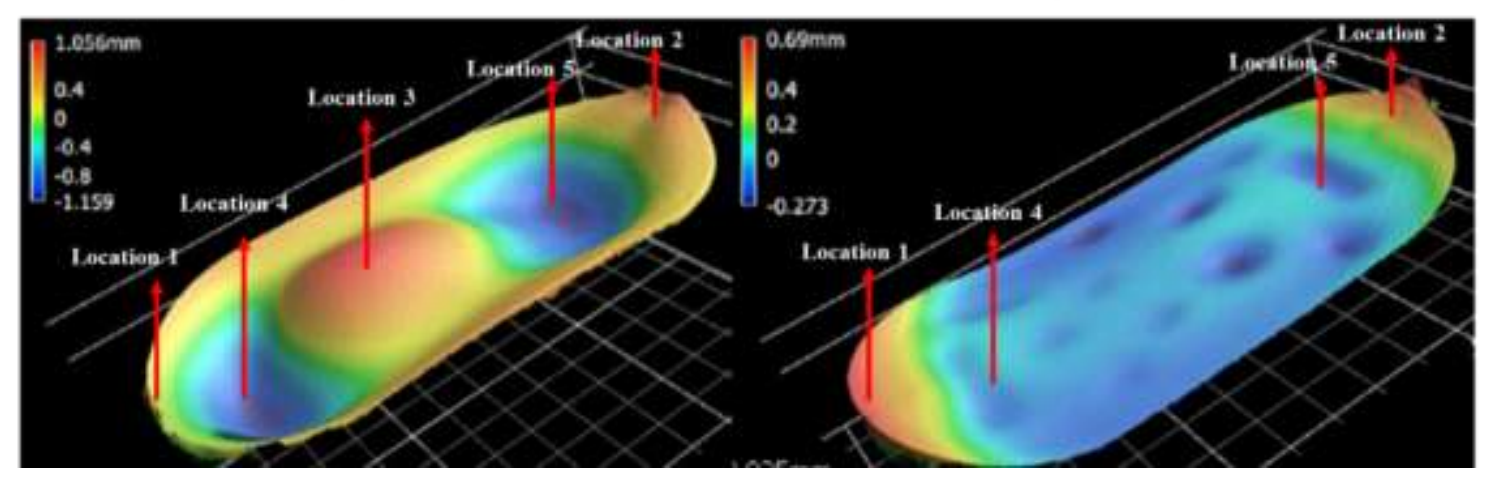

Figure 2.13 (a) Deformation analysis for experiments with $5 \mathrm{~mm}$ part thickness, (b) Warpage analysis for experiments with $3 \mathrm{~mm}$ part thickness

Figure 2.14 shows mold-filling simulation results for frozen layers near the cavity's surface after a cooling time of 12 s. In Figure 2.14a, it can be noticed that no region on the part with $5 \mathrm{~mm}$ wall thickness has reached its freezing temperature after the entire cycle. However, a cooling time of $12 \mathrm{~s}$ resulted to be enough to freeze most of the part with $3 \mathrm{~mm}$ wall thickness, as shown in Figure 2.14b. If the part has not completely frozen after the cooling phase, then the part is likely to face part quality defects due to the melted regions. 
(a) $5 \mathrm{~mm}$ part thickness

(b) $3 \mathrm{~mm}$ part thickness

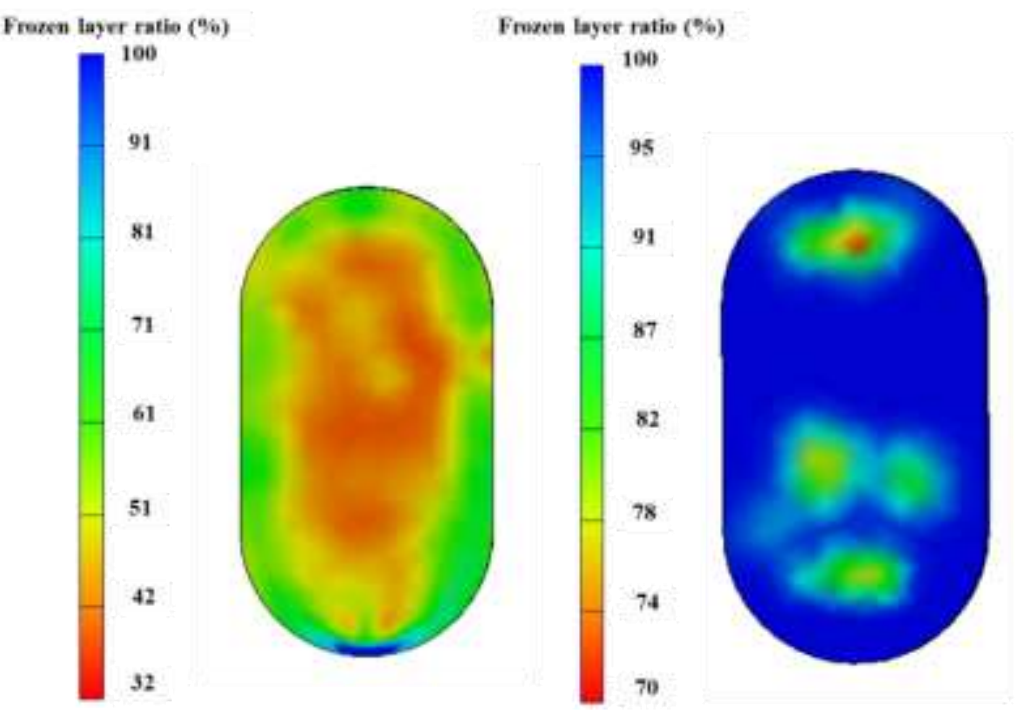

Figure 2.14 Mold-filling simulations for frozen layer ratio using: (a) mold with $5 \mathrm{~mm}$ cavity depth (back-view), (b) mold with $3 \mathrm{~mm}$ cavity depth (back-view)

Figure 2.15 shows the melt temperature of the blue-colored regions that resulted in sink marks on the injection molded parts with $5 \mathrm{~mm}$ part thickness and $3 \mathrm{~mm}$ part thickness. The locations that indicated sink marks on the injection molded parts did not reach its freeze temperature, as shown on Figure 2.15. For the part with $3 \mathrm{~mm}$ wall thickness, it can be noticed that the temperature difference between the melt temperature at the locations and the material's freeze temperature is is $12{ }^{\circ} \mathrm{C}$. However, the temperature difference for the part with $5 \mathrm{~mm}$ wall thickness was $46{ }^{\circ} \mathrm{C}$. Due to the higher temperature difference on the part with $5 \mathrm{~mm}$ wall thickness, the severity of the sink marks were larger. 

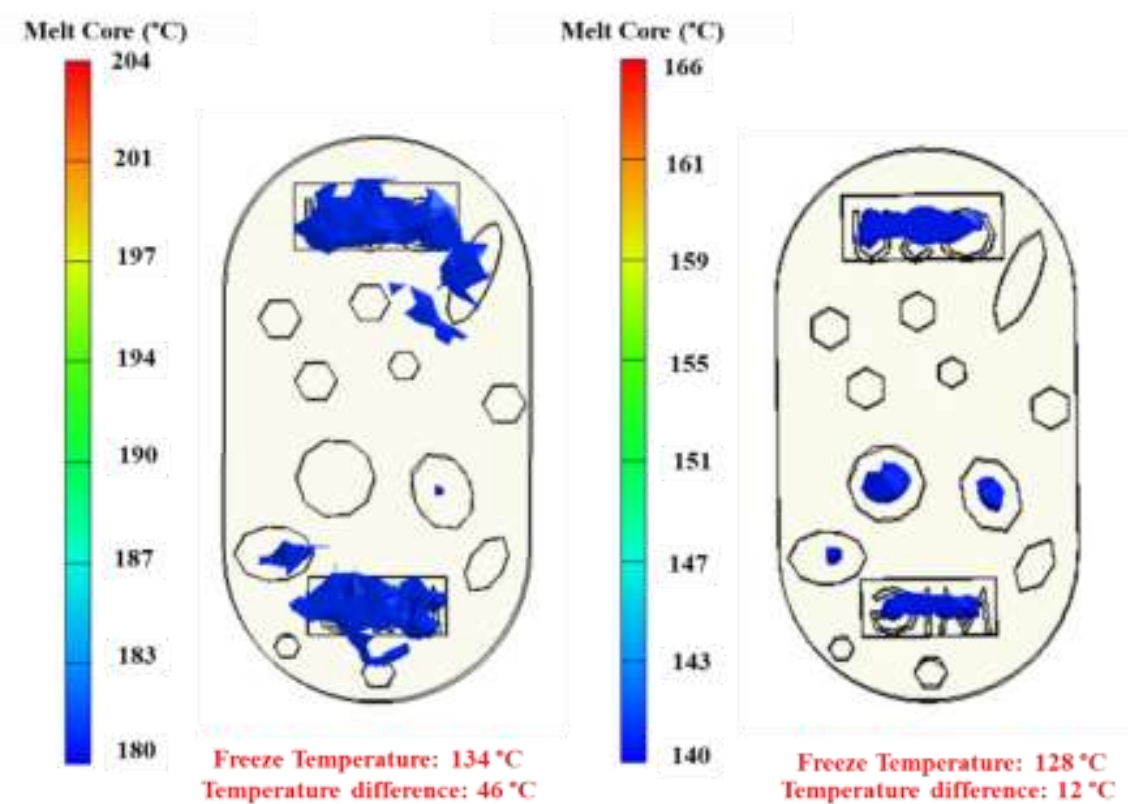

Figure 2.15 Mold-filling simulations for melt regions using: (a) mold with $5 \mathrm{~mm}$ cavity depth (back-view), (b) mold with 3 mm cavity depth (back-view)

\subsubsection{L-PBF MOLDS IN MATERIAL DESIGN}

Figure 2.16 shows injection molded parts using polypropylene with 0 wt. \%, 1 wt. \% and 2 wt. \% blowing agents (BA). The parts in Figure 2.16 were injection molded using the post-machined mold with $3 \mathrm{~mm}$ cavity depth under an injection pressure of $11 \mathrm{MPa}$, injection velocity of $25 \mathrm{~mm} / \mathrm{s}$, melt temperature of $226^{\circ} \mathrm{C}$ and cooling time of 15 seconds. The locations shown in Figure 2.16a are affected by sink marks. Figure 2.17 plots the sink depth for all 9 conditions of the Design of Experiment (DOE), comparing simulation and experimental results. Conditions 1-3 contain 0 wt. \% BA, Conditions 4-6 contain 1 wt. \% BA, and Conditions 7-9 contain 2 wt. \% BA. It can be noticed that simulation and experimental results indicate that increasing the amount of blowing agent results in a 
significant reduction in the depth of sink marks. However, simulations indicated no different between the parts with 1 wt. \% BA and 2 wt. \% BA.

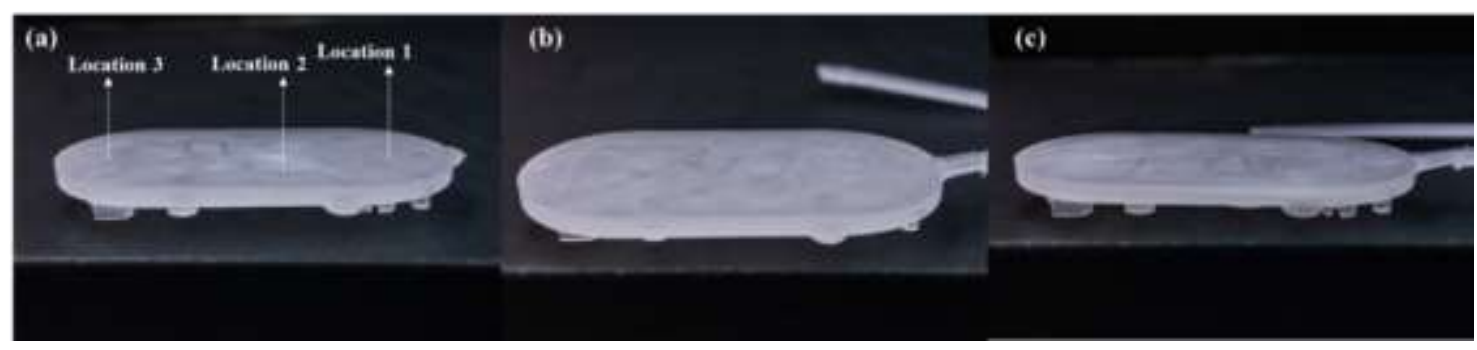

Figure 2.16 Injection molded parts using the machined mold with $3 \mathrm{~mm}$ mold depth (side-view): (a) 0 wt. \% BA, (b) 1 wt. \% BA, (c) 2 wt. \% BA

(a)

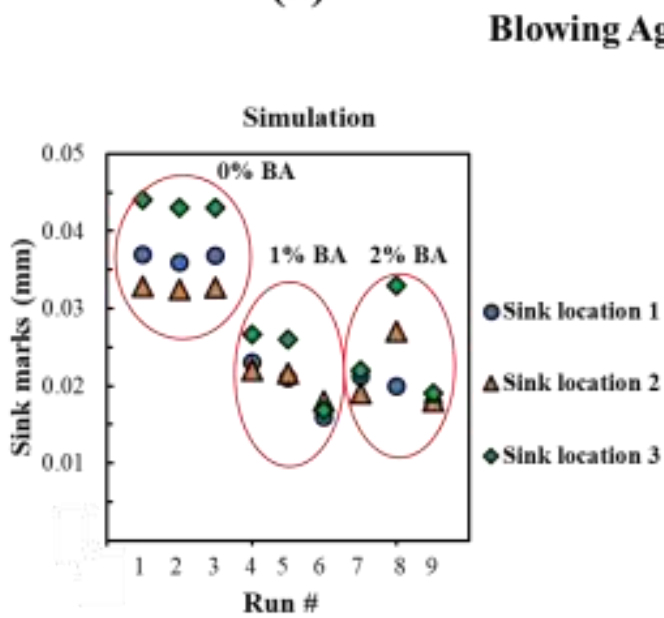

(b)

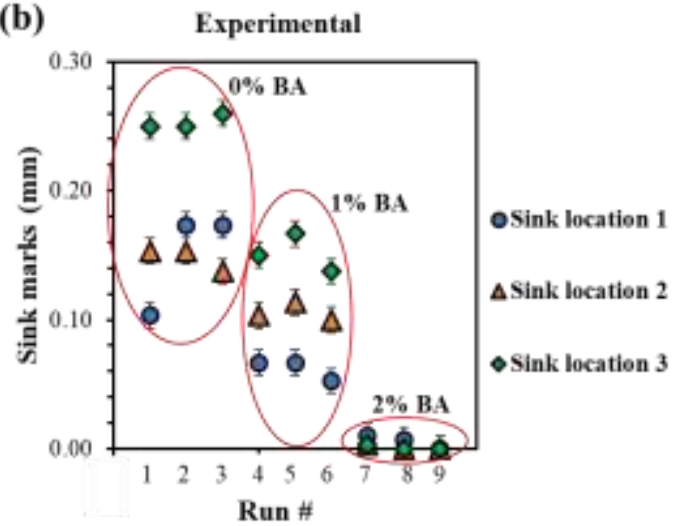

Figure 2.17 (a) Simulation plot of sink depth using the $3 \mathrm{~mm}$ mold cavity with: 0,1 , and 2 wt. \% BA, (b) Experimental plot of sink depth using the $3 \mathrm{~mm}$ mold cavity with: 0, 1, and 2 wt. $\%$ BA

Figure 2.18 shows deformation results extracted through laser scanning microscopy of the experimental parts in the design of experiment using $0 \mathrm{wt} . \% \mathrm{BA}, 1 \mathrm{wt}$. \% BA and $2 \mathrm{wt}$. $\%$. In Figure 2.15a, the scale bar's red section indicates that parts with 0 wt. \% BA resulted with a warpage ranging at $0.3-0.41 \mathrm{~mm}$ on the opposite ends of the part. In Figure 2.18b, parts with 1 wt. \% BA decreased the warpage range to $0.2-0.33 \mathrm{~mm}$ on the same locations. 
In Figure 2.18c, it can be seen that warpage reduced even more on parts with 2 wt. \% BA. Furthermore, it can be noticed that sink depth has decreased with the increase of blowing agents. As blowing agents are incorporated into the injection molded parts, the dark blue and green regions in Figure 2.18a become less visible. Using 2 wt. \% BA, it can be noticed that there is more uniformity throughout the blue region of the part, as shown on Figure

\subsection{8c.}

(a) 0 wt. $\%$ BA

(b) 1 wt. $\%$ BA

(c) 2 wt. $\%$ BA

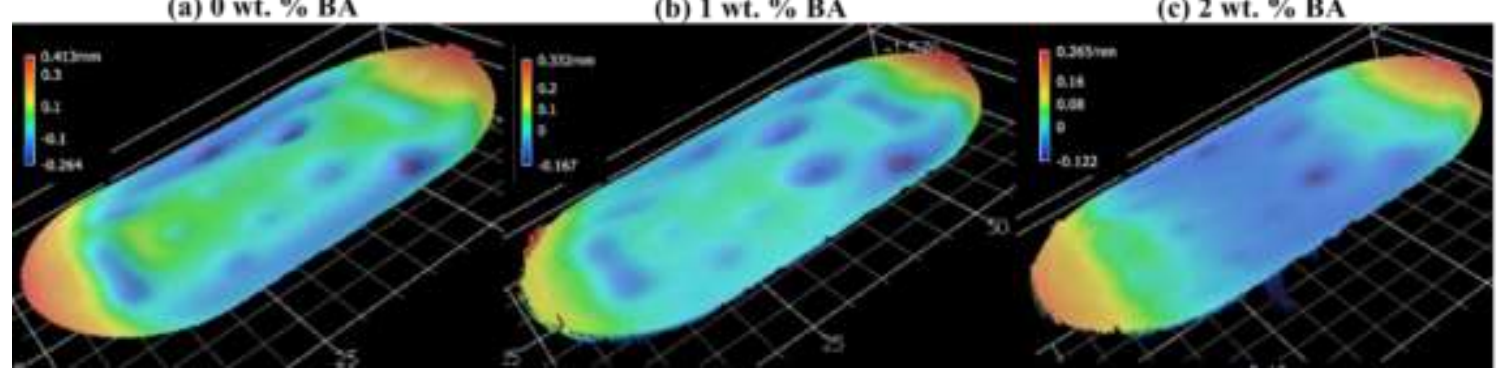

Figure 2.18 Analysis of sink marks and warpage using the laser scanning microscope for experiments with $3 \mathrm{~mm}$ mold cavity at: (a) 0 wt. \% BA, (b) 1 wt. \% BA, (c) 2 wt. \% BA

Table 2.5 shows the p-values extracted from the ANOVA using Minitab. The output captured from Minitab is shown in the Appendix, Figure D.9 to Figure D.11 for Location 1 through Location 3. It can be noticed that the p-values of blowing agents for all sink locations are less than an $\alpha$ of 0.05 , indicating that the concentration of blowing agent is a significant factor for the decrease of sink marks. In contrast, the p-values of injection velocity and packing pressure are above 0.05 . Therefore, injection velocity and pack pressure are not significant factors for the decrease of sink marks. 


\begin{tabular}{|c|c|c|c|}
\hline Factors & Sink Location 1 & Sink Location 2 & Sink Location 3 \\
\hline Blowing agent (\%) & 0.04 & 0.001 & 0.005 \\
\hline Injection velocity (mm/s) & 0.60 & 0.40 & 0.80 \\
\hline Pack pressure (MPa) & 0.46 & 0.73 & 0.29 \\
\hline
\end{tabular}

Table 2.5 P-values from the Analysis Of Variance (ANOVA) for sink marks at Location 1, Location 2, and Location 3

Figure 2.19 displays the effect of each factor on the set response, sink marks. Aiming to minimize our response, sink marks, the lowest data point is captured amongst the levels for each factor. It can be noticed that blowing agent of $2 \%$ is the most significant level to decrease sink marks. In comparison, sink marks were not significantly affected by the changes in injection velocity and packing pressure.

(a)

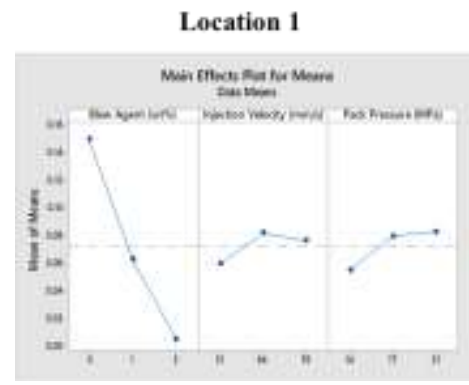

(b)

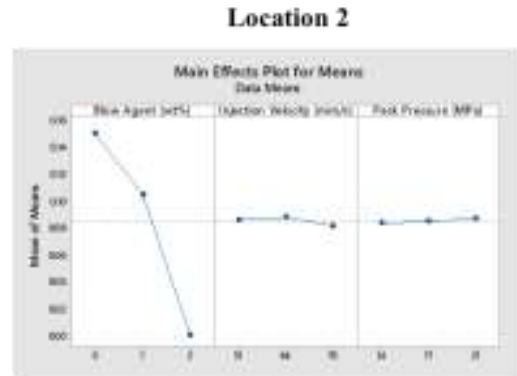

(c)

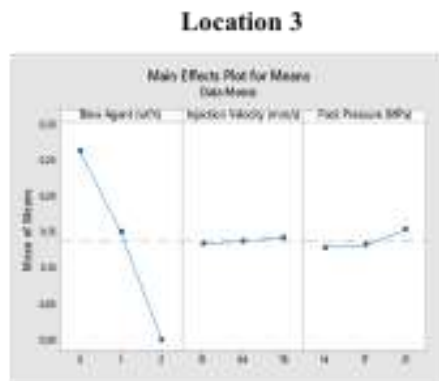

Figure 2.19 Main effects plot for means of sink marks with 3 replicates at (a) Location 1, (b) Location 2, (c) Location 3

Figure 2.20 plots warpage results for all 9 conditions of the Design of Experiment (DOE) using mold-filling simulation with blowing agents. As well as experimental results, simulation results indicate a reduction in warpage with blowing agents. 


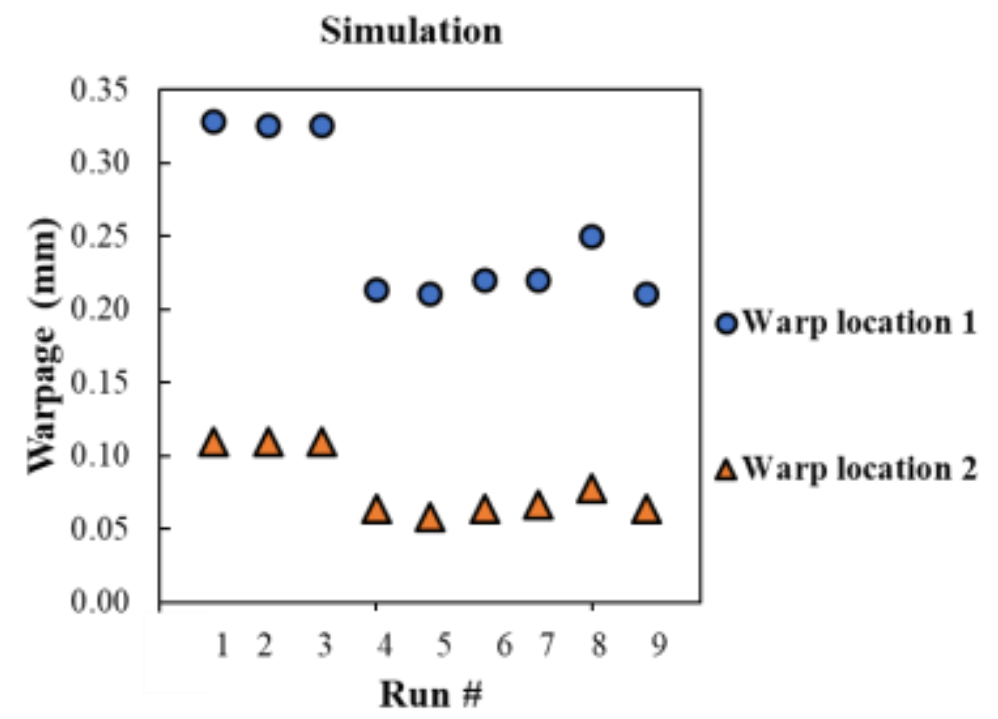

Figure 2.20 Simulation plot of warpage using the $3 \mathrm{~mm}$ mold cavity with: 0,1 , and $2 \mathrm{wt}$. $\% \mathrm{BA}$

\subsection{CONCLUSIONS}

In this paper, 17-4 PH stainless steel tooling for injection molding was fabricated by LPBF and evaluated through a series of experiments and simulations. Based on the results, the following conclusions emerge:

1) Injection molded parts using the as-printed mold did not achieve good part quality. Therefore, machining operations on L-PBF fabricated molds are necessary to improve part quality, avoid discrepancies in the part, reduce surface roughness, adjust draft angles, and perform other mold design adjustments. A better understanding of draft angles during the design of L-PBF fabricated molds can save time spent in post-machining.

2) Parts with thin walls tend to cool faster and achieve better part quality in terms of sink marks and warpage. The reduction in part thickness resulted in better part quality, indicated 
by experiments and simulations. L-PBF fabricated molds enable a quicker verification of changes in part geometry than traditionally manufactured molds do.

3) Experimental results indicated that the location of sink marks and warpage could be accurately predicted in computer-aided simulations, but their magnitude was not well described. Also, the results from simulations indicated that warpage was more sensitive than sink marks to the effects of processing conditions such as cooling time, in qualitative agreement to experimental data. Changes in the constitutive equations governing sink mark predictions may be needed on simulation platforms to address this discrepancy.

4) The additional of chemical blowing agent concentration to the polypropylene improved the part quality in terms of sink marks based on the results from experiments and simulations. L-PBF fabricated molds enable a quicker verification of blowing agent concentration than traditionally manufactured molds do. The results from simulations indicated that the depth of sink marks was not sensitive to the effects of increased blowing agent concentration from 1 wt. $\%$ to 2 wt., in contrast to experimental data. Changes in the constitutive equations governing sink mark predictions may be needed on simulation platforms to address this discrepancy.

5) Moldex3D simulation platform served to accurately predict mold-filling behavior and analysis of the fraction of frozen layer to explain the cause of sink marks and warpage as a function of changes in geometry (part thickness) and material (blowing agents).

6) Tooling for injection molding fabricated by L-PBF can help identify improvements in part design, material composition of polymers, and simulation methods quicker than traditionally manufactured molds. 


\section{CHAPTER 3}

\section{LASER-POWDER BED FUSION FABRICATED TOOLING FOR PLASTIC INJECTION MOLDING WITH CONFORMAL COOLING CHANNELS}

\subsection{INTRODUCTION}

Injection molding is a widely used manufacturing process for plastic parts, requiring a high demand in part production and part quality [5]. Therefore, any reduction in cycle time would be significant to mass production. In the injection molding cycle, cooling time accounts for $70 \%$ of the cycle [45] [34]. In traditional manufacturing, conventional cooling channels are straight-hole passages built into the injection mold insert to decrease cooling time and increase temperature uniformity for part quality [15]. However, design constraints in traditional manufacturing do not always allow conventional cooling channels to cool down a complex part uniformly [37].

Additive manufacturing (AM) processes, such as laser-powder bed fusion (L-PBF) have the potential to alleviate this drawback. L-PBF, also known as selective laser melting (SLM), is an additive manufacturing method that melts the metal powders layer by layer using a laser to form 3D structures depending on the CAD file $[17,38]$. AM enables the 3D printing of mold inserts conformal cooling channels. Conformal cooling channels are cooling passage holes that follow the part's geometry [35]. By following the part's geometry, the part is cooled in a much more uniform manner. The fabrication of tooling 
for injection molding using the L-PBF process decreases geometric constraints, while decreasing build times and cost [14-16]. In the past, various independent research studies have been reported on tooling with conformal cooling channels [4, 15, 16, 26, 27, 37]. However, there are, to the best of our knowledge, not many studies in the open literature on the performance of the L-PBF fabricated two-sided tooling with conformal cooling channels for injection molding that integrate experiments and mold-filling simulations with evaluation on printing defects, machining operations, molded part quality, and conformal cooling channel distances from the mold's cavity.

To address this gap, the present performed a mold-evaluation study with conformal cooling channels on the cavity-side and and core-side L-PBF fabricated molds. This study uses two cavity-side molds with conformal cooling channels at different depths, $8 \mathrm{~mm}$ and $4 \mathrm{~mm}$. The L-PBF fabricated molds were evaluated using experiments and mold-filling simulations as a function of print defects, machining operations, sink marks, and conformal cooling channel distances from the mold's cavity. The results provide an insight into opportunities and challenges in two-sided L-PBF fabricated molds for injection molding.

\subsection{MATERIALS \& METHODS}

The mold designs selected for this project has a half comb-shaped cavity and core, as shown in Figure 3.1. The molds were fabricated through L-PBF process using an M2 Dual Laser with 400W laser by Concept Laser in Dallas, Texas. The printing process took approximately 17 hours. The L-PBF fabricated mold was subject to stress relief and remove from the build plate using wire EDM. 
The starting material to fabricate the tooling with conformal cooling channels for injection molding using L-PBF process was 17-4 PH stainless steel powder. The powder size distribution is centered on $30 \mu \mathrm{m}$ with a $\mathrm{D}_{10}$ of 15 and $\mathrm{D}_{90}$ of $45 \mu \mathrm{m}$. Mechanical and corrosion properties in previous material development studies performed by our group showed that 17-4 PH stainless steel could be used as a starting material for the fabrication of injection mold tools [6-10].

The two designs for the cavity-side molds contained conformal cooling channels at two different distances, $4 \mathrm{~mm}$ and $8 \mathrm{~mm}$, from the mold's surface, as shown in Figure 3.1b. The core-side mold contained conformal cooling channels $8 \mathrm{~mm}$ from the mold cavity, as shown in Figure 3.1a. The hole diameter of the conformal cooling channels for all the LPBF fabricated molds are $4 \mathrm{~mm}$. A core-side mold was also fabricated with conformal cooling channels located $8 \mathrm{~mm}$ from the surface. The dimensions of the designed mold were $81 \mathrm{~mm}$ in length, $61 \mathrm{~mm}$ in width and $27 \mathrm{~mm}$ in height.

Characterization for dimensional tolerance and surface roughness of the as-printed molds were performed using Vernier calipers and a surface profilometer, respectively. Prior to injection molding trials, the as-printed cavity and core-side molds were machined. Machining operations performed on the as-printed molds were surface grinding, EDM, milling, drilling, tapping to improve surface finish, and draft angles. After machining, the molds were fitted to a MUD frame for conducting injection molding studies.

The polymer material used for injection molding trials was Styron 478, high-impact polystyrene. Injection molding trials with the machined molds were performed using A 110-ton Cincinnati Milacron VT110-7 injection mold press at Plastic Products Co. (PPC). 
The injection molding trials with the core and cavity-side molds were ran under the process conditions shown in Table 3.1.

Table 3. 1 Process conditions for injection molding using the core and cavity-side molds

\begin{tabular}{|c|c|c|c|}
\hline Parameters & Cooling time (s) & Packing time (s) & Holding time (s) \\
\hline Run 1 & 10 & 1 & 1 \\
\hline Run 2 & 25 & 1 & 1 \\
\hline Run 3 & 10 & 2 & 1 \\
\hline
\end{tabular}

The computer-aided simulations were performed using Moldex3D platform to evaluate the mold-filling behavior of injection molding as a function of conformal cooling channels with different depths from the mold's cavity. Moldex3D Designer platform was used to mesh the part design and set the conformal cooling channels. Then, the meshed files were transferred to the Moldex3D Simulation platform. Moldex3D Simulation platform was used to Run simulations and evaluate part quality as a function of sink marks.

The weight and density of the injection molded parts, shown in Figure 3.5b, were characterized using a Mettler Toledo scale and Archimedes principle, at the Materials Innovation Guild, University of Louisville. Part dimensions were measured using Vernier calipers. Part quality, such as sink marks, warpage, air traps, and weld lines were visually noticeable. In this study, a dial gage was not ideal to measure sink depth for this moldevaluation study. 


\subsection{RESULTS \& DISCUSSION}

\subsubsection{MATERIALS IN L-PBF MOLDS}

Table 3.2 summarizes the physical and mechanical properties of 17-4 PH stainless steel for injection mold tooling in three conditions: as-printed, heat-treated, and hot isostatic pressing (HIP).

Table 3. 2 Properties of 17-4 PH stainless steel fabricated by L-PBF

\begin{tabular}{|c|c|c|c|}
\hline Property & As-printed & Heat-treated & HIP \\
\hline $\begin{array}{c}\text { Density } \\
\text { (\% theoretical') }\end{array}$ & $97.5 \pm 0.5$ & $98 \pm 0.5$ & $99.5 \pm 0.3$ \\
\hline $\begin{array}{c}\text { UTS } \\
\text { (MPa) }\end{array}$ & $950 \pm 50$ & $1300 \pm 30$ & $1450 \pm 20$ \\
\hline $\begin{array}{c}\text { Hardness } \\
\text { (HRC) }\end{array}$ & $28 \pm 2$ & $45 \pm 1$ & $36 \pm 2$ \\
\hline $\begin{array}{c}\text { Elongation } \\
\text { (\%) }\end{array}$ & $16 \pm 1$ & $2 \pm 1$ & $11 \pm 1$ \\
\hline \multicolumn{2}{|c|}{$*$ theoretical density: $7.87 \mathrm{~g} / \mathrm{cm}^{3}$ (cast part) } \\
\hline
\end{tabular}

It can be observed that as-printed parts can achieve density values close to heat-treated and HIP-processed parts, ranging between $97-99 \%$. For parts processed with heat-treatment techniques, ultimate tensile strength (UTS) ranges between 1430-1470 MPa for HIP parts and 1270-1330 MPa for heat-treated parts. However, as-printed parts achieve a lower ultimate tensile strength of $900-1000 \mathrm{MPa}$. Hardness is a common mechanical property characterized for steels. HIP and heat-treatment processes strengthens parts to increase the material's hardness. As observed, heat-treatment and HIP causes a decrease in elongation. The present study used as-printed parts for further evaluation, as the strengths and hardness 
seemed acceptable for the unfilled polystyrene material being injection molded in relatively small production runs.

\subsubsection{AS-PRINTED L-PBF MOLD EVALUATION}

Figures 3.1a and 3.1b show the drawings for the core-side mold and cavity-side mold with conformal cooling channels. The core-side mold contained conformal cooling channels 8 $\mathrm{mm}$ from the mold cavity. The two designs for the cavity-side molds were evaluated at two different conformal cooling channel distances from the mold cavity, $8 \mathrm{~mm}$ and $4 \mathrm{~mm}$, as shown in Figures 3.1c and 3.1d, respectively.

(a)

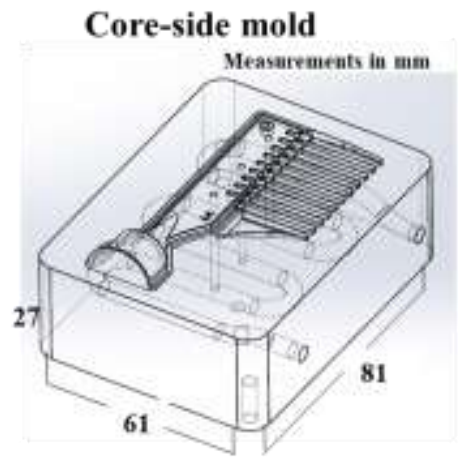

(c) Cavity-side mold 1 (side-view)

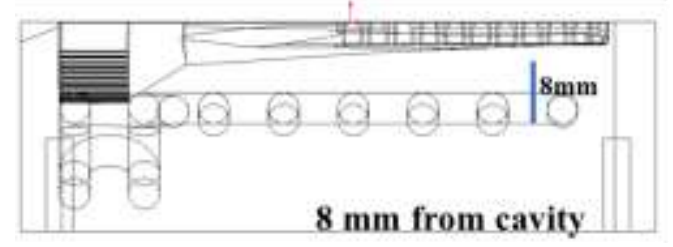

(b)

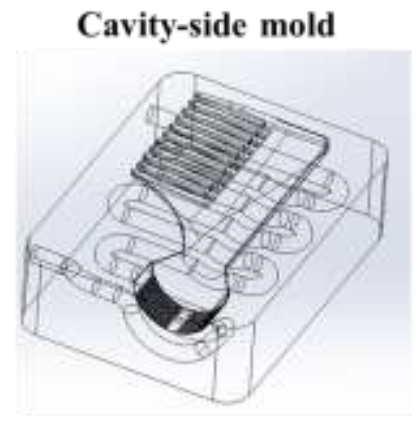

(d)

Cavity-side mold 2 (side-view)

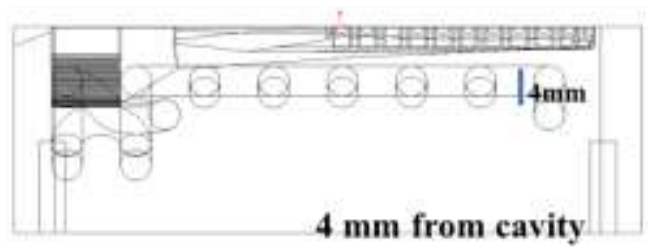

Figure 3.1 (a) Core-side mold design, (b) Cavity-side mold design, (c) Cavity-side mold design with conformal cooling at $8 \mathrm{~mm}$ depth, (d) Cavity-side mold design with conformal cooling channels at $4 \mathrm{~mm}$ depth

Figure 3.2 shows the as-printed core-side and cavity-side molds fabricated by $17-4 \mathrm{PH}$ stainless steel. Figure 3.2a shows the as-printed core-side mold with conformal cooling 
channels at $8 \mathrm{~mm}$ depth. Figures 3.2b and 3.2c show the as-printed cavity-side molds with conformal cooling channels at $8 \mathrm{~mm}$ depth and $4 \mathrm{~mm}$ depth, respectively.

(a)

Core-side mold

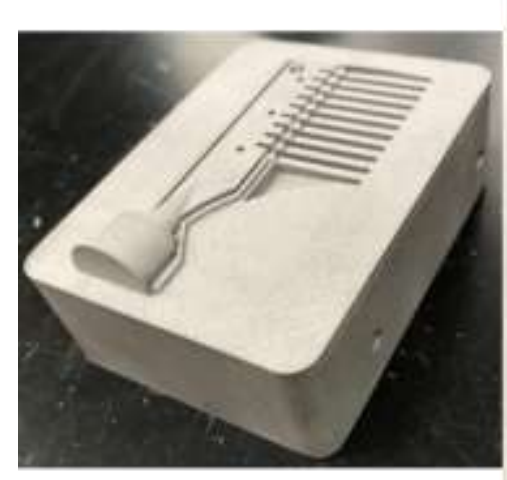

(b) Cavity-side mold (top-view) $8 \mathrm{~mm}$ from cavity

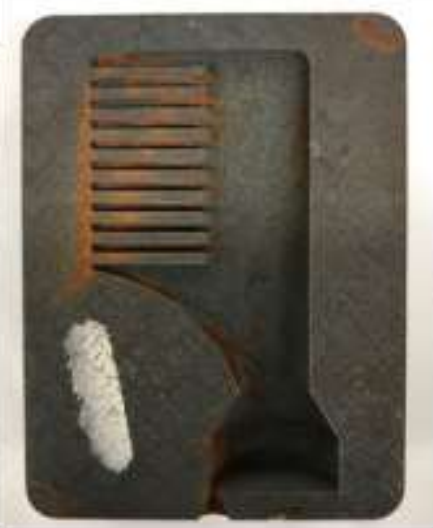

(c)

Cavity-side mold (top-view) $4 \mathrm{~mm}$ from cavity

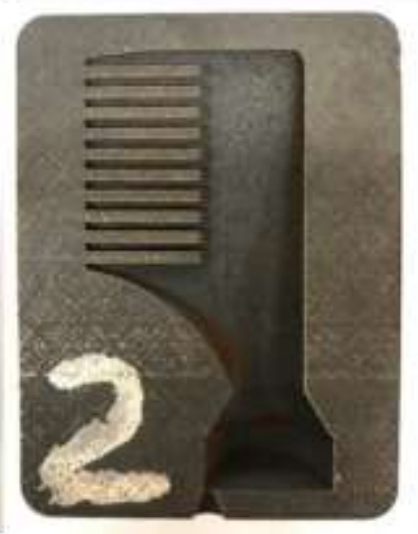

Figure 3.2 (a) As-printed core-side mold with conformal cooling channels at $8 \mathrm{~mm}$ depth, (b) As-printed cavity-side mold design with conformal cooling channels at $8 \mathrm{~mm}$ depth, (c) As-printed cavity-side mold design with conformal cooling channels at $4 \mathrm{~mm}$ depth

Various materials were used to fabricate L-PBF molds in our group. The L-PBF fabricated mold using $420 \mathrm{PH}$ stainless steel demonstrated print defects, such as porosity on the cavity's surface and delamination, as shown in Figure 3.3a and Figure 3.3b, respectively. The delamination on the L-PBF fabricated mold was caused due to residual stresses. Print defects were not observed on the L-PBF fabricated molds using 17-4 PH stainless steel. Independent studies pointed to processing conditions that eliminate $3 \mathrm{D}$ printing defects, such as porosity and delamination. 
(a)

(b)

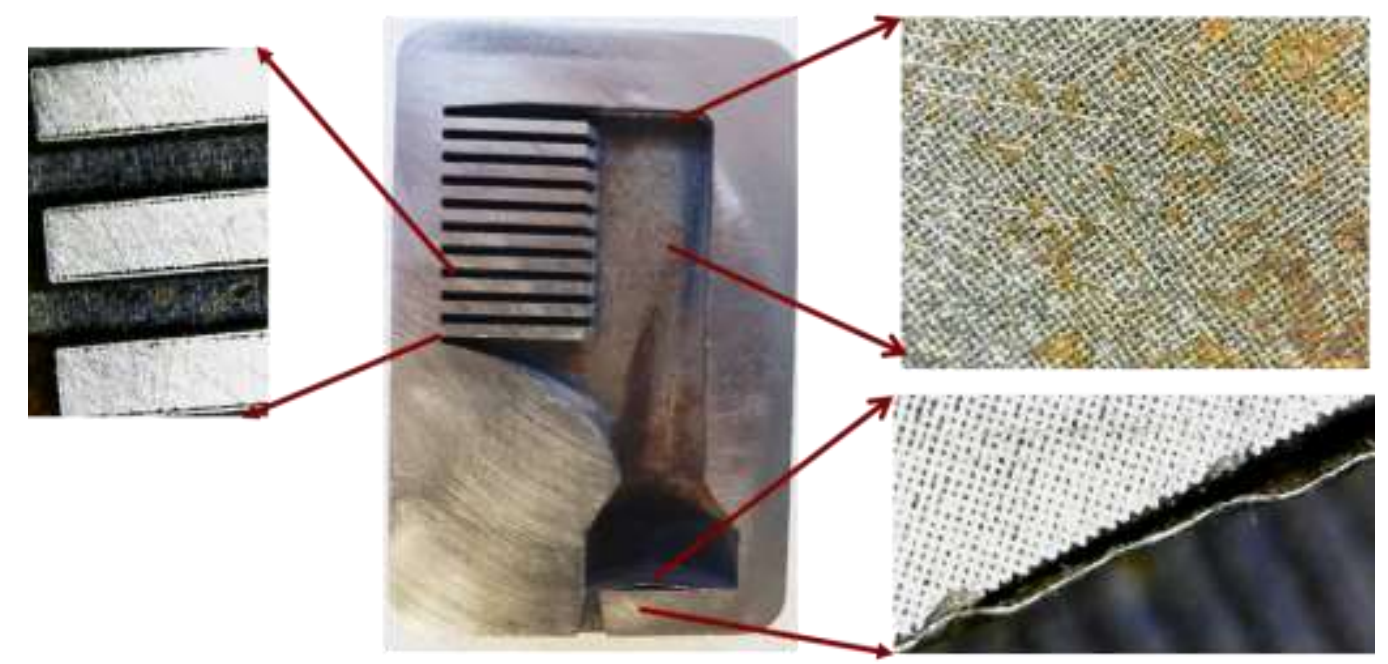

Figure 3.3 Print defects (a) Porosity in L-PBF fabricated molds, (b) Delamination

\subsubsection{LASER-POWDER BED FUSION FABRICATED MOLDS IN MACHINING OPERATIONS}

Figure 3.4 shows the machined core-side and cavity-side molds fabricated by 17-4 PH stainless steel. Figure 3.4a shows the machined core-side mold with conformal cooling channels at $8 \mathrm{~mm}$ depth. Figures 3.4b and 3.4c show the machined cavity-side molds with conformal cooling channels at $8 \mathrm{~mm}$ depth and $4 \mathrm{~mm}$ depth, respectively. As stated previously, machining operations are necessary to achieve good part quality on molded parts due to the mold's surface finish. Therefore, the as-printed molds were not used for injection molding in this study. 
(a)

Core-side mold

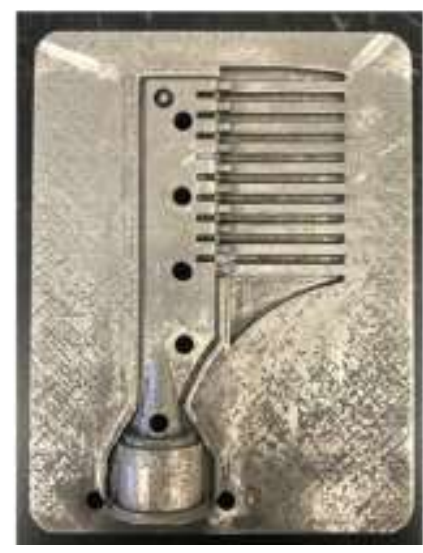

(b)

Cavity-side mold (top-view) $8 \mathrm{~mm}$ from cavity

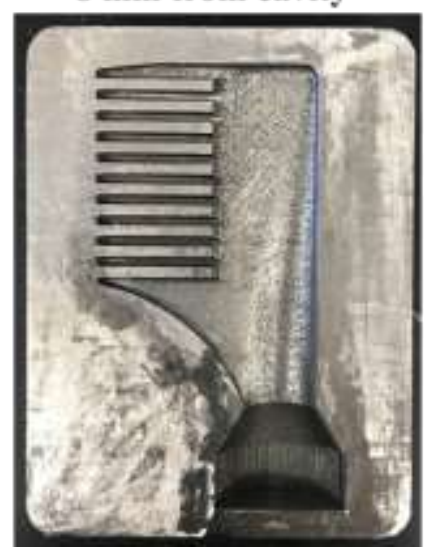

(c)

Cavity-side mold (top-view) $4 \mathrm{~mm}$ from cavity

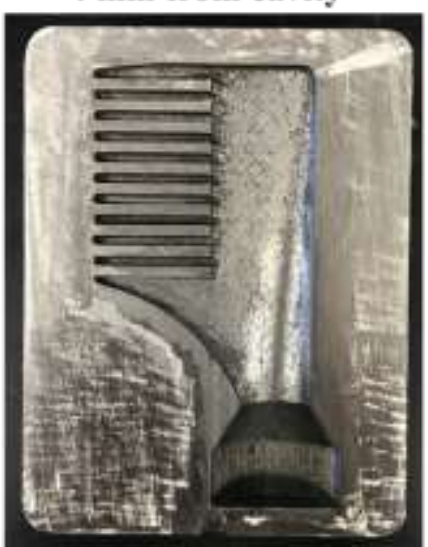

Figure 3.4 (a) Machined core-side mold with conformal cooling channels at $8 \mathrm{~mm}$ depth, (b) Machined cavity-side mold design with conformal cooling channels at $8 \mathrm{~mm}$ depth,

(c) Machined cavity-side mold design with conformal cooling channels at $4 \mathrm{~mm}$ depth

Table 3.3 indicates the surface roughness measurements of the as-printed and the postmachined cavity-side and core-side molds. On the as-printed molds, the surface roughness was $7.1 \pm 0.1 \mu \mathrm{m}$. On the post machined mold's top surface, the surface roughness for the core-side mold, cavity-side mold 1 and cavity-side mold 2 was $4.3 \pm 0.2 \mu \mathrm{m}, 1.1 \pm 0.1 \mu \mathrm{m}$, and $0.5 \mu \mathrm{m}$, respectively. On the post machined mold's cavity, the surface roughness for the core-side mold, cavity-side mold 1 and cavity-side mold 2 was $1.5 \pm 0.1 \mu \mathrm{m}, 1.5 \pm 0.1$ $\mu \mathrm{m}$, and $1.1 \pm 0.1 \mu \mathrm{m}$, respectively. It can be noticed that the surface roughness on the machined molds is smoother with the objective of achieving good part quality. Lastly, it was more difficult to machine the cavity of the L-PBF molds because of the part design and its complex features. 
Table 3. 3 Surface roughness measurements $(\mu \mathrm{m})$ of the as-printed mold and machined mold

\begin{tabular}{|c|c|c|c|}
\hline Mold & As-Printed Mold & \multicolumn{2}{|c|}{ Machined Mold } \\
\hline Conformal cooling channels & Top $(\boldsymbol{\mu m})$ & Top $(\boldsymbol{\mu m})$ & Cavity $(\boldsymbol{\mu m})$ \\
\hline Core-side mold & $7.0 \pm 0.1$ & $4.0 \pm 0.2$ & $1.5 \pm 0.1$ \\
\hline $\begin{array}{c}\text { Cavity-side mold 1 } \\
\text { conformal cooling channels at } \\
8 \text { mm depth }\end{array}$ & $7.1 \pm 0.1$ & $1.1 \pm 0.1$ & $1.5 \pm 0.1$ \\
\hline $\begin{array}{c}\text { Cavity-side mold 2 } \\
\text { conformal cooling channels at } \\
4 \text { mm depth }\end{array}$ & $7.1 \pm 0.1$ & 0.5 & $1.1 \pm 0.1$ \\
\hline
\end{tabular}

Figure 3.5a shows the comb-shaped drawing of the cavity-side and core-side molds.

Figure 3.5b shows injection molded parts with polystyrene using the core-side mold and cavity-side mold with conformal cooling channels at $4 \mathrm{~mm}$ depth under a cooling time of $10 \mathrm{~s}$ and packing time of $2 \mathrm{~s}$, Run 1.

(a)

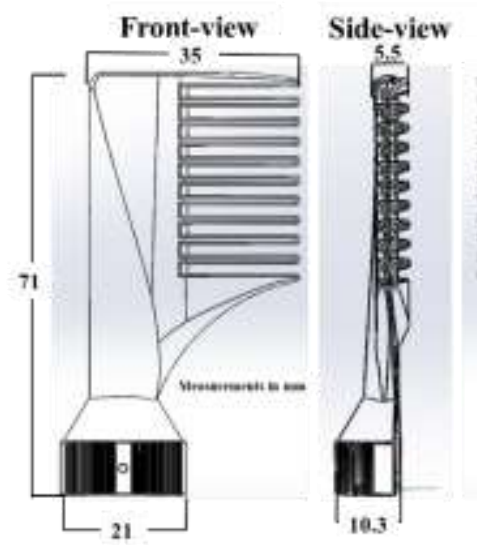

Back-view

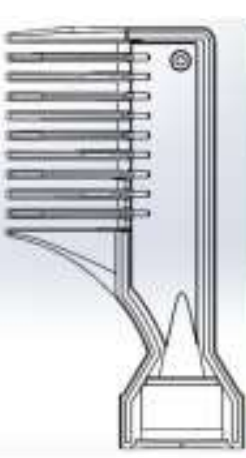

Front-view

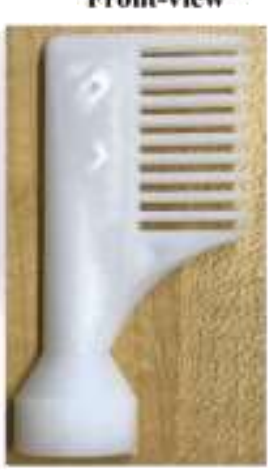

(b)

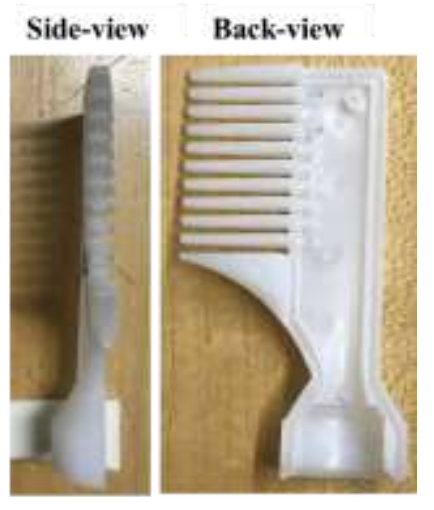

Figure 3.5 (a) Part drawing, (b) Injection molded parts

The initial injection molding trial to test the L-PBF fabricated molds, named T0, faced issues as the molded parts were found to break. Further analysis indicated that the parts 
were breaking due to the lack of an ejector pin at the bottom region to force the part out, as shown in Figure 3.6b. Ejector pins are typically placed on the core-side mold so as to remove the part from the mold cavity after the cooling phase. Due to the parts breaking, 3 additional ejector pins were machined into the bottom region of the core-side mold, as shown in Figure 3.6c. Injection-molded parts with the additional ejector pins machined into the L-PBF fabricated molds avoided any cracks on the bottom of the part. The part in Figure 3.6d was injection molded under Run 1 using the core and cavity with conformal cooling channels at $4 \mathrm{~mm}$ depth.

(a)

3 ejeetor pin design

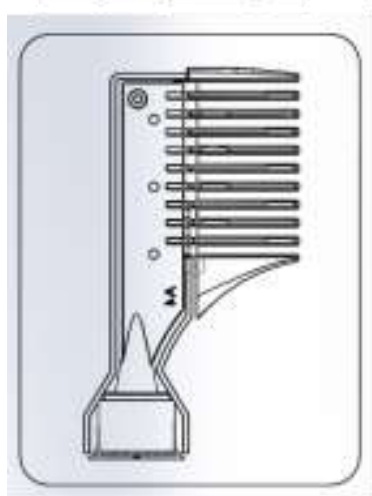

(b)

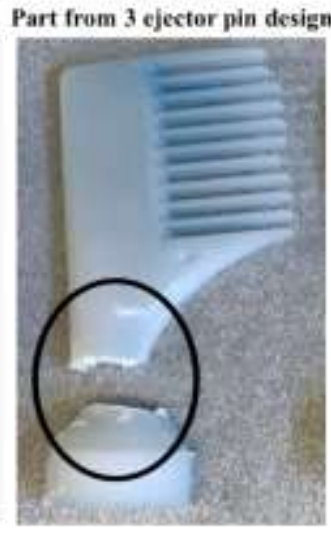

(c)

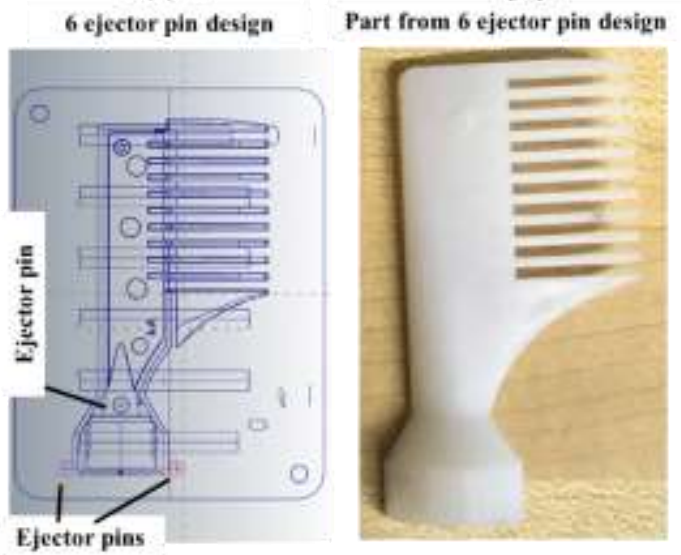

Figure 3.6 (a) Core-side mold design with 3 ejector pins, (b) Injection molded part using the 3 ejector pin mold design, (c) Core-side mold design with 6 ejector pins, (d) Injection molded part using the 6 ejector pin mold design

During injection molding trials with the cavity-side mold with conformal cooling channels at $8 \mathrm{~mm}$ depth, further issues were found with the material getting stuck between the comb's teeth during the interface between the cavity-side and core-side molds in the injection molding trials, as shown in Figure 3.7a. It can be noticed in Figure 3.7b that the stuck material on the core-side mold blocked the entrance of the molten material, causing features to crush on the injection molded parts. To address this issue, further machining 
was performed on the core-side mold by adjusting the draft angles on the comb's teeth to improve the interface between both molds. The interface between the core and cavity-side molds were adjusted to lock without causing the teeth to distort. Due to these modifications, the features were not crushed during further testing of the L-PBF fabricated molds. These results indicate that a better understanding of draft angles and ejector pins in the design and fabrication of L-PBF molds can save time spent in post-machining.

(a)

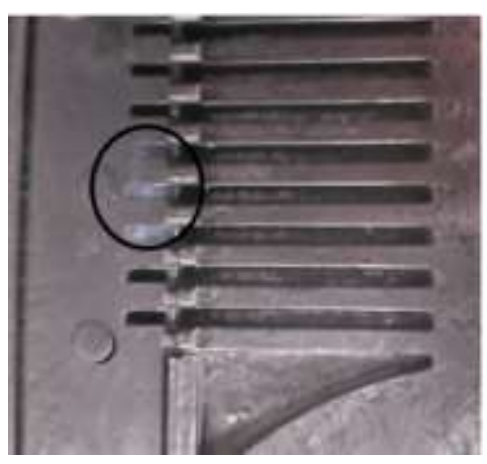

(b)

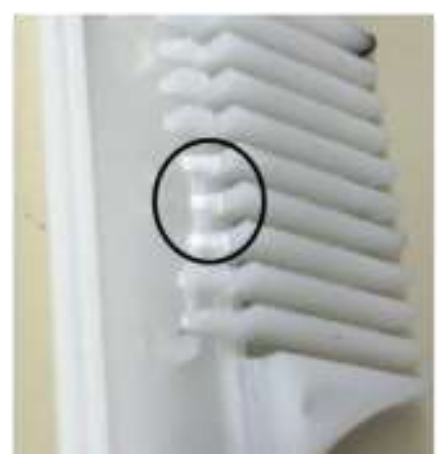

(c)

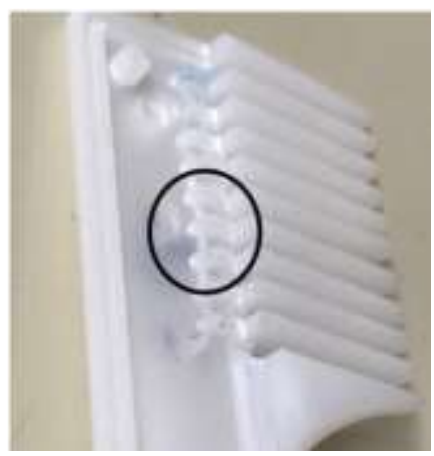

Figure 3.7 (a) Core-side mold with draft angle issues, (b) Injection molded part with defects caused by draft angle issues, (c) Injection molded part with improved draft angles

\subsubsection{LASER-POWDER BED FUSION FABRICATED MOLDS IN PART DESIGN}

The injection molded part parts were meshed with three different cooling channel systems: part without conformal cooling channels, part with conformal cooling channels at $8 \mathrm{~mm}$ from the mold cavity, and part with conformal cooling channels at $4 \mathrm{~mm}$ from the mold cavity. 
(a)

No cooling channels

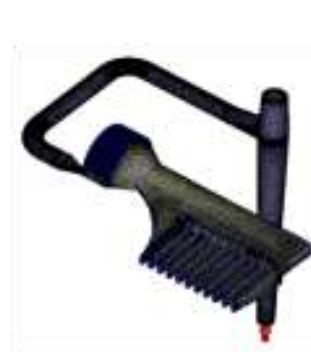

(b)

Conformal cooling channels

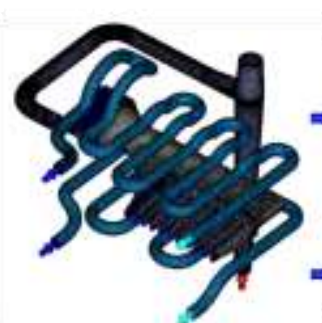

(c)

Conformal cooling channels $8 \mathrm{~mm}$ from mold cavity (d)

Conformal cooling channels $4 \mathrm{~mm}$ from mold cavity

Figure 3.8 Simulation mesh of the part with: (a) No conformal cooling channels, (b)

Conformal cooling channels, (c) Conformal cooling channels at $8 \mathrm{~mm}$ depth, (d)

Conformal cooling channels at $4 \mathrm{~mm}$ depth

The mold-filling behavior of the experimental trials were compared to computer-aided simulations of the part-design. As shown in Figure 3.9, the mold-filling behavior for the simulations and experiments correlate with each other. It can be concluded that molding simulation platforms can serve to predict the mold-filling behavior in injection molding. Furthermore, it can be noticed that this part-design could be completely filled in $0.73 \mathrm{~s}$.

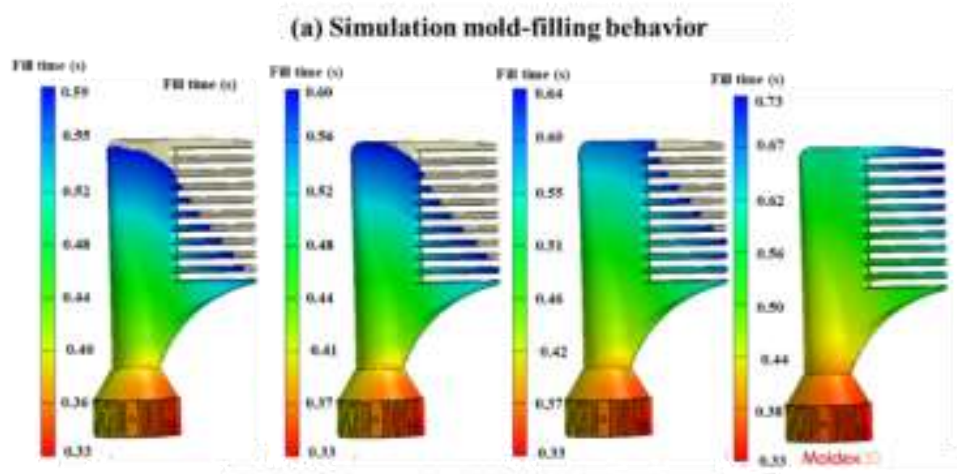

(b) Experimental mold-filling behavior

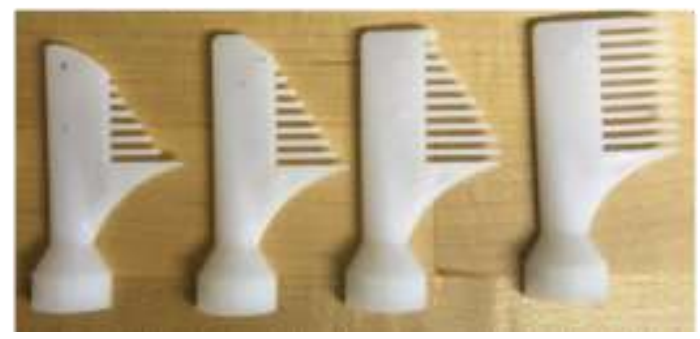

Figure 3.9 (a) Simulation mold-filling behavior, (b) Experimental mold-filling behavior 
Figure 3.10 illustrates a simulation comparison of sink marks between injection molded parts with no conformal cooling channels, conformal cooling channels at $8 \mathrm{~mm}$ depth, and conformal cooling channels at $4 \mathrm{~mm}$ depth. The processing conditions used for this comparison were ran under a cooling time of $10 \mathrm{~s}$ and packing time of $2 \mathrm{~s}$. Sink mark locations are indicated in green for the parts. Sink marks are usually located on the regions with larger volume, as they would usually contain a larger temperature difference throughout the thickness. The severity of the sink at the green locations are indicated in the scale bar. It can be noticed that simulations indicate a low sink depth range of 0.03-0.05 mm. Furthermore, simulations indicated the same locations and severity of sink marks for no conformal cooling channels, conformal cooling channels at $8 \mathrm{~mm}$ depth, and conformal cooling channels at $4 \mathrm{~mm}$ depth. In this study, we evaluate sink mark Locations 1,2 , and 3, indicated in Figure 3.10.

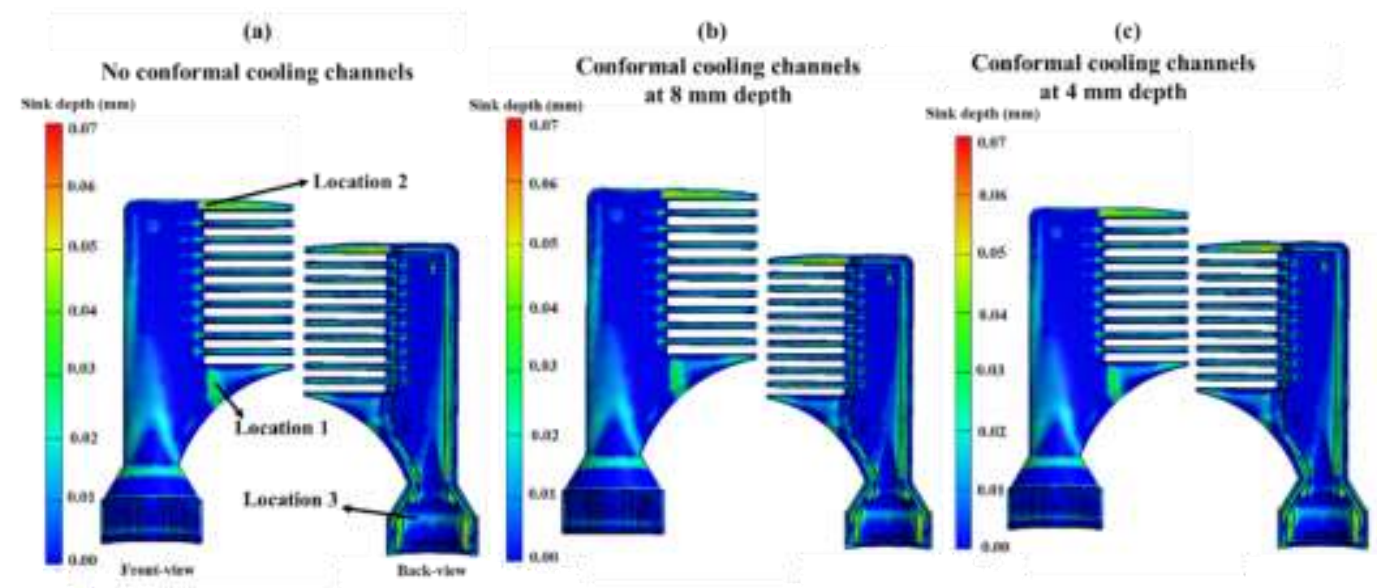

Figure 3.10 Simulations with sink mark results at condition 1 using (a) No conformal cooling channels, (b) Conformal cooling channels at $8 \mathrm{~mm}$ from the mold cavity, (c) Conformal cooling channels at $4 \mathrm{~mm}$ from the mold cavity

Figure 3.11 illustrates the sink mark Locations 1, 2, and 3 on the injection molded parts. The sink locations were equal for molded parts with all cooling channel systems: no 
conformal cooling channels, conformal cooling channels at $8 \mathrm{~mm}$ depth, and conformal cooling channels at $4 \mathrm{~mm}$ depth. Furthermore, it can be noticed that sink marks in experimental trials were showed at the same locations as simulations accurately predicted.

Figure 3.11c shows a cross-section of the sink at Location 3. In this study, a dial gage was not suitable to accurately measure the sink depth for this part geometry. However, sink depth for this part design will be quantified using a laser scanning machine and presented in future studies.

(a)

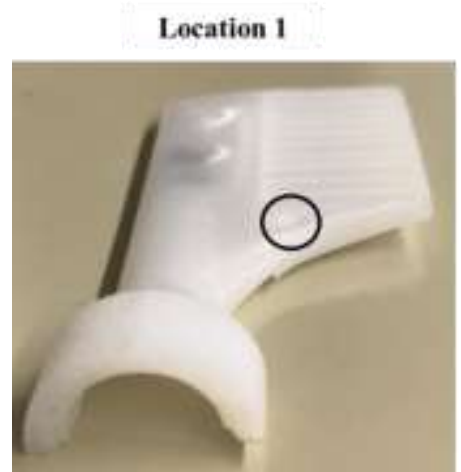

(b)

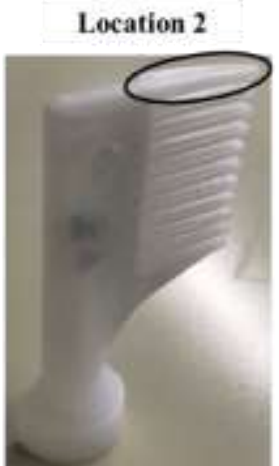

(c)

Location 3

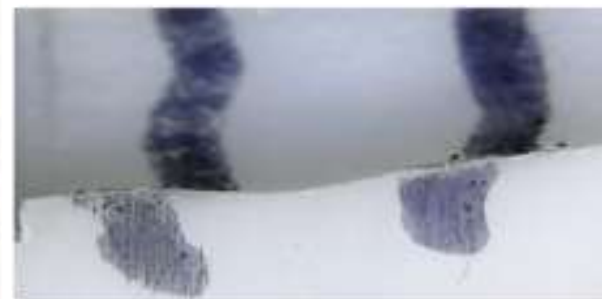

Figure 3.11 Sink mark locations on experimental parts using the L-PBF fabricated mold with conformal cooling channels at $4 \mathrm{~mm}$ depth, conformal cooling channels at $8 \mathrm{~mm}$ depth, and no conformal cooling channels: (a) Location 1, (b) Location 2, (c) Location 3 cross-section

Figure 3.12 plots a quantitative simulation comparison of sink marks between molded parts with no conformal cooling channels, conformal cooling channels at $8 \mathrm{~mm}$ depth, and conformal cooling channels at $4 \mathrm{~mm}$ depth. The plots represent the three sink mark locations indicated in Figure 3.10 for all three designs. It can be noticed that the sink depths for the respective locations are the same for all three cooling channel systems. Furthermore, simulations indicate that the sink depth is most severe at Location 2 and least severe at Location 3. 
(a)

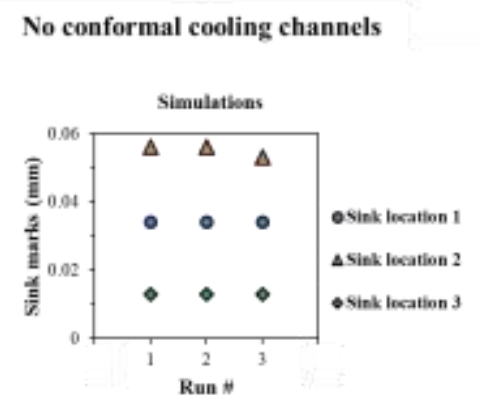

(b)

Conformal cooling channels at $8 \mathrm{~mm}$ depth

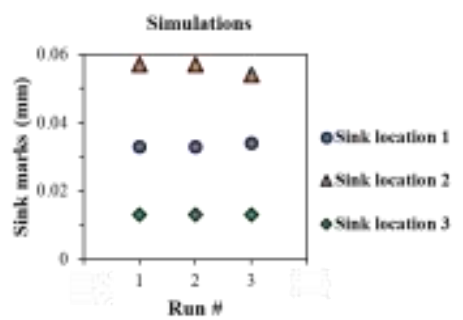

(c)

Conformal cooling channels at $4 \mathrm{~mm}$ depth

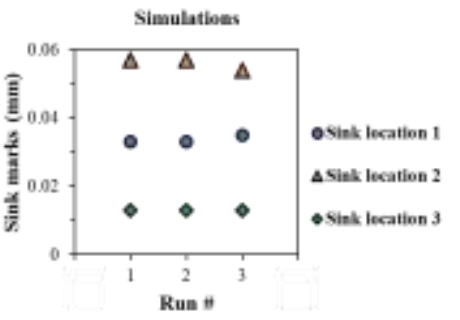

Figure 3.12 Simulation plot with sink mark defects using (a) No conformal cooling channels, (b) Conformal cooling channels at $8 \mathrm{~mm}$ from the mold cavity, (c) Conformal cooling channels at $4 \mathrm{~mm}$ from the mold cavity

Figure 3.13 shows mold-filling results for frozen regions after a cooling time of $10 \mathrm{~s}$ between injection molded parts with no conformal cooling channels, conformal cooling channels at $8 \mathrm{~mm}$ depth, and conformal cooling channels at $4 \mathrm{~mm}$ depth. As shown in the scale bar, it can be noticed that Location 1 and Location 3 are 19-40\% frozen prior to ejection of the part. Due to the molten material within those regions, sink marks were created due to the difference in temperature between the center and surface of the part. Location 2 was frozen $88-99 \%$ frozen, not $100 \%$ due to the sink mark formed at that location. 
(a)

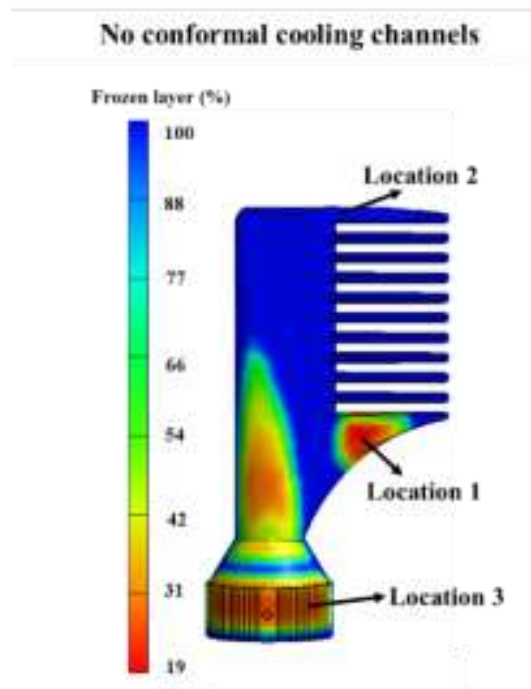

(b)

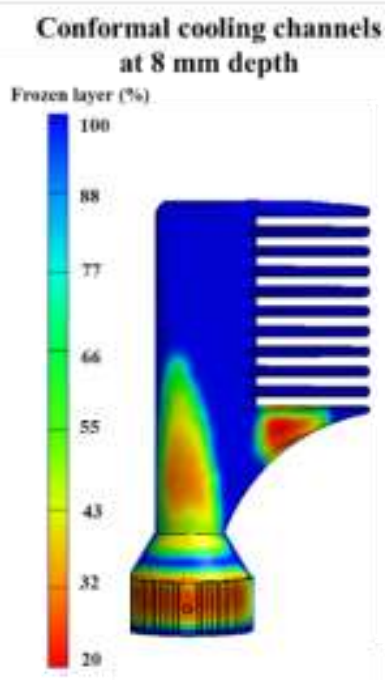

(c)

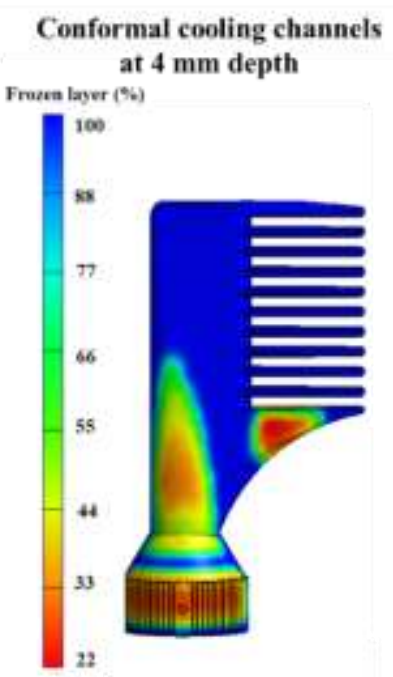

Figure 3.13 Simulations with frozen layer results at Run 1 using (a) No conformal cooling channels, (b) Conformal cooling channels at $8 \mathrm{~mm}$ from the mold cavity, (c) Conformal cooling channels at $4 \mathrm{~mm}$ from the mold cavity

Simulations indicated that the conformal cooling channels affected the temperature uniformity distribution on the surface of the molded parts, as shown in Figure 3.14. It can be noticed that the uniformity distribution with conformal cooling channels increases, as it is placed closer to the mold's cavity. The difference on surface temperature with conformal cooling channels was decreased by $5^{\circ} \mathrm{C}$. No difference in surface temperature was noticed between conformal cooling channels at $8 \mathrm{~mm}$ depth and $4 \mathrm{~mm}$ depth. 
(a)

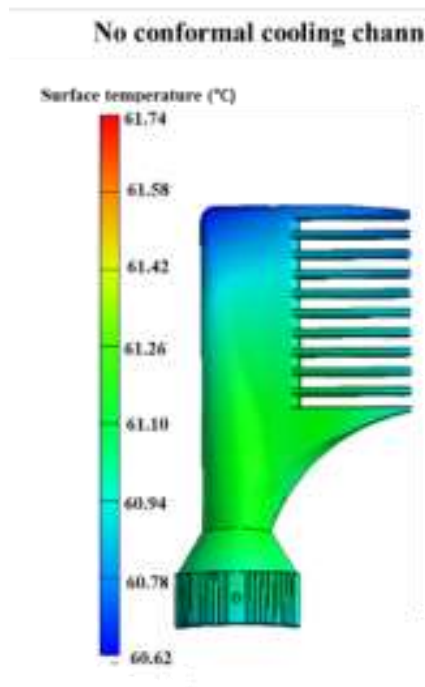

(b)

(c)

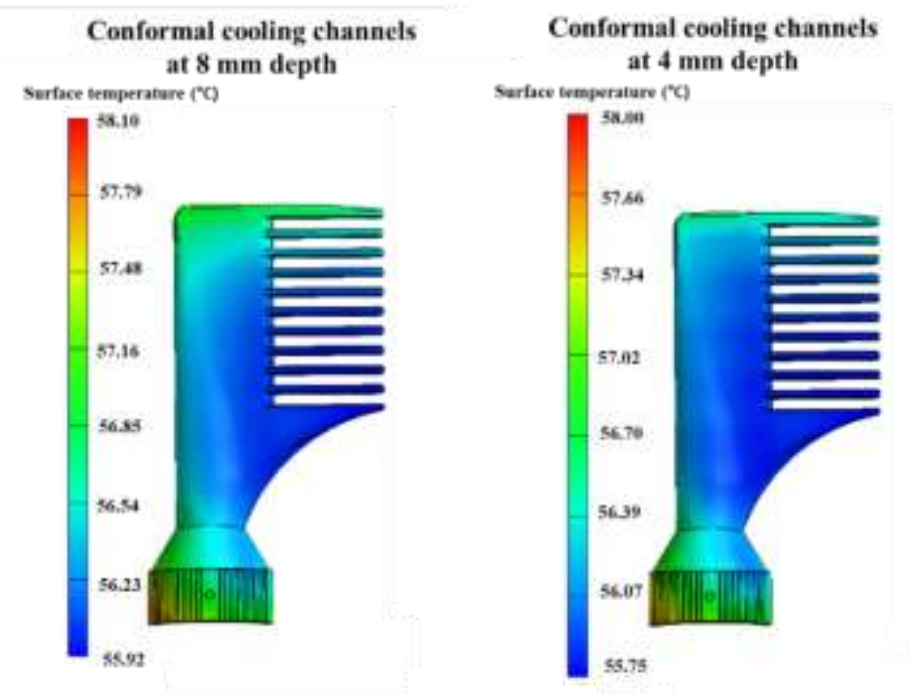

Figure 3.14 Simulations with surface temperature results at Run 1 using (a) No conformal cooling channels, (b) Conformal cooling channels at $8 \mathrm{~mm}$ from the mold cavity, (c) Conformal cooling channels at $4 \mathrm{~mm}$ from the mold cavity

Conformal cooling channels usually affect the surface of the part. Hence, it is difficult to cool down the center of thicker regions without any direct cooling systems placed around them. Figure 3.15 shows the temperature difference between the center and surface of Location 1 at run 1 with conformal cooling channels at $4 \mathrm{~mm}$ depth. The scale bar indicates a large difference in temperature between the center and surface of the part. Therefore, the shrinkage caused by the temperature difference in those regions created sink marks. It was noticed that conformal cooling channels for this part design did not largely cool down the center temperature at Location 1. Due to this, the difference between the center temperature and surface temperature remained large. 
(a)

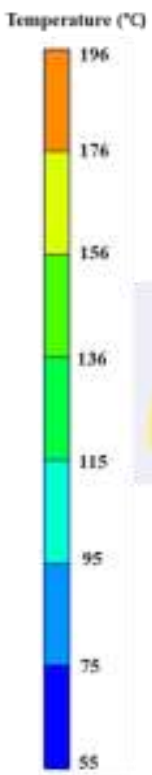

(b)

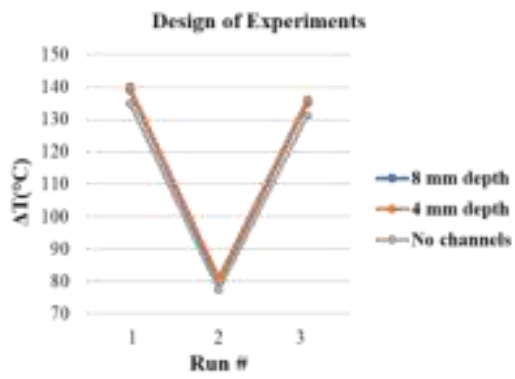

Figure 3.15 (a) Simulation results of surface temperature and internal temperature at run 1 (b) Simulations plot with difference in temperature at all conditions using no conformal cooling channels, conformal cooling channels at $8 \mathrm{~mm}$ depth, and $4 \mathrm{~mm}$ depth

Figure 3.16 illustrates a simulation comparison of cooling temperatures of molten regions after a cooling time of $10 \mathrm{~s}$ between injection molded parts with no conformal cooling channels, conformal cooling channels at $8 \mathrm{~mm}$ depth, and conformal cooling channels at 4 mm depth. It can be noticed that sink mark regions were at a relatively high temperature. After $10 \mathrm{~s}$ of cooling time provided, the part is ejected from the cavity even if there are molten regions within the part. Locations 1,2 , and 3 were at a temperature above the material's freezing temperature. There is a slight decrease of molten material with conformal cooling channels. Figure 3.17 replicates the same simulation comparison of cooling temperature, but after a cooling time of $25 \mathrm{~s}$. With an increase in cooling time to $25 \mathrm{~s}$, Location 2 displays no molten material in mold-filling simulations. Additionally, the molten volume at Location 1 and Location 3 decreases with a larger cooling time. 
(a)

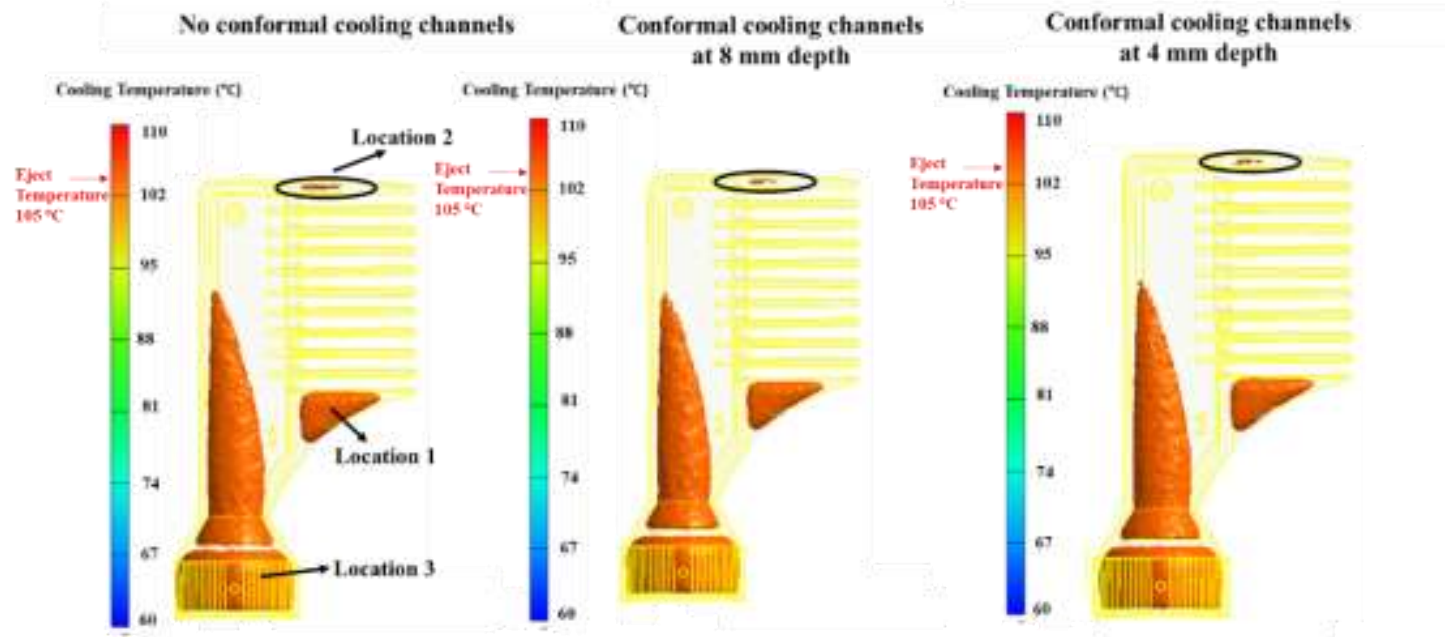

Figure 3.16 Simulations with cooling temperature results after a cooling time of $10 \mathrm{~s}$ using (a) No conformal cooling channels, (b) Conformal cooling channels at $8 \mathrm{~mm}$ from the mold cavity, (c) Conformal cooling channels at $4 \mathrm{~mm}$ from the mold cavity

(a)

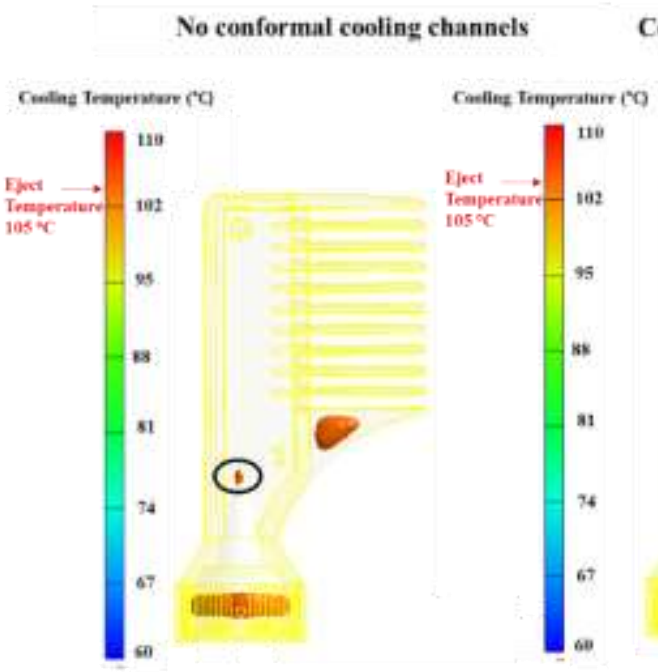

(b)

Conformal cooling channels at $8 \mathrm{~mm}$ depth (c)

Conformal cooling channels at $4 \mathrm{~mm}$ depth

Figure 3.17 Simulations with cooling temperature results after a cooling time of $25 \mathrm{~s}$ using (a) No conformal cooling channels, (b) Conformal cooling channels at $8 \mathrm{~mm}$ from the mold cavity, (c) Conformal cooling channels at $4 \mathrm{~mm}$ from the mold cavity

Figure 3.18 shows mold-filling simulation results for heat transfer after a cooling time of $10 \mathrm{~s}$ of injection molded parts with no conformal cooling channels, conformal cooling channels at $8 \mathrm{~mm}$ depth, and conformal cooling channels at $4 \mathrm{~mm}$ depth. During the cooling 
phase, the molten plastic solidifies as heat conduction occurs through the mold's wall. The mold dissipates the heat from the material and the difference in temperatures stabilizes after a while, according to the $2^{\text {nd }}$ law of thermodynamics. It can be noticed that heat flux between the mold and molten material to dissipate heat was slightly increased by 0.20 $\mathrm{J} / \mathrm{s} . \mathrm{cm}^{2}$ on thicker regions with conformal cooling channels at $4 \mathrm{~mm}$ depth. However, this difference in heat flux was not relatively large for this part design to make a difference in part quality. Lastly, as shown in the scale bar, it can be seen that the heat flux is larger on the thicker regions because there is more heat to be extracted from those locations.

(a)

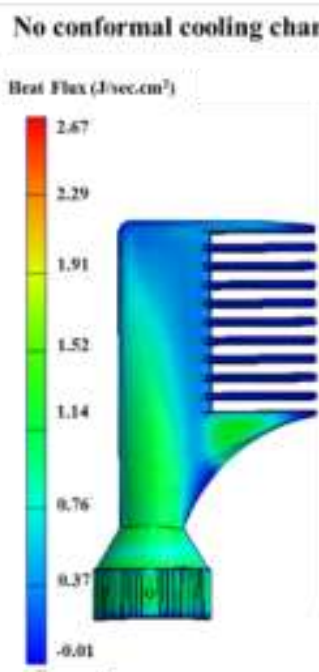

(b)

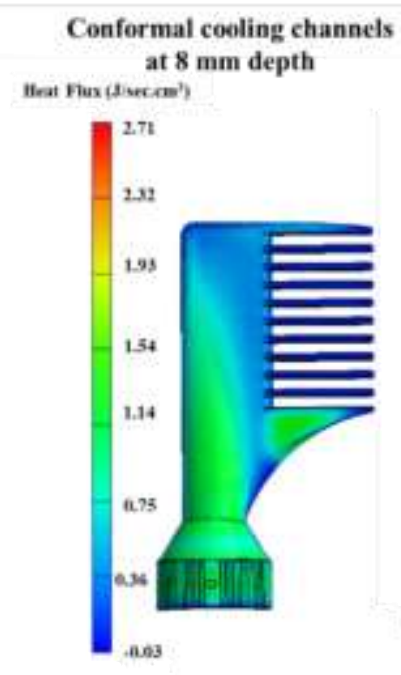

(c)

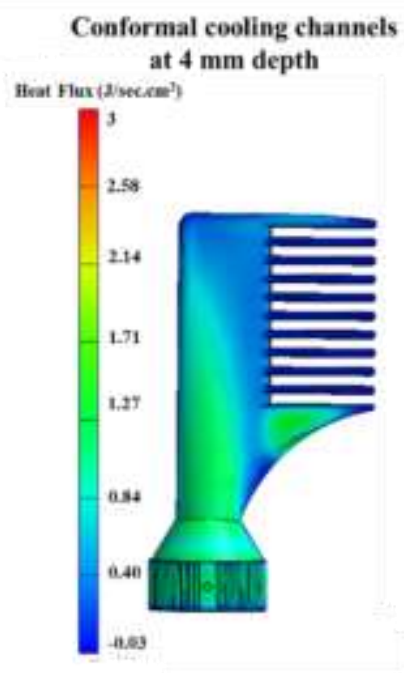

Figure 3.18 Simulations with heat flux results at Run 1 using (a) No conformal cooling channels, (b) Conformal cooling channels at $8 \mathrm{~mm}$ from the mold cavity, (c) Conformal cooling channels at $4 \mathrm{~mm}$ from the mold cavity

Figure 3.19 illustrates in-stress caused by the force of the ejector pins. Ejector pin marks are commonly caused by the part not having enough cooling time or a high ejection pressure by the injection molding machine. In this study, as the ejector pin marks were 
noticed with molded parts under cooling times of 10 and $25 \mathrm{~s}$, we concluded that the ejector pin marks were mainly caused because of the machine's high ejection pressure.

(a)

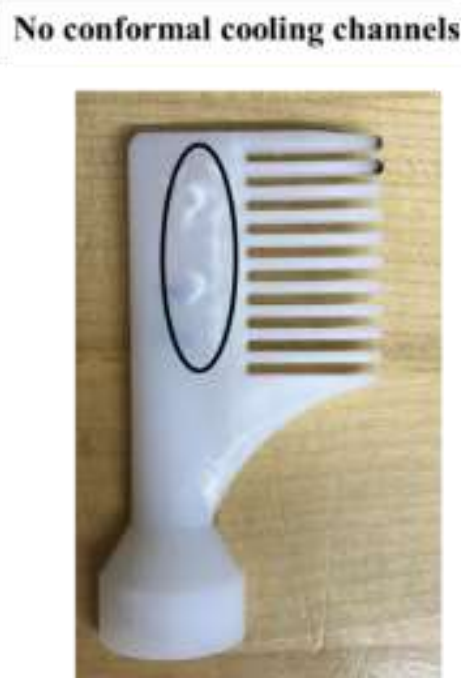

(b)

Conformal cooling channels at $8 \mathrm{~mm}$ depth

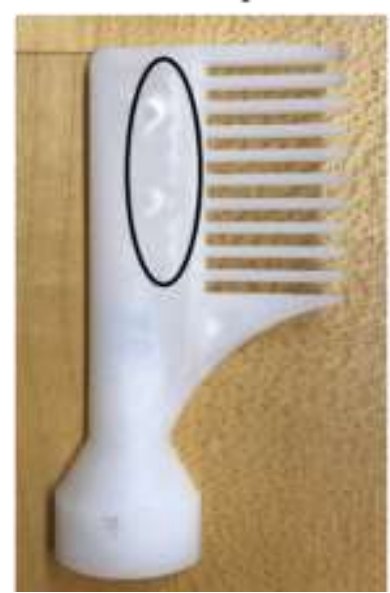

(c)

Conformal cooling channels at $4 \mathrm{~mm}$ depth

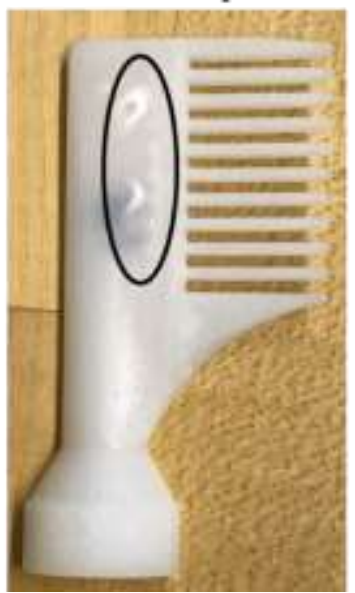

Figure 3.19 In-stress on experimental parts after a cooling time of $10 \mathrm{~s}$ using L-PBF fabricated mold with (a) conformal cooling channels at $4 \mathrm{~mm}$ depth, (b) conformal cooling channels at $8 \mathrm{~mm}$ depth, (c) No conformal cooling channels

\subsection{CONCLUSIONS}

In this paper, 17-4 PH stainless steel core-and-cavity tooling for injection molding was fabricated by L-PBF and evaluated through a series of experiments and simulations. Based on the results, the following conclusions emerge:

1) $3 \mathrm{D}$ printing defects, such as porosity and delamination are possible complications when tooling for injection molding is fabricated using L-PBF process. Independent studies pointed to processing conditions, which were used in this study, that overcame these 3D printing defects, enabling this mold-evaluation study to be conducted. 
2) Injection molded parts using the as-printed mold did not achieve good part quality. Therefore, machining operations on L-PBF fabricated molds are necessary to improve part quality, avoid discrepancies in the part, reduce surface roughness, adjust draft angles, and perform other mold design adjustments. A better understanding of draft angles and ejector pins during the design of L-PBF fabricated molds can save time spent in post-machining.

3) The Moldex3D simulation platform served to predict mold-filling behavior and fill time of the experimental parts. Furthermore, the platform accurately captured sink mark locations. In this study, a dial gage was not appropriate to measure sink depths in molded parts with this part design. Sink depth for this part design will be quantified using a laser scanning machine and presented in future studies by this group.

4) Simulations indicated that the conformal cooling channel design influenced the surface temperature distribution of the part. However, simulations indicated no alleviation by conformal cooling channels in the center temperature of the thickest region. This study indicates that existing simulation tools based on the Moldex3D platform may be satisfactory for pre-screening parts that are suitable for injection molding using molds and conformal cooling channels and L-PBF processes.

5) There was not a significant difference in part quality or cooling with the incorporation of conformal cooling channels for this geometry based on simulations and experiments. Additional mold designs need to be evaluated to understand when to use conformal cooling channels in tooling fabricated using L-PBF. 


\section{CHAPTER 4}

\section{CONCLUSIONS AND FUTURE WORK}

\subsection{CONCLUSIONS}

In this paper, 17-4 PH stainless steel tooling for injection molding was fabricated by LPBF and evaluated through a series of experiments and simulations. Based on the results, the following conclusions emerge:

1) $3 \mathrm{D}$ printing defects, such as porosity and delamination are possible complications when tooling for injection molding is fabricated using L-PBF process. Independent studies pointed to processing conditions, which were used in this study, that overcame these 3D printing defects, enabling this mold-evaluation study to be conducted.

2) Injection molded parts using the as-printed mold did not achieve good part quality. Therefore, machining operations on L-PBF fabricated molds are necessary to improve part quality, avoid discrepancies in the part, reduce surface roughness, adjust draft angles, and perform other mold design adjustments. A better understanding of draft angles and ejector pins during the design of L-PBF fabricated molds can save time spent in post-machining.

3) Parts with thin walls tend to cool faster and achieve better part quality in terms of sink marks and warpage. The reduction in part thickness better part quality, indicated by experiments and simulations. L-PBF fabricated molds enable a quicker verification of changes in part geometry than traditionally manufactured molds do. 
4) Experimental results indicated that the location of sink marks and warpage could be accurately predicted in computer-aided simulations, but their magnitude was not well described. Also, the results from simulations indicated that warpage was more sensitive than sink marks to the effects of processing conditions such as cooling time, in qualitative agreement to experimental data. Changes in the constitutive equations governing sink mark predictions may be needed on simulation platforms to address this discrepancy.

5) The additional of chemical blowing agent concentration to the polypropylene improved the part quality in terms of sink marks based on the results from experiments and simulations. L-PBF fabricated molds enable a quicker verification of blowing agent concentration than traditionally manufactured molds do. The results from simulations indicated that the depth of sink marks was not sensitive to the effects of increased blowing agent concentration from 1 wt. \% to 2 wt., in contrast to experimental data. Changes in the constitutive equations governing sink mark predictions may be needed on simulation platforms to address this discrepancy.

6) Moldex3D simulation platform served to accurately predict mold-filling behavior and fill time of the experimental parts. Analysis of the fraction of frozen layer in simulations allow to explain the cause of sink marks and warpage as a function of changes in geometry (part thickness) and material (blowing agents).

7) Simulations indicated that the conformal cooling channel design influenced the surface temperature distribution of the part. However, simulations indicated no alleviation by conformal cooling channels in the center temperature of the thickest region. This study indicates that existing simulation tools based on the Moldex3D platform may be 
satisfactory for pre-screening parts that are suitable for injection molding using molds and conformal cooling channels and L-PBF processes.

8) There was not a significant difference in part quality with the incorporation of conformal cooling channel on the part design of Chapter 3. Mold designs need to be evaluated to understand when to use conformal cooling channels in tooling fabricated using L-PBF.

\subsection{FUTURE WORK}

The current research furthers its study in evaluating more part designs with conformal cooling channels and understanding when to incorporate conformal cooling channels. Moldex3D simulation platform will be used for verification of mold-filling behavior, part design, gate design, multi-cavity molds and conformal cooling channels. Another sector of future studies entail evaluating injection molded parts using the L-PBF fabricated molds with $420 \mathrm{PH}$ stainless steel. Further studies will be implemented on the understanding of sink mark magnitude using computer-aided simulations. For comparative quantification, sink depths on experimental parts will be measured using a laser scanning machine. Future experiments will also test the L-PBF fabricated molds in Chapter 3 using blowing agents to eliminate sink defects presented. Finally, a cost-benefit analysis and a simulation-led

protocol will be developed to assess the favorable part and mold designs for using L-PBF fabricated molds with conformal cooling channels relative to CNC-machined tooling. 


\section{REFERENCES}

1. Injection Molded Plastics Market Size Report By Raw Material By Application And Segment Forecasts. [Online]; Grand View Research.

2. Dimla, D., M. Camilotto, and F. Miani, Design and optimisation of conformal cooling channels in injection moulding tools. Journal of Materials Processing Technology, 2005. 164: p. 1294-1300.

3. Morris, A. Plastic Injection Moulding - An Introduction. 2001 [Online]; Available: https://www.azom.com/article.aspx?ArticleID=265.

4. Lei Xie, L.S., and Bingyan Jiang, Production of Injection Molding Tooling with CC using 3DP

5. Schwartz, J. Trends For Plastic Molding By Industry. 2017 [Online]; Available from: https://revpart.com/trends-plastic-molding-industry/.

6. Understanding the Tool Making Process. [Online]; Available from: http://www.dienamics.com.au/blog/understanding-tool-making-process/.

7. Injection Mold Making \& Tooling. [Online]; Available from: http://www.abtecinc.com/custom-plastic-injection-molding/mold-making/.

8. Mechanisms, C. Everything You Need To Know About Injection Molding. [Online]; Available from: https://www.creativemechanisms.com/blog/everythingyou-need-to-know-about-injection-molding.

9. Weaver, T., Thomas, J.., Atre. S.V., German R., Time compression-rapid steel tooling for an ever-changing world. Materials \& Design 21: p. 409-415. 2000.

10. German, R.M. and J Thomas, Large, low-production quantity components via polymer-assisted shaping and sintering technologies. P/M Science \& Technology Briefs 4: p. 9-13.2002

11. German, R.M., Weaver, T.J., Thomas, J.A., Griffo, A., Atre. S.V. Powdered material rapid production tooling method and objects produced therefrom. US Patent.2002

12. Marc. High Level Processes: Powder Bed Fusion. [Online]; Available from: https://www.bintoa.com/powder-bed-fusion/.2017 
13. Franchetti, M. and C. Kress, An economic analysis comparing the cost feasibility of replacing injection molding processes with emerging additive manufacturing techniques. The International Journal of Advanced Manufacturing Technology,. 88(9-12): p. 2573-2579. 2016

14. Irrinki, H., Mechanical properties and microstructure evolution of 17-4 PH stainless steel processed by laser-powered bed fusion,University of Louisville, 2016.

15. Jahan, S.A. and El-Mounayri H., Optimal Conformal Cooling Channels in 3D Printed Dies for Plastic Injection Molding. Procedia Manufacturing, 5: p. 888-900. 2016.

16. Huang, R., et al., Environmental and economic implications of distributed additive manufacturing: The case of injection mold tooling. Journal of Industrial Ecology, 2017.

17. Concept Laser, a.G.A.c. Selective laser melting (SLM). [Online]; Available from: https://www.concept-laser.de/en/glossar/selective-laser-melting.html.

18. S. Ahn, Chung, S.T., Atre S.V., Park, S.J., German R.M., Integrated filling, packing and cooling CAE analysis of powder injection moulding parts. Powder Metallurgy 51.2013

19. Atre S.V., Park S.J., Zauner R., German R.M., Process simulation of powder injection moulding: identification of significant parameters during mould filling phase. Powder Metallurgy. 50: p. 76-85.2013

20. Park SJ, Ahn S, Kang T.G., German R.M., A review of computer simulations in powder injection molding. International Journal of Powder Metallurgy: p. 3746.2010 .

21. Lee S.W., Ahn S., Whang C.J., Park S.J., Atre S.V., Kim J., German R.M., Effects of process parameters in plastic, metal, and ceramic injection molding processes. Korea-Australia Rheology Journal 23: p. 127.2011.

22. Urval R., Lee S., Atre S.V., Park S.J., German R.M., Optimization of process conditions in powder injection moulding of microsystem components using a robust design method: part I. primary design parameters. Powder Metallurgy 51: p. 133-142.2013.

23. Saifullah A. and Masood S. Finite element thermal analysis of conformal cooling channels in injection moulding. in 5th Australasian Congress on Applied Mechanics (ACAM 2007). 2007.

24. Zhenhao, Xi., Chen J., Liu T., Sheng L., Experiment and simulation of foaming injection molding of polypropylene/nano-calcium carbonate composites by 
supercritical carbon dioxide. Chinese Journal of Chemical Engineering, 24(1): p. 180-189. 2016.

25. Mohamed, O.A., Masood SH, and Saifullah A., A Simulation Study of Conformal cooling channels in plastic injection molding. International Journal of Engineering Research, 2(5): p. 344-348. 2013.

26. $\mathrm{Xu}, \mathrm{X}$., Sachs S. and Allen, The design of conformal cooling channels in injection molding tooling. Polymer Engineering \& Science, 41(7): p. 1265-1279. 2001.

27. Sachs, E., Wylonics E., Allen S., Cima M.., Guo H. Production of injection molding tooling with conformal cooling channels using the three dimensional printing process. Polymer Engineering \& Science, 40(5): p. 1232-1247. 2004

28. Hsu, F., et al., Investigation on conformal cooling system design in injection molding. Advances in Production Engineering \& Management, 8(2): p. 107. 2013.

29. Irrinki H, B.B., Kate K., Atre S.V.., Material selection for the production of injection moulding tooling by Additive Manufacturing. Metal Additive Manufacturing, p. 77-89. 2016.

30. H.Irrinki, S.N., M. Ahlfors, O. Gulsoy, J. Stitzel, S.V.Atre Effect of Powder Attributes and Hot isostatic Pressing on the Mechanical Properties and Microstructures of 17-4 PH Stainless Steel Processed via Laser-Powder Bed Fusion, in Additive Manufacturing with Powder Metallurgy (AMPM).San Antonio, USA. 2018

31. Irrinki H., S.D.N., Atre S.V., Mechanical Properties and Microstructures of Bronze Processed by Laser-Powder Bed Fusion, in Additive Manufacturing with Powder Metallurgy (AMPM), San Antonio, USA. 2018

32. Nath S.D., Irrinki H., Kearns M., Gulsoy O. Atre S.V. Mechanical Properties and Microstructures of 420 Stainless Steel Processed by Laser-Powder Bed Fusion, in Additive Manufacturing with Powder Metallurgy (AMPM). San Antonio, USA. 2018.

33. Nath S.D., Irrinki H., Kearns M., Gulsoy O. Atre S.V., Role of Powder Attributes on the Mechanical Properties and Microstructures of 420 Stainless Steel Processed by Laser-Powder Bed Fusion, in Additive Manufacturing with Powder Metallurgy (AMPM). San Antonio, USA. 2018:

34. Park, H.-S. and Pham N.H., Design of conformal cooling channels for an automotive part. International Journal of Automotive Technology, 10(1): p. 87-93. 2009.

35. Hall M., and Krystofik M. Conformal Cooling White Paper. Rochester Institute of Technology. Aug. 2015. 
36. Beard, R. Why Conformal Cooling Makes Sense. 2014 [Online]; Available from: https://www.ptonline.com/articles/why-conformal-cooling-makes-ense.

37. Armillotta, A., R. Baraggi, and S. Fasoli, SLM tooling for die casting with conformal cooling channels. The International Journal of Advanced Manufacturing Technology, 71(1-4): p. 573-583. 2013.

38. About Additive Manufacturing: Powder Bed Fusion. [Online]. Available from: http://www.lboro.ac.uk/research/amrg/about/the7categoriesofadditivemanufacturi ng/powderbedfusion/.

39. Irrinki H., et al., Effects of powder attributes and laser powder bed fusion (L-PBF) process conditions on the densification and mechanical properties of 17-4 PH stainless steel. Jom, 68(3): p. 860-868. 2016.

40. Irrinki H., Harper T., Badwe S., Stitzel J., Gulsoy O., Gupta G. Atre S.V., Effects of powder characteristics and processing conditions on the corrosion performance of 17-4 PH stainless steel fabricated by laser-powder bed fusion. Progress in Additive Manufacturing, 2018.

41. Irrinki, H., et al., Effects of particle characteristics on the microstructure and mechanical properties of 17-4 PH stainless steel fabricated by laser-powder bed fusion. Powder Technology, 331: p. 192-203. 2018.

42. Pasebani, S., et al., Effects of atomizing media and post processing on mechanical properties of 17-4 PH stainless steel manufactured via selective laser melting. Additive Manufacturing, 22: p. 127-137. 2018.

43. Irrinki H., Dilip J., Pasebani S., Atre S.V., Effects of particle characteristics on the microstructure and mechanical properties of 17-4 PH stainless steel fabricated by laser-powder bed fusion,. Powder Technology, 331. 2018.

44. Irrinki H., Nath S.D., Ahlfors M., Gulsoy O., Stitzel J., Atre S.V., Effects of Hot Isostatic Pressing on the Mechanical Properties and Microstructures of 17-4 PH Stainless Steel Fabricated by Laser-Powder Bed Fusion.2018.

45. Jahan S.A., Wu T., Zhang Y., Zhang ., Tovar A., Elmounayri H., Thermomechanical design optimization of conformal cooling channels using design of experiments approach. Procedia Manufacturing, 10: p. 898-911. 2017. 


\section{APPENDICES}

\section{APPENDIX A \\ MATERIAL PROPERTIES FOR INJECTION MOLDED PARTS}

Table A. 1 Physical and mechanical properties for part material used for injection molding trials in Chapter 2

\begin{tabular}{|c|c|}
\hline Material Type & Thermoplastic polypropylene \\
\hline Trade name & Celstran PP GF30-05CN01/10 \\
\hline Melt Temperature $\left({ }^{\circ} \mathbf{C}\right)$ & $190-231$ \\
\hline Mold Temperature $\left({ }^{\circ} \mathbf{C}\right)$ & $32-65$ \\
\hline Freeze Temperature $\left({ }^{\circ} \mathbf{C}\right)$ & 134 \\
\hline
\end{tabular}

Table A. 2 Physical and mechanical properties for part material used for injection molding trials in Chapter 3

\begin{tabular}{|c|c|}
\hline Material Type & High-impact polystyrene \\
\hline Trade name & Styron 478 \\
\hline Melt Temperature $\left({ }^{\circ} \mathbf{C}\right)$ & $193-232$ \\
\hline Tensile modulus $(\mathbf{M P a})$ & 2000 \\
\hline Elongation $(\boldsymbol{\%})$ & 60 \\
\hline
\end{tabular}

(a)

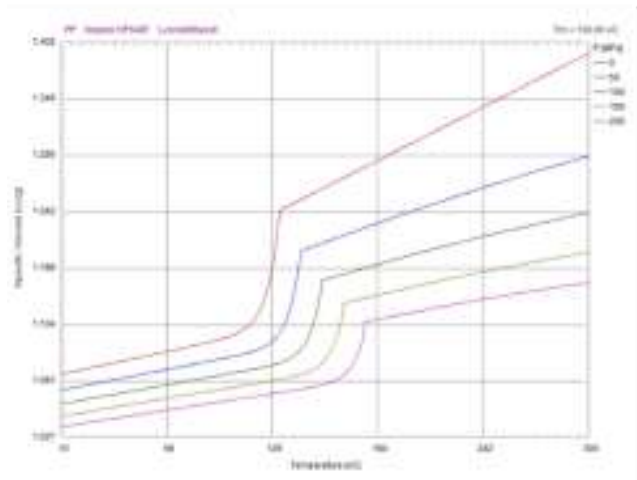

(b)

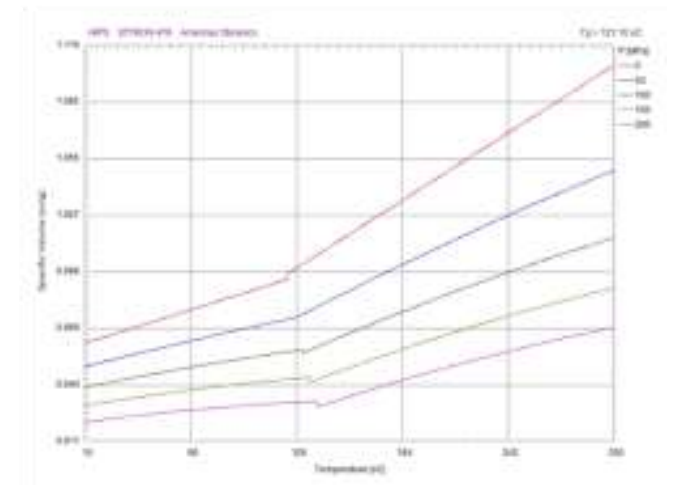

Figure A. 1 (a) PVT graph for thermoplastic polypropylene, (b) PVT graph for highimpact polystyrene 
(a)

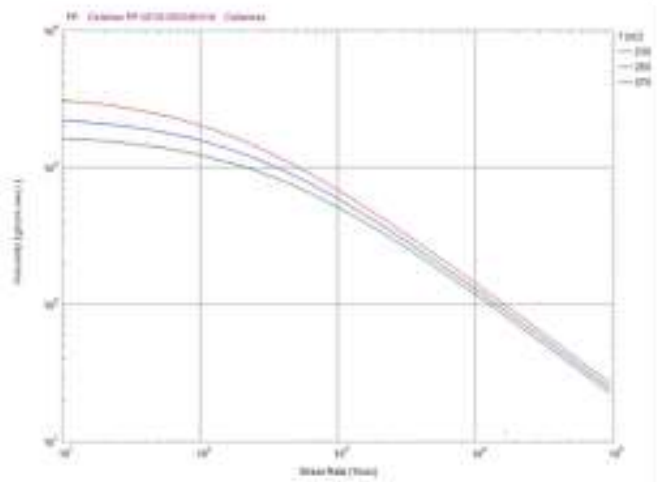

(b)

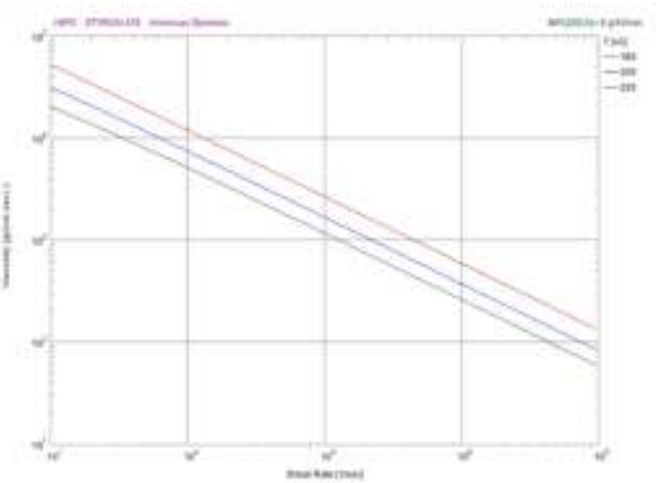

Figure A. 2 (a) Viscosity graph for thermoplastic polystyrene, (b) Viscosity graph for high-impact polystyrene 


\section{APPENDIX B}

EXPERIMENTAL PROCESSING CONDITIONS OF THE INJECTION MOLDED PARTS USING THE L-PBF FABRICATED TOOLING IN CHAPTER 2

Table B. 1 Constant process parameters for all experimental trials

\begin{tabular}{|c|c|c|c|c|}
\hline $\begin{array}{c}\text { Mold } \\
\text { temperature (·C) }\end{array}$ & $\begin{array}{c}\text { Melt temperature } \\
\mathbf{( \cdot C )}\end{array}$ & $\begin{array}{c}\text { Ram position } \\
(\mathbf{m m})\end{array}$ & $\begin{array}{c}\text { Pack time } \\
(\mathbf{s})\end{array}$ & $\begin{array}{c}\text { Fill time } \\
(\mathbf{s})\end{array}$ \\
\hline 50 & 226.66 & 50 & 2 & 0.9 \\
\hline
\end{tabular}

Table B. 2 Processing conditions using the as-printed mold

\begin{tabular}{|c|c|c|}
\hline Run & Injection Pressure (MPa) & Cooling Time (s) \\
\hline 1 & 30 & 12 \\
\hline 2 & 45 & 60 \\
\hline 3 & 45 & 12 \\
\hline 4 & 45 & 60 \\
\hline
\end{tabular}

Table B. 3 Processing conditions using the machined mold with $5 \mathrm{~mm}$ cavity depth

\begin{tabular}{|c|c|c|c|}
\hline Run & $\begin{array}{c}\text { Cooling time } \\
(\mathbf{s})\end{array}$ & $\begin{array}{c}\text { Melt } \\
\text { Temperature (C) }\end{array}$ & $\begin{array}{c}\text { Injection Pressure } \\
(\mathbf{M P a})\end{array}$ \\
\hline 1 & 12 & 226.66 & 30 \\
\hline 2 & 60 & 226.66 & 45 \\
\hline 3 & 12 & 226.66 & 45 \\
\hline 4 & 60 & 226.66 & 30 \\
\hline 5 & 40 & 204.44 & 45 \\
\hline 6 & 40 & 226.66 & 45 \\
\hline 7 & 40 & 204.44 & 30 \\
\hline 8 & 40 & 185 & 30 \\
\hline
\end{tabular}


Table B. 4 Processing conditions using the machined mold with $3 \mathrm{~mm}$ cavity depth

\begin{tabular}{|c|c|c|c|}
\hline Run & $\begin{array}{c}\text { Cooling time } \\
(\mathbf{s})\end{array}$ & $\begin{array}{c}\text { Injection velocity } \\
(\mathbf{m m} / \mathbf{s})\end{array}$ & $\begin{array}{c}\text { Injection pressure } \\
(\mathbf{M P a})\end{array}$ \\
\hline 1 & 15 & 25.4 & 10.34 \\
\hline 2 & 12 & 25.4 & 10.34 \\
\hline 3 & 12 & 25.4 & 13.79 \\
\hline 4 & 12 & 50.8 & 10.34 \\
\hline 5 & 12 & 12.7 & 10.34 \\
\hline 6 & 20 & 12.7 & 10.34 \\
\hline 7 & 40 & 12.7 & 10.34 \\
\hline 8 & 60 & 12.7 & 10.34 \\
\hline
\end{tabular}




\section{APPENDIX C}

DIMENSIONS, WEIGHTAND DENSITY RESULTS OF EXPERIMENTS AND

SIMULATIONS USING THE AS-PRINTED AND MACHINED MOLD FROM

\section{CHAPTER 2}

Table C. 1 Dimensions of the injection molded parts with $5 \mathrm{~mm}$ part thickness, $3 \mathrm{~mm}$ part thickness, and $3 \mathrm{~mm}$ part thickness with blowing agent

\begin{tabular}{|c|c|c|c|}
\hline Molded part & Height $(\mathbf{m m})$ & Length $\mathbf{( m m})$ & Thickness $(\mathbf{m m})$ \\
\hline $5 \mathrm{~mm}$ part thickness & $63.2 \pm 1.0$ & $34.8 \pm 0.1$ & $5.0 \pm 0.1$ \\
\hline $3 \mathrm{~mm}$ part thickness & $63.5 \pm 0.1$ & $34.3 \pm 0.1$ & $3.0 \pm 0.1$ \\
\hline $\begin{array}{c}\text { mm part thickness } \\
\text { with BA }\end{array}$ & $64.0 \pm 0.1$ & $34.5 \pm 0.1$ & $3.0 \pm 0.1$ \\
\hline
\end{tabular}

(a)

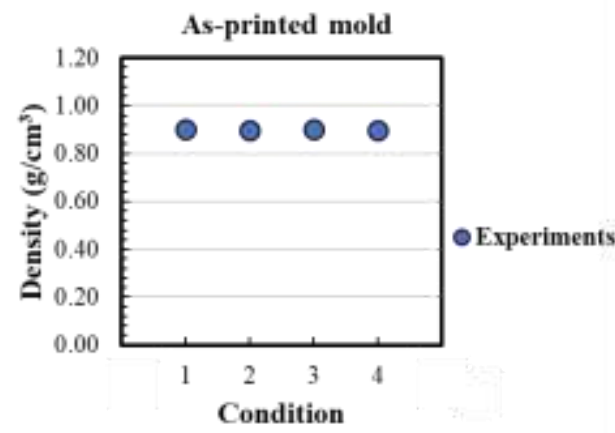

(b)

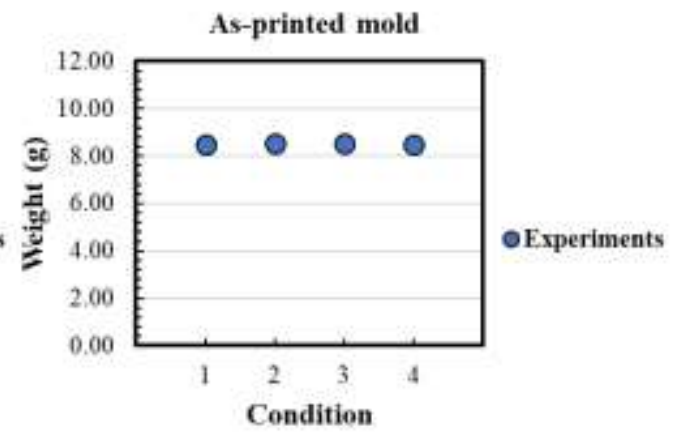

Figure C. 1 (a) Density plot for experimental parts from the as-printed mold, (b) Weight plot for experimental parts from the as-printed mold 
(a)

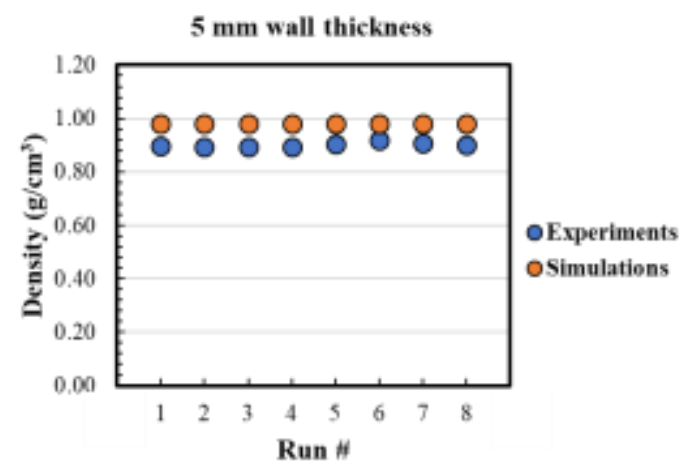

(b)

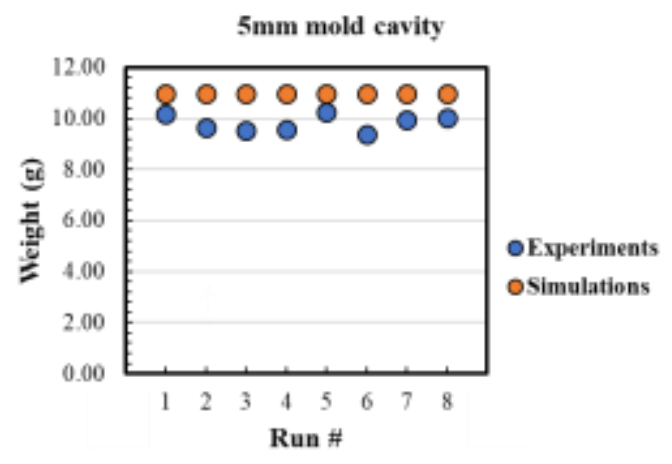

Figure C. 2 (a) Density plot for experimental parts from the machined mold with $5 \mathrm{~mm}$ cavity thickness, (b) Weight plot for experimental parts from the machined mold with 5 mm cavity thickness

(a)

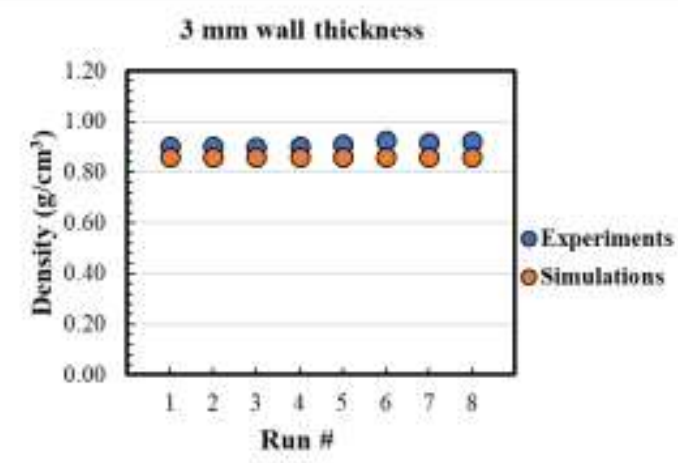

(b)

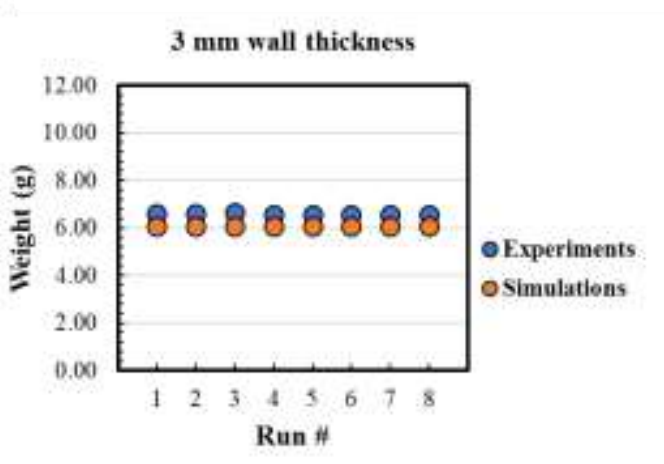

Figure C. 3 (a) Density plot for experimental parts from the machined mold with $3 \mathrm{~mm}$ cavity thickness, (b) Weight plot for experimental parts from the machined mold with 3 mm cavity thickness 
(a)

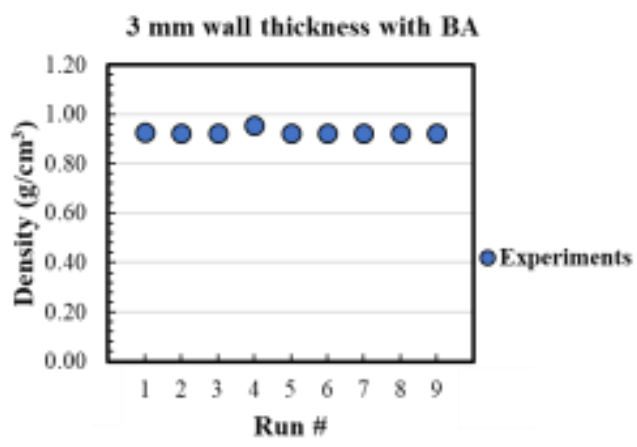

(b)

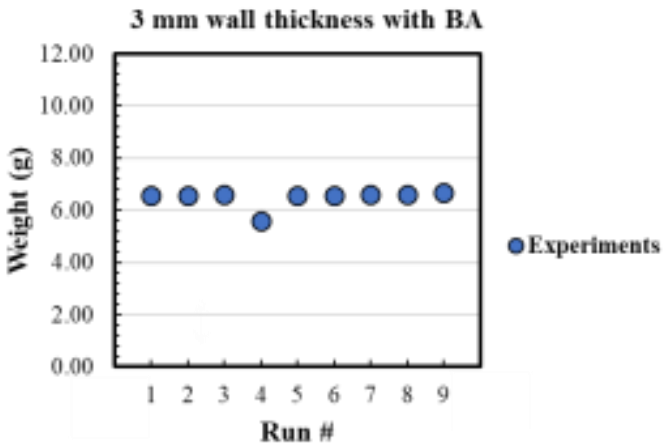

Figure C. 4 (a) Density plot for experimental parts with blowing agents from the machined mold with $3 \mathrm{~mm}$ cavity thickness, (b) Weight plot for experimental parts with blowing agents from the machined mold with $3 \mathrm{~mm}$ cavity thickness 
EXPERIMENTAL AND SIMULATION RESULTS FOR THE PART-DESIGN IN

\section{CHAPTER 2}

(a)

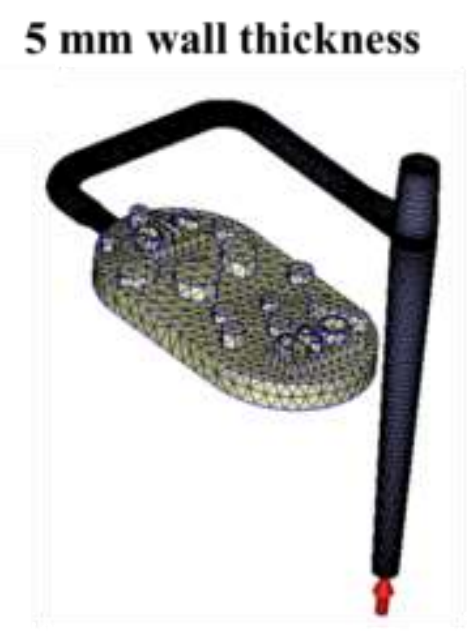

(b)

\section{$3 \mathrm{~mm}$ wall thickness}

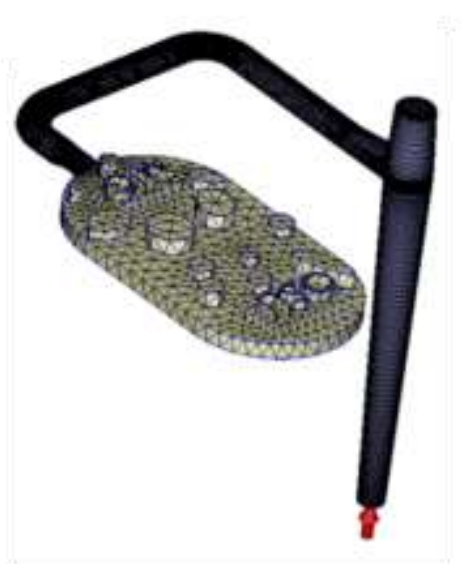

Figure D.1 3D mesh using Moldex3D designer platform for (a) part with $5 \mathrm{~mm}$ wall thickness, (b) part with $3 \mathrm{~mm}$ wall thickness

(a)

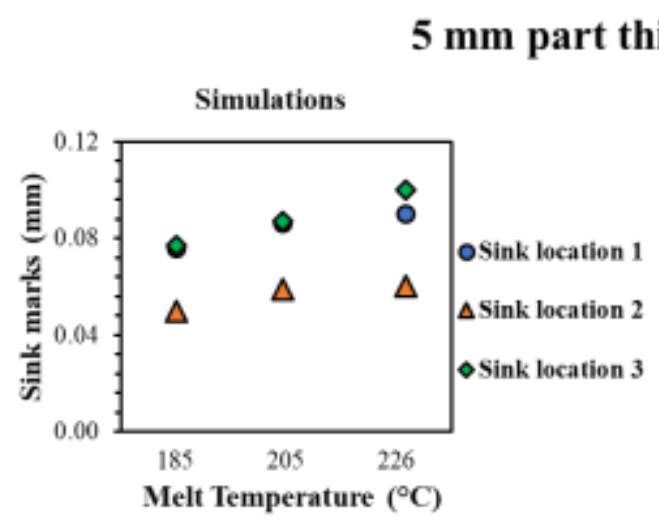

(b)

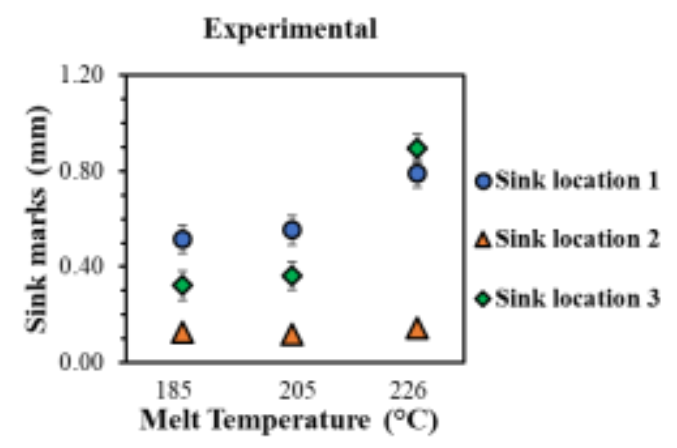

Figure D.2 (a) Simulation plot of sink marks using the $5 \mathrm{~mm}$ mold cavity with Melt Temperatures $\left({ }^{\circ} \mathrm{C}\right): 185,204,226$, (b) Experimental plot of sink marks for the $5 \mathrm{~mm}$ mold cavity with Melt Temperatures $\left({ }^{\circ} \mathrm{C}\right): 185,204,226$ 
(a)

(b)

\section{$3 \mathrm{~mm}$ part thickness}
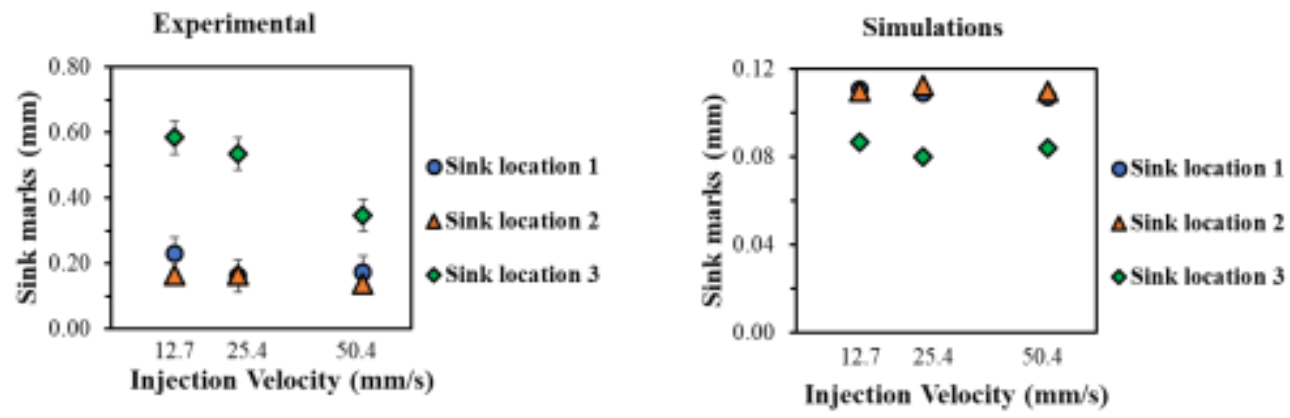

Figure D.3 (a) Simulation plot of sink marks using the $3 \mathrm{~mm}$ mold cavity with Injection Velocity (mm/s): 12.7, 25.4, 50.4, (b) Experimental plot of warpage for the $3 \mathrm{~mm}$ mold cavity with Injection Velocity $(\mathrm{mm} / \mathrm{s}): 12.7,25.4,50.4$

(a)

(b)

\section{$5 \mathrm{~mm}$ part thickness}
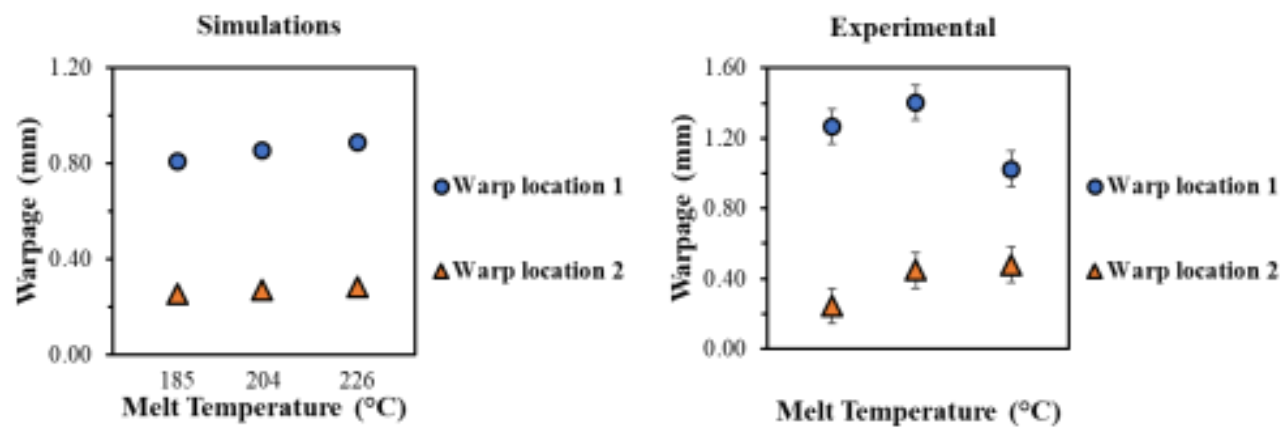

Figure D.4 (a) Simulation plot of warpage using the $5 \mathrm{~mm}$ mold cavity with Melt Temperatures $\left({ }^{\circ} \mathrm{C}\right): 185,204,226$, (b) Experimental plot of warpage for the $5 \mathrm{~mm}$ mold cavity with Melt Temperatures $\left({ }^{\circ} \mathrm{C}\right): 185,204,226$ 
(a)

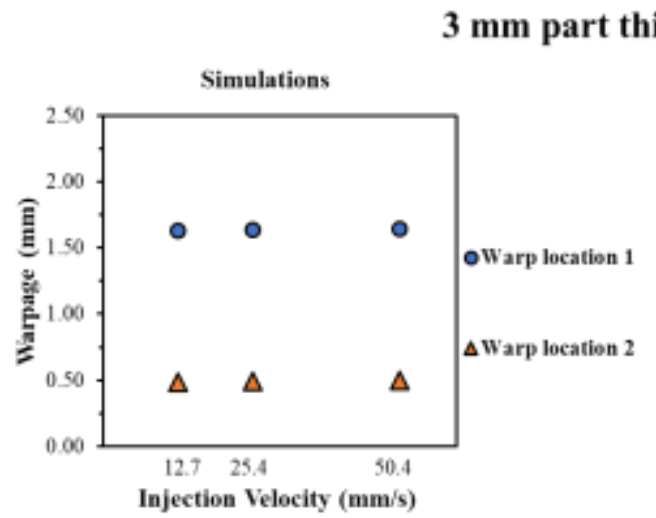

(b)

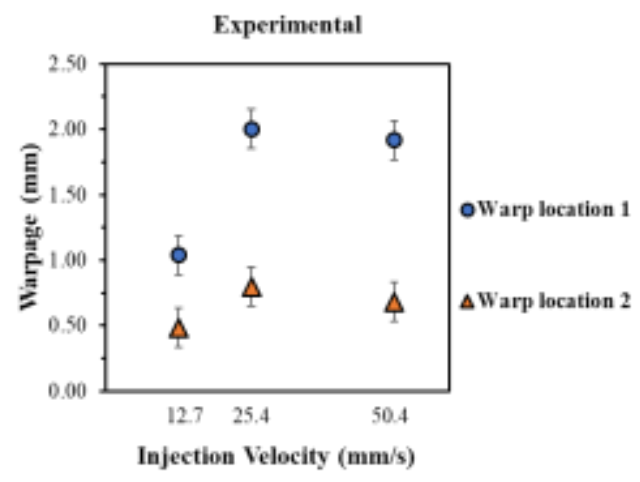

Figure D.5 (a) Simulation plot of warpage using the $3 \mathrm{~mm}$ mold cavity with Injection Velocity (mm/s): 12.7, 25.4, 50.4, (b) Experimental plot of warpage for the $3 \mathrm{~mm}$ mold cavity with Injection Velocity (mm/s): 12.7, 25.4, 50.4
(a) $5 \mathrm{~mm}$ part thickness
(b) $3 \mathrm{~mm}$ part thickness

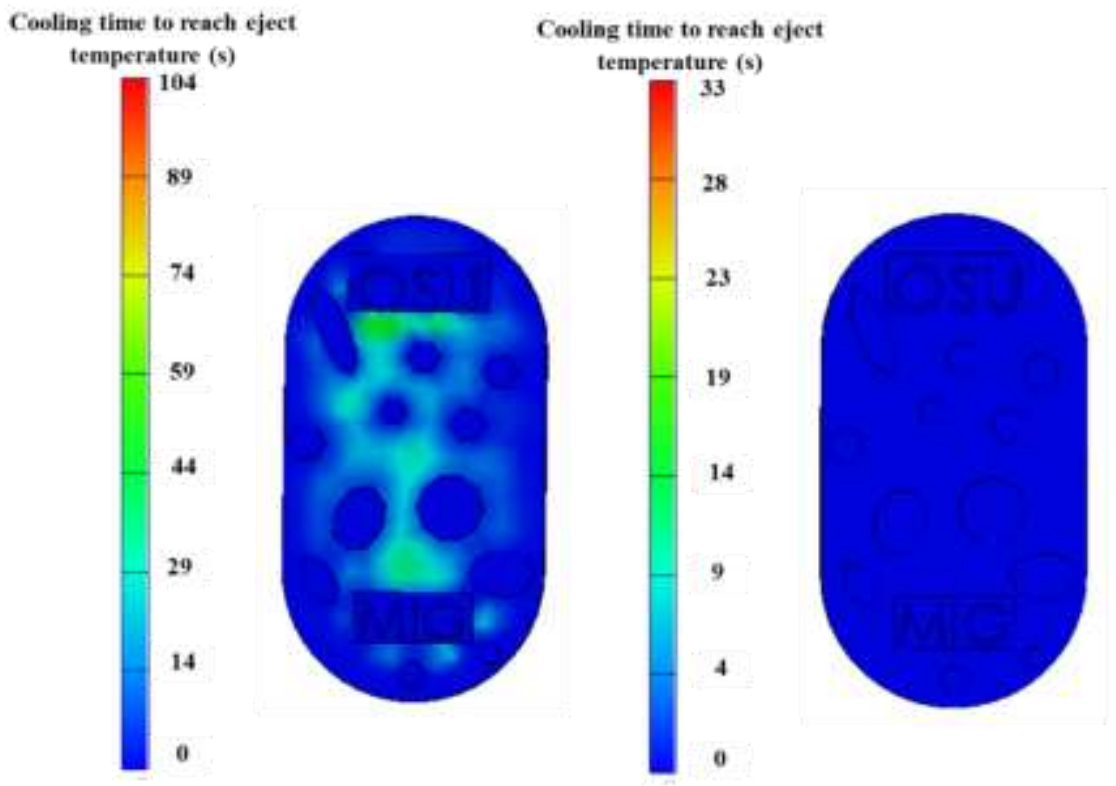

Figure D.6 Mold-filling simulation results for cooling time to reach eject temperature using: (a) mold with $5 \mathrm{~mm}$ cavity depth (front-view), (b) mold with $3 \mathrm{~mm}$ cavity depth (front-view) 

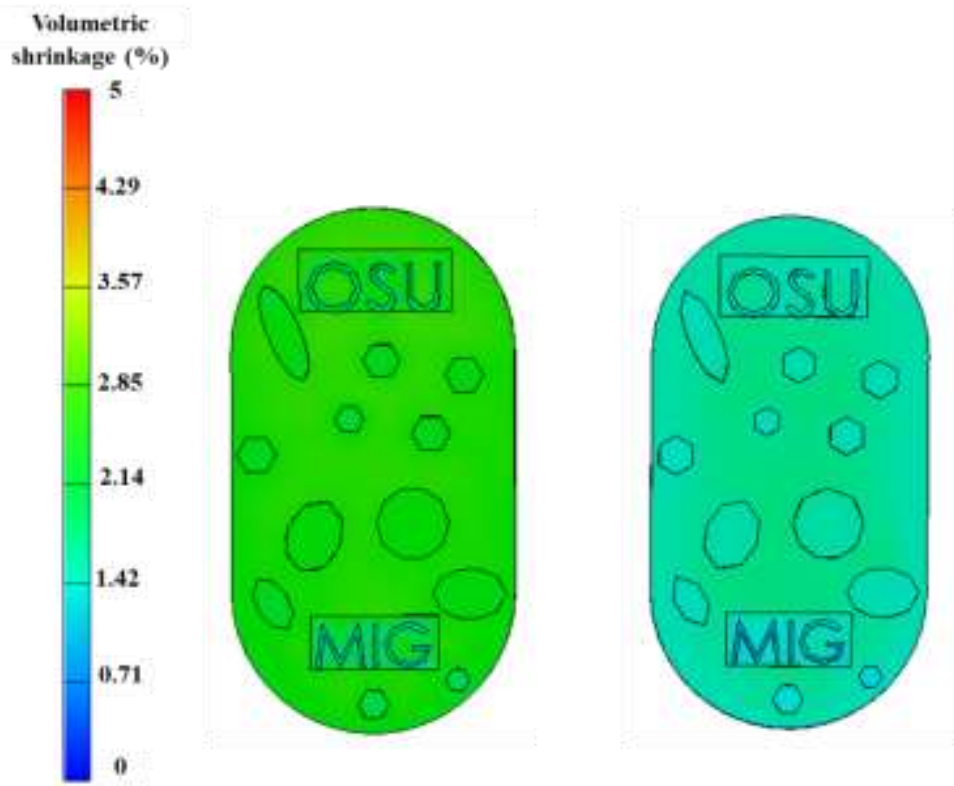

Figure D.7 Mold-filling simulation results for volumetric shrinkage using: (a) mold with $5 \mathrm{~mm}$ cavity depth (front-view), (b) mold with $3 \mathrm{~mm}$ cavity depth (front-view)

(a) $5 \mathrm{~mm}$ part thickness

(b) $3 \mathrm{~mm}$ part thickness
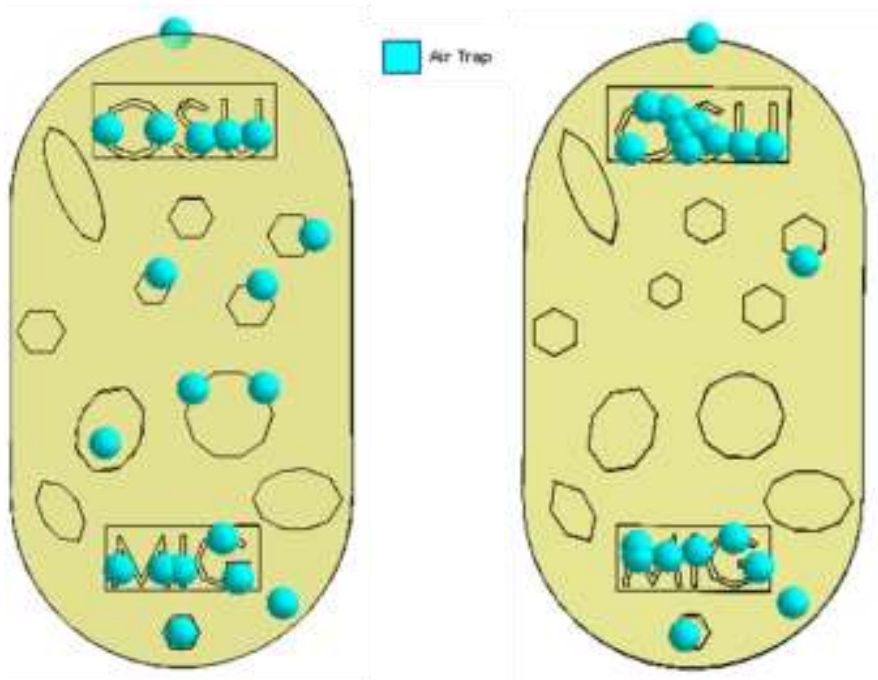

Figure D.8 Mold-filling simulation results for air trap using: (a) mold with $5 \mathrm{~mm}$ cavity depth (front-view), (b) mold with $3 \mathrm{~mm}$ cavity depth (front-view) 
Analysis of Variance for Means

\begin{tabular}{lrrrrrr} 
Source & DF & Seq SS & Adj SS & Adj MS & F & P \\
\hline Blow Agent (wt\%) & 2 & 0.031714 & 0.031714 & 0.015857 & 26.37 & 0.037 \\
Injection Velocity (mm/s) & 2 & 0.000802 & 0.000802 & 0.000401 & 0.67 & 0.600 \\
Pack Pressure (MPa) & 2 & 0.001380 & 0.001380 & 0.000690 & 1.15 & 0.466 \\
Residual Error & 2 & 0.001202 & 0.001202 & 0.000601 & & \\
Total & 8 & 0.035099 & & & &
\end{tabular}

Figure D.9 Analysis of variance for means of sink marks at sink Location 1

\section{Analysis of Variance for Means}

\begin{tabular}{lrrrrrr} 
Source & DF & Seq SS & Adj SS & Adj MS & F & P \\
\hline Blow Agent (wt\%) & 2 & 0.035484 & 0.035484 & 0.017742 & 756.37 & 0.001 \\
Injection Velocity $(\mathrm{mm} / \mathrm{s})$ & 2 & 0.000069 & 0.000069 & 0.000035 & 1.47 & 0.404 \\
Pack Pressure (MPa) & 2 & 0.000017 & 0.000017 & 0.000009 & 0.37 & 0.731 \\
Residual Error & 2 & 0.000047 & 0.000047 & 0.000023 & & \\
Total & 8 & 0.035617 & & & &
\end{tabular}

Figure D.10 Analysis of variance for means of sink marks at sink Location 2

\section{Analysis of Variance for Means}

\begin{tabular}{lrrrrrr} 
Source & DF & Seq SS & Adj SS & Adj MS & F & P \\
\hline Blow Agent (wt\%) & 2 & 0.104689 & 0.104689 & 0.052344 & 220.83 & 0.005 \\
Injection Velocity (mm/s) & 2 & 0.000119 & 0.000119 & 0.000059 & 0.25 & 0.800 \\
Pack Pressure (MPa) & 2 & 0.001119 & 0.001119 & 0.000559 & 2.36 & 0.298 \\
Residual Error & 2 & 0.000474 & 0.000474 & 0.000237 & & \\
Total & 8 & 0.106400 & & & &
\end{tabular}

Figure D.11 Analysis of variance for means of sink marks at sink Location 3 


\section{APPENDIX E}

EXPERIMENTAL PROCESSING CONDITIONS OF THE INJECTION MOLDED PARTS USING THE L-PBF FABRICATED TOOLING IN CHAPTER 3

Table E. 1 Constant process parameters for all experimental trials

\begin{tabular}{|c|c|}
\hline Processing parameters & Description \\
\hline Part material & HIP Polystyrene \\
\hline Mold material & $17-4$ PH stainless steel \\
\hline Water circulating Q $\left(\mathrm{cm}^{3} / \mathrm{sec}\right)$ & 139 \\
\hline Water temperature $\left({ }^{\circ} \mathrm{C}\right)$ & 40 \\
\hline Mold temperature $\left({ }^{\circ} \mathrm{C}\right)$ & 60 \\
\hline Melt temperature $\left({ }^{\circ} \mathrm{C}\right)$ & 204 \\
\hline VP switchover $(\mathrm{mm})$ & 10.16 \\
\hline Injection pressure $(\mathrm{MPa})$ & 118 \\
\hline Injection volume $\left(\mathrm{cm}^{3}\right)$ & 24 \\
\hline Pack pressure $(\%)$ & 30 \\
\hline Fill time $(\mathrm{s})$ & 0.65 \\
\hline Eject temperature & 105 \\
\hline Injection velocity $(\mathrm{mm} / \mathrm{s})$ & 25.4 \\
\hline Mold open time $(\mathrm{s})$ & 5 \\
\hline
\end{tabular}

Table E. 2 Processing conditions using the machined mold with conformal cooling channels at $4 \mathrm{~mm}$ from the mold cavity

\begin{tabular}{|c|c|c|}
\hline Run & Pack time (s) & Cooling time (s) \\
\hline 1 & 2 & 10 \\
\hline 2 & 2 & 25 \\
\hline 3 & 3 & 10 \\
\hline
\end{tabular}

Table E. 3 Processing conditions using the machined mold with conformal cooling channels at $8 \mathrm{~mm}$ from the mold cavity and no conformal cooling channels

\begin{tabular}{|c|c|c|c|}
\hline Run & Pack time (s) & Cooling time (s) & BA (wt. \%) \\
\hline 1 & 2 & 10 & 0 \\
\hline 2 & 2 & 25 & 0 \\
\hline 3 & 2 & 25 & 1 \\
\hline 4 & 3 & 10 & 0 \\
\hline
\end{tabular}




\section{APPENDIX F}

\section{COMPUTER-AIDED SIMULATION SETUP FOR PART-DESIGN IN CHAPTER 3}

(a)

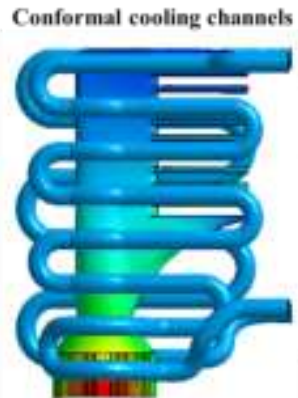

(b)

Conformal cooling channels $8 \mathrm{~mm}$ from mold cavity

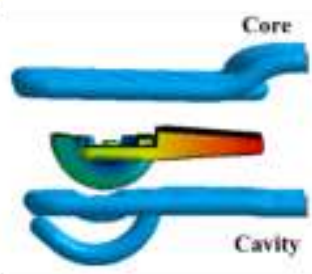

(c)

Conformal coeling channels $4 \mathrm{~mm}$ from mold eavity

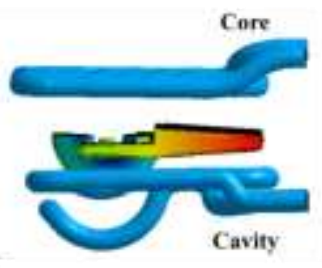

(d)

No cooling channels

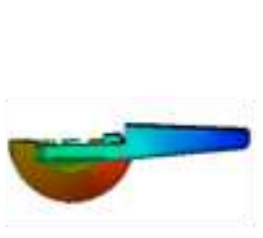

Figure F.1 (a) Simulation setup of part design, (b) Simulation of part design with conformal cooling channels at $8 \mathrm{~mm}$ depth, (c) Simulation part design with conformal cooling channels at $4 \mathrm{~mm}$ depth, (d) Simulation part design with none

(a)

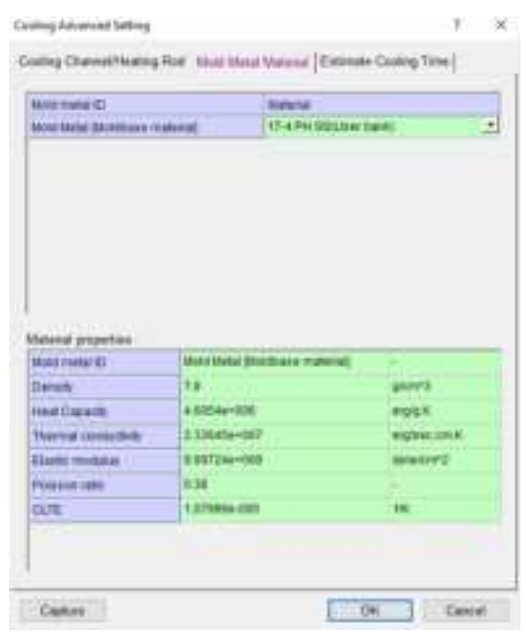

(b)

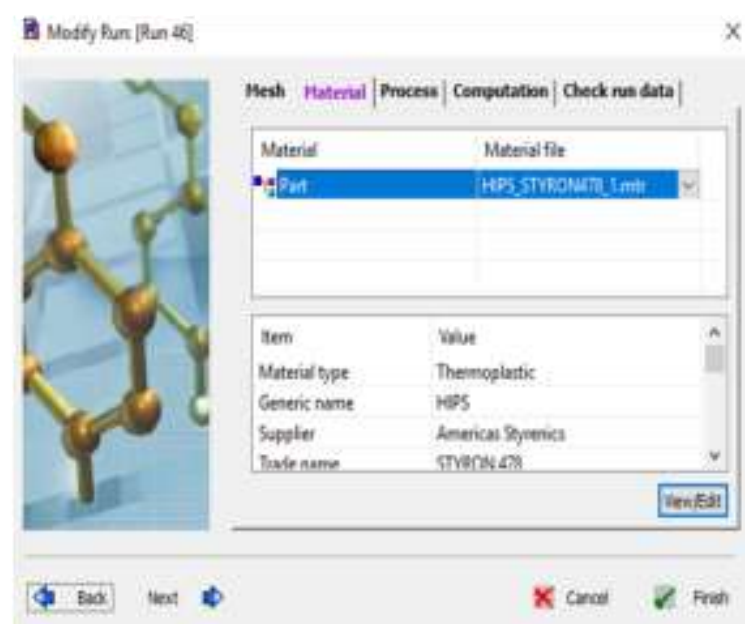

Figure F.2 (a) Simulation process interface setup for mold material, (b) Simulation process interface setup for molded part material 
(a)

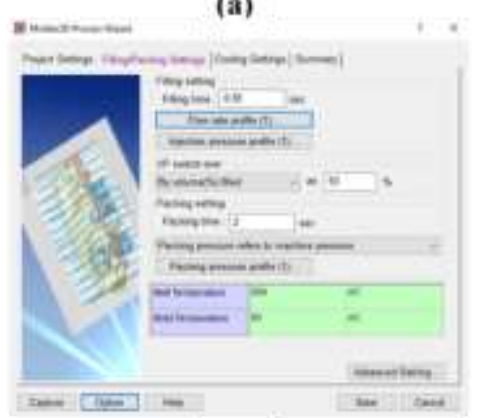

(c)

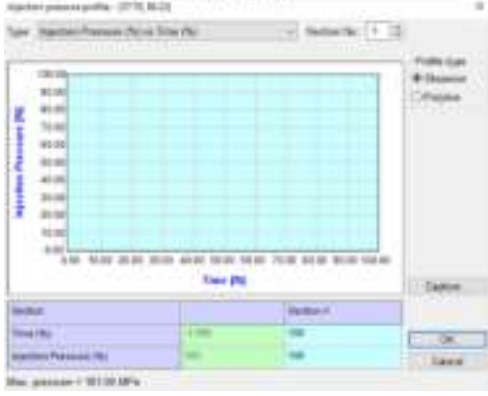

(b)

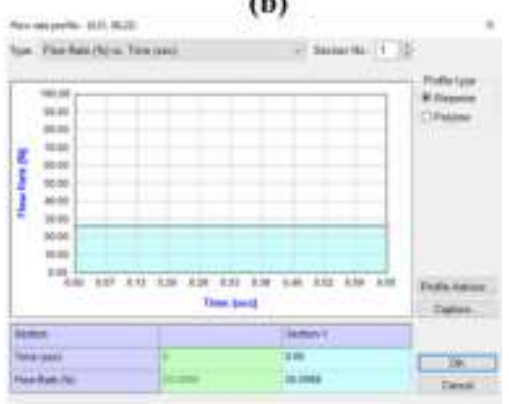

(d)

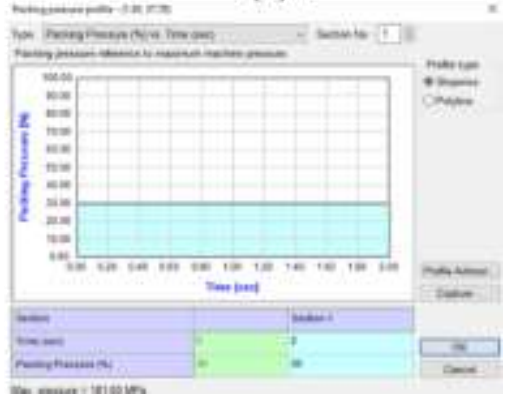

Figure F.3 (a) Simulation process interface setup for filling/packing settings, (b) Simulation process interface setup for flow rate profile, (c) Simulation process interface setup for injection pressure, (d) Simulation process interface setup for packing pressure

(a)

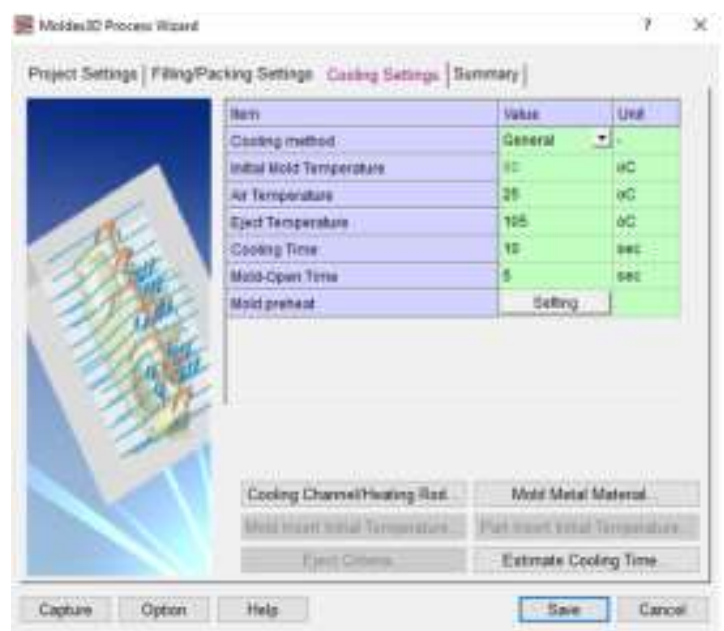

(b)

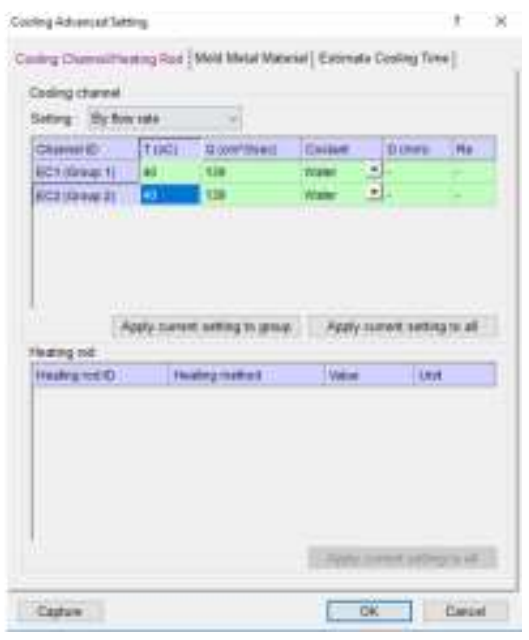

Figure F.4 (a) Simulation process interface setup for cooling settings, (b) Simulation process interface setup for conformal cooling channels 
APPENDIX G

DIMENSIONS, WEIGHTAND DENSITY RESULTS OF THE L-PBF FABRICATED

MOLDS, EXPERIMENTS AND SIMULATIONS USING THE PART DESIGN FROM

CHAPTER 3

Table G. 1 As-printed and machined mold density and dimensions for the core-side, cavity-side 1 and cavity-side 2 molds

\begin{tabular}{|c|c|c|c|c|c|c|c|}
\hline Measurements & $\begin{array}{c}\text { As- } \\
\text { designed }\end{array}$ & \multicolumn{3}{|c|}{ As-printed } & \multicolumn{4}{c|}{ Machined } \\
\hline & all & Core & $\begin{array}{c}\text { Cavity } \\
\mathbf{1}\end{array}$ & $\begin{array}{c}\text { Cavity } \\
\mathbf{2}\end{array}$ & Core & $\begin{array}{c}\text { Cavity } \\
\mathbf{1}\end{array}$ & $\begin{array}{c}\text { Cavity } \\
\mathbf{2}\end{array}$ \\
\hline Length (mm) & 82 & 81.7 & 81.8 & 81.8 & 80.9 & 80.9 & 80.9 \\
\hline Width (mm) & 62 & 61.8 & 61.8 & 61.8 & 61.4 & 61.45 & 61.45 \\
\hline Height (mm) & 27 & 27.1 & 27.1 & 27.1 & 25.7 & 25.7 & 25.6 \\
\hline $\begin{array}{c}\text { Hole diameter } \\
(\mathbf{m m})\end{array}$ & \multicolumn{7}{|c|}{4} \\
\hline Weight (g) & - & 1010 & 951 & 955 & 920 & 885 & 882 \\
\hline Volume (cm $\mathbf{( m )}$ & - & 132.9 & 125.1 & 125.2 & - & - & - \\
\hline Density (g/ cm $\left.\mathbf{c m}^{\mathbf{3}}\right)$ & - & 7.6 & 7.6 & 7.6 & - & - & - \\
\hline
\end{tabular}

*Cavity 1: conformal cooling channels $8 \mathrm{~mm}$ from mold cavity, Cavity 2: conformal cooling channels $4 \mathrm{~mm}$ from mold cavity

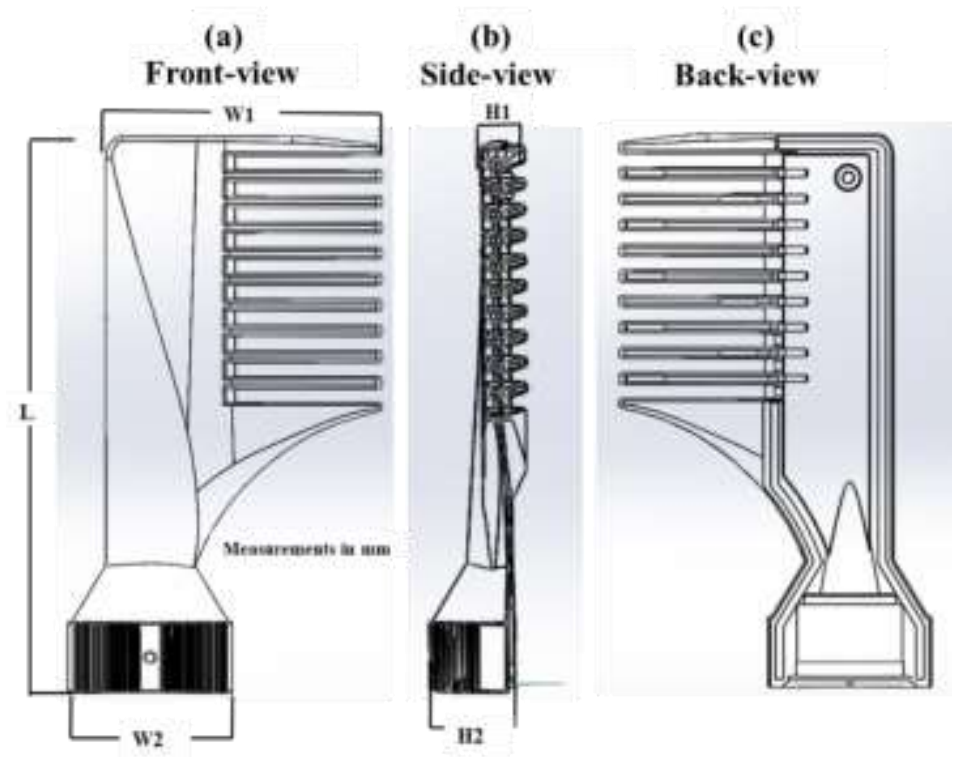

Figure G.1 Part design for the L-PBF fabricated cavity-side and core-side molds in Chapter 3 (a) Front-view, (b) Side-view, (c) Back view 
Table G. 2 Dimensions of the injection molded parts from using the cavity side mold with no conformal cooling channels, conformal cooling channels at $8 \mathrm{~mm}$ depth and conformal cooling channels at $4 \mathrm{~mm}$ depth

\begin{tabular}{|c|c|c|c|c|c|}
\hline DIMENSIONS & L & W1 & W2 & H1 & H2 \\
\hline $\begin{array}{c}\text { No conformal } \\
\text { cooling channels }\end{array}$ & $70.6 \pm 0.2$ & $35.2 \pm 0.1$ & $20.5 \pm 0.1$ & $5.2 \pm 0.1$ & $10.3 \pm 0.1$ \\
\hline $\begin{array}{c}\text { Cavity side mold } \\
\text { with conformal } \\
\text { cooling channels } \\
\text { at 8 mm depth }\end{array}$ & $70.6 \pm 0.2$ & 35.3 & $20.4 \pm 0.1$ & $5.3 \pm 0.1$ & $10.2 \pm 0.1$ \\
\hline $\begin{array}{c}\text { Cavity side mold } \\
\text { with conformal } \\
\text { cooling channels } \\
\text { at } 4 \text { mm depth }\end{array}$ & $70.7 \pm 0.2$ & $35.3 \pm 0.1$ & $20.6 \pm 0.1$ & $5.2 \pm 0.1$ & $10.3 \pm 0.1$ \\
\hline
\end{tabular}

(a)

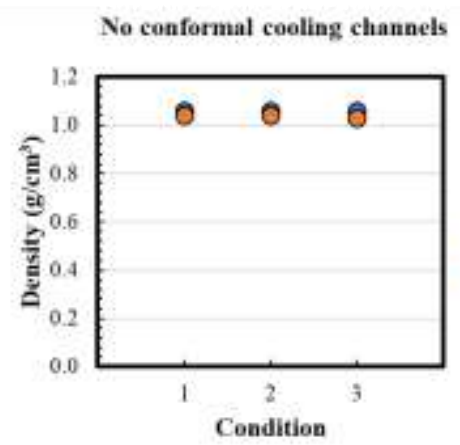

(b)

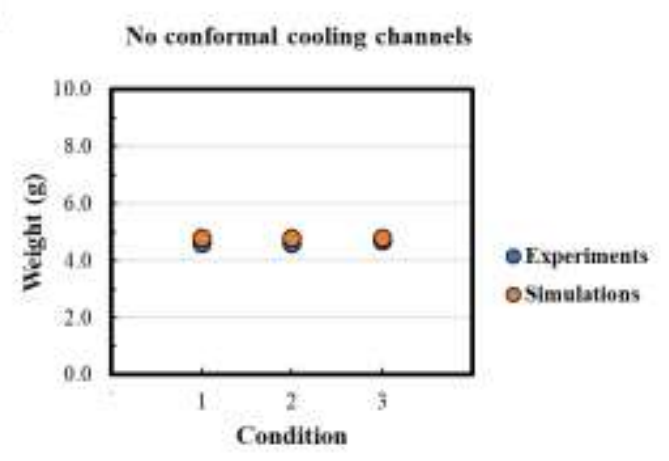

Figure G.2 (a) Density plot for experimental parts from the machined mold with no conformal cooling channels, (b) Weight plot for experimental parts from the machined mold with no conformal cooling channels 
(a)

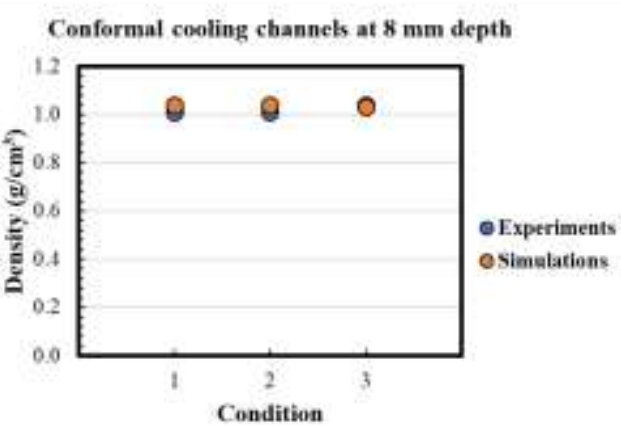

(b)

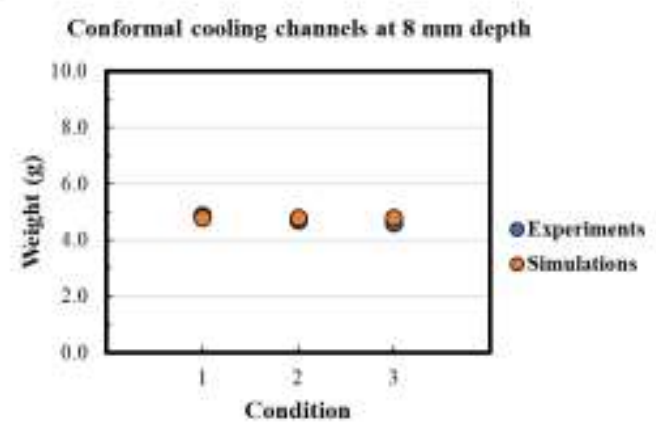

Figure G.3 (a) Density plot for experimental parts from the machined mold with conformal cooling channels at $8 \mathrm{~mm}$ depth, (b) Weight plot for experimental parts from the machined mold with conformal cooling channels at $8 \mathrm{~mm}$ depth

(a)

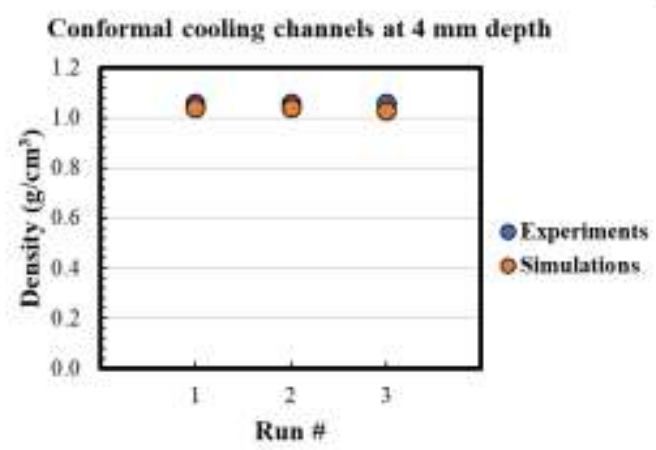

(b)

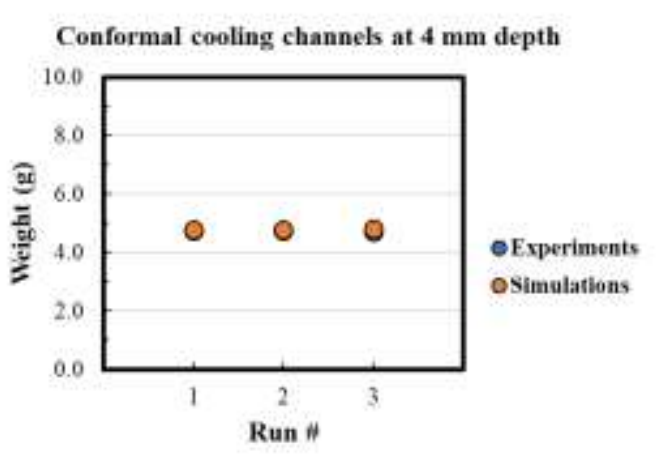

Figure G.4 (a) Density plot for experimental parts from the machined mold with conformal cooling channels at $4 \mathrm{~mm}$ depth, (b) Weight plot for experimental parts from the machined mold with conformal cooling channels at $4 \mathrm{~mm}$ depth 
EXPERIMENT AND SIMULATION RESULTS OF THE PART-DESIGN IN

\section{CHAPTER 3}

(a)

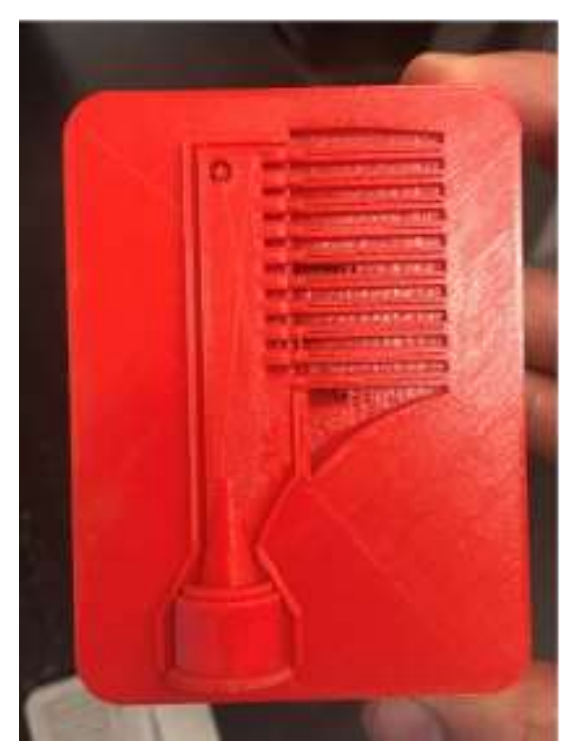

(b)

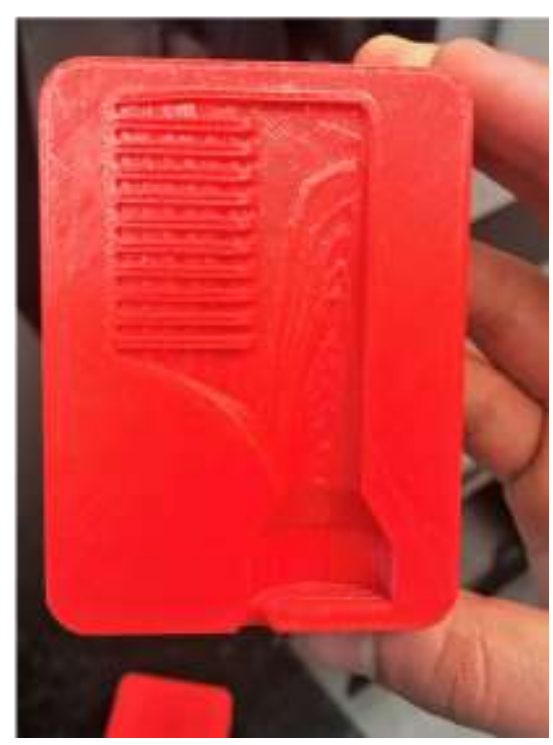

Figure H. 1 (a) 3D Printed core-side mold, (b) 3D Printed cavity-side mold

(a)

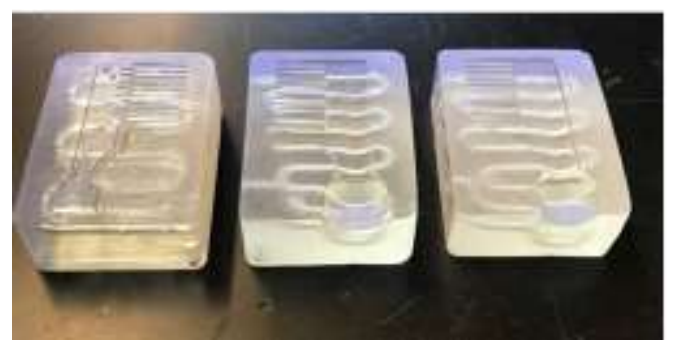

(b)

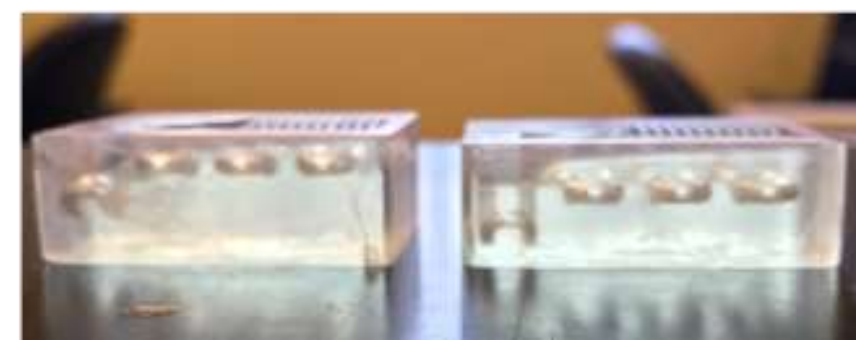

Figure H. 2 (a) 3D Printed molds for design evaluation, (b) 3D Printed molds with conformal cooling channels at $8 \mathrm{~mm}$ depth and $4 \mathrm{~mm}$ depth 
(a)

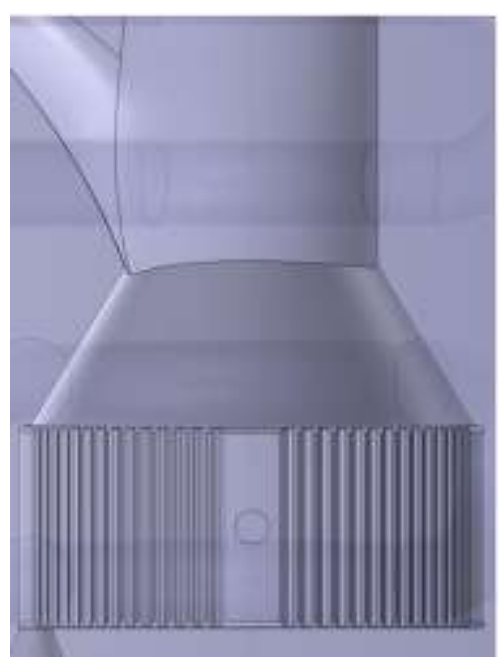

(b)

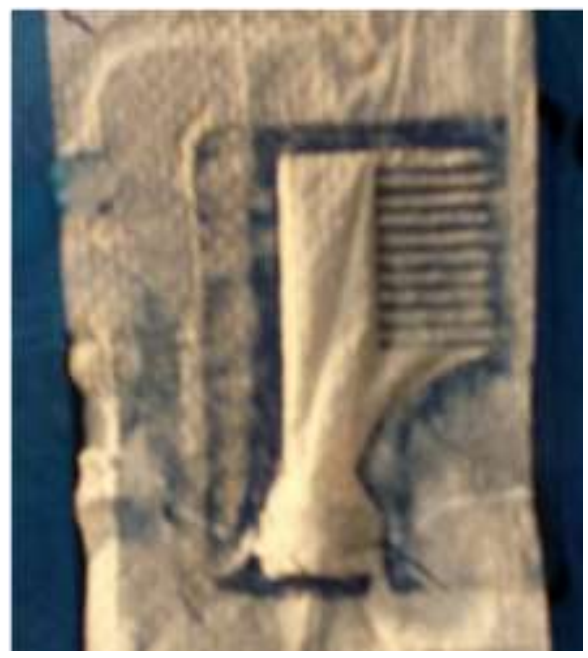

Figure H. 3 (a) Die-lock condition, (b) Cavity and core interface testing

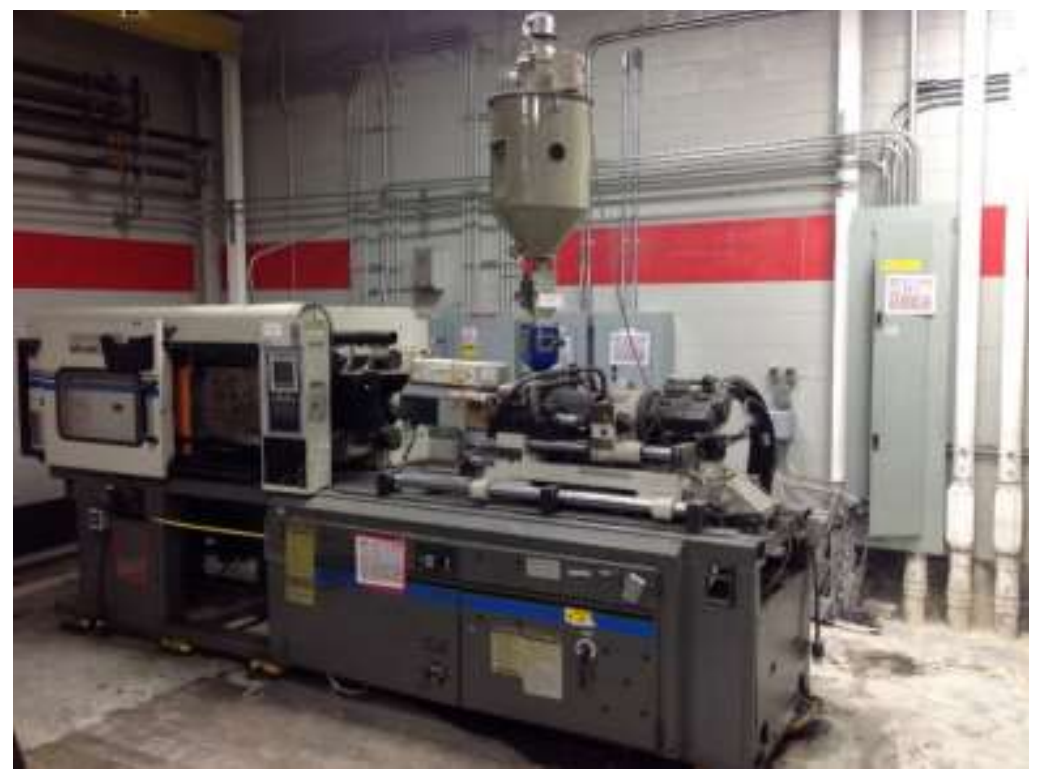

Figure H. 4 Injection molding press for experimental trials: Cincinnati Milacron (CML) VT-110 
(a)

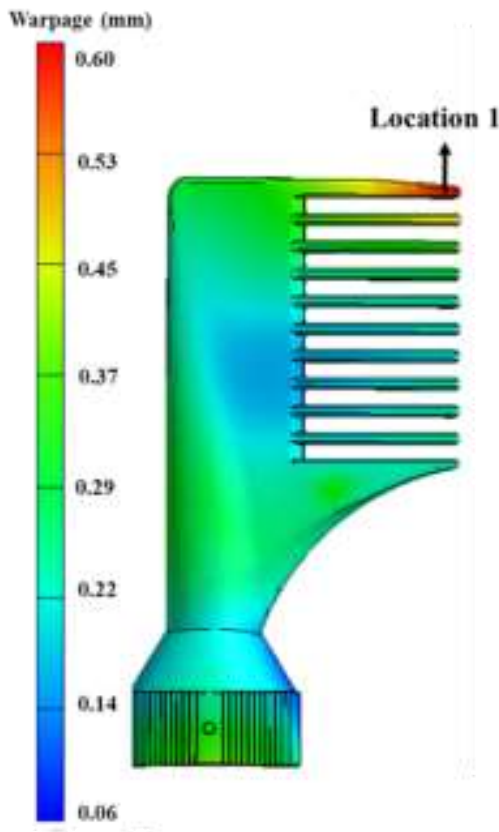

(b)

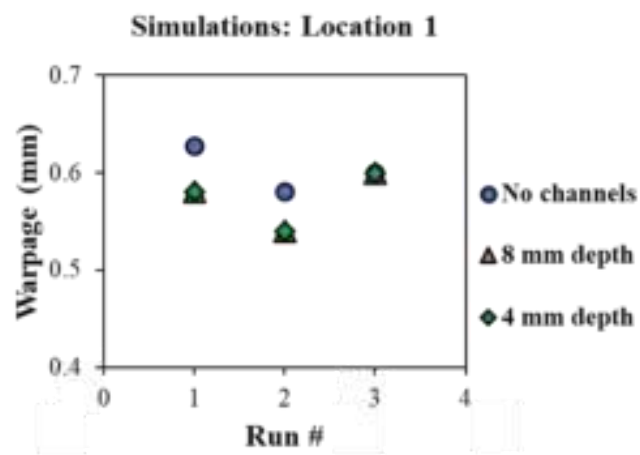

Figure H. 5 (a) Simulation part design with warpage defects (b) Simulation plot with warpage defects for all 3 runs with no conformal cooling channels, conformal cooling channels at $8 \mathrm{~mm}$ depth and conformal cooling channels at $4 \mathrm{~mm}$ depth

(a)

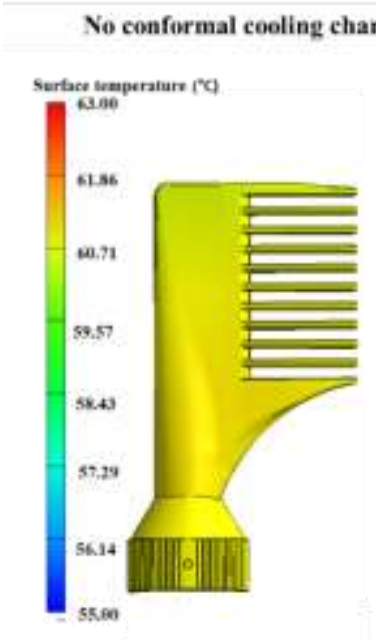

(b)

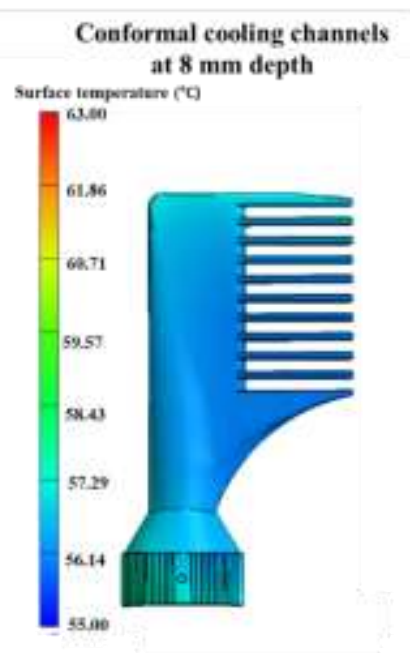

(c)

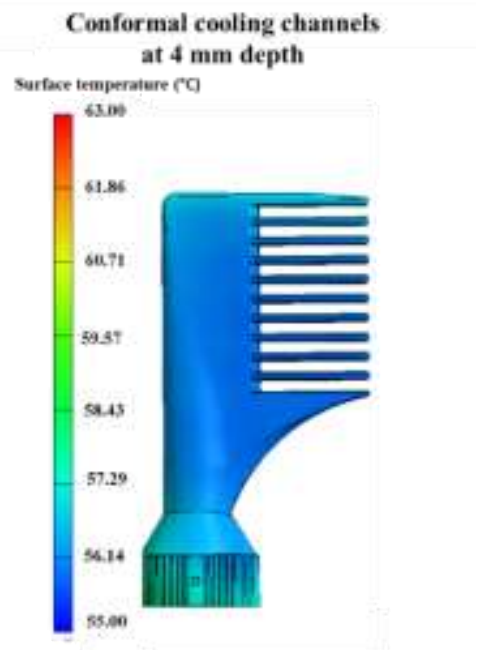

Figure H. 6 Simulations with surface temperature results at run 1 using (a) No conformal cooling channels, (b) Conformal cooling channels at $8 \mathrm{~mm}$ from the mold cavity, (c) Conformal cooling channels at $4 \mathrm{~mm}$ from the mold cavity 
(a)

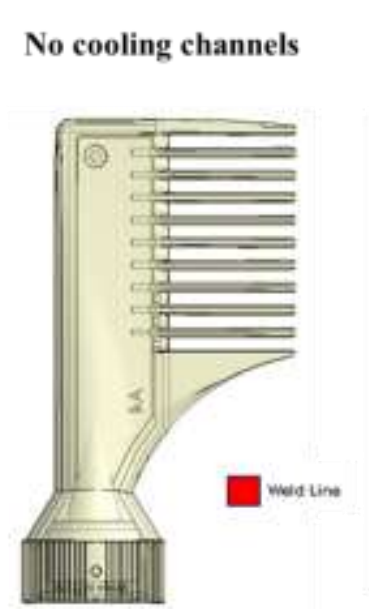

(b)

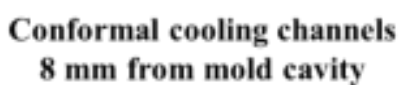

$8 \mathrm{~mm}$ from mold cavity

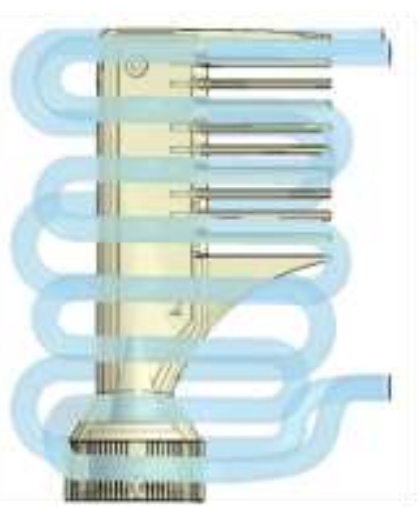

(c)

Conformal cooling channels $4 \mathrm{~mm}$ from mold cavity

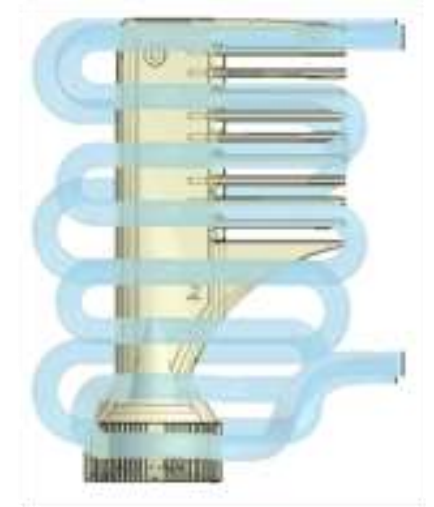

Figure H. 7 Simulations with surface temperature results at run 1 using (a) No conformal cooling channels, (b) Conformal cooling channels at $8 \mathrm{~mm}$ from the mold cavity, (c) Conformal cooling channels at $4 \mathrm{~mm}$ from the mold cavity

(a)

No conformal cooling channels

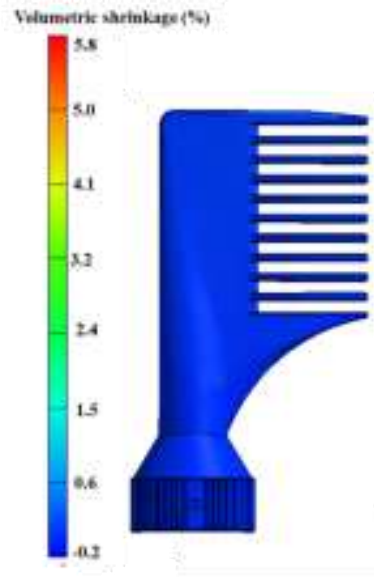

(b)

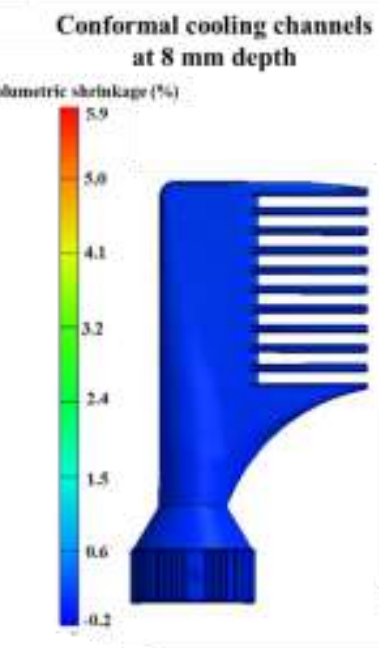

(c)

Conformal cooling cbannels at $4 \mathrm{~mm}$ depth

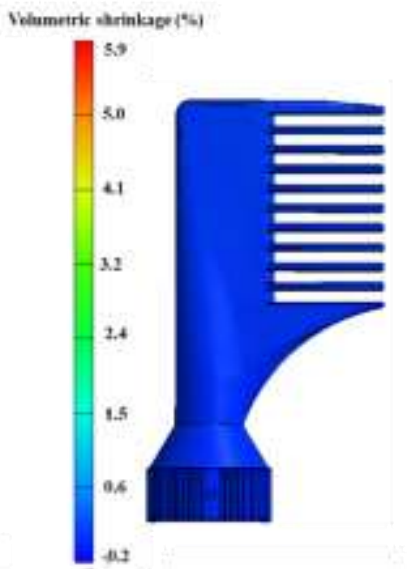

Figure H. 8 Simulations with packing volumetric shrinkage results at run 1 using (a) No conformal cooling channels, (b) Conformal cooling channels at $8 \mathrm{~mm}$ from the mold cavity, (c) Conformal cooling channels at $4 \mathrm{~mm}$ from the mold cavity 
(a)

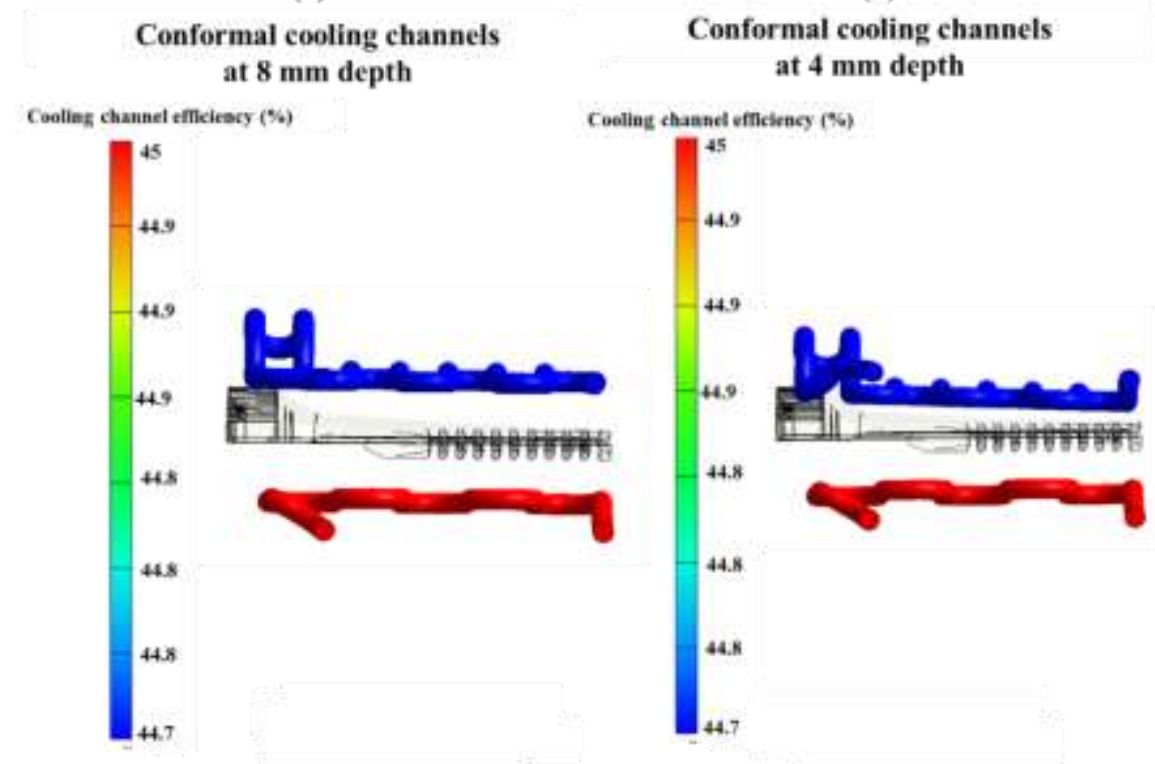

Figure H. 9 Simulations with cooling channel efficiency results at run 1 using (a) Conformal cooling channels at $8 \mathrm{~mm}$ from the mold cavity, (b) Conformal cooling channels at $4 \mathrm{~mm}$ from the mold cavity

(a)

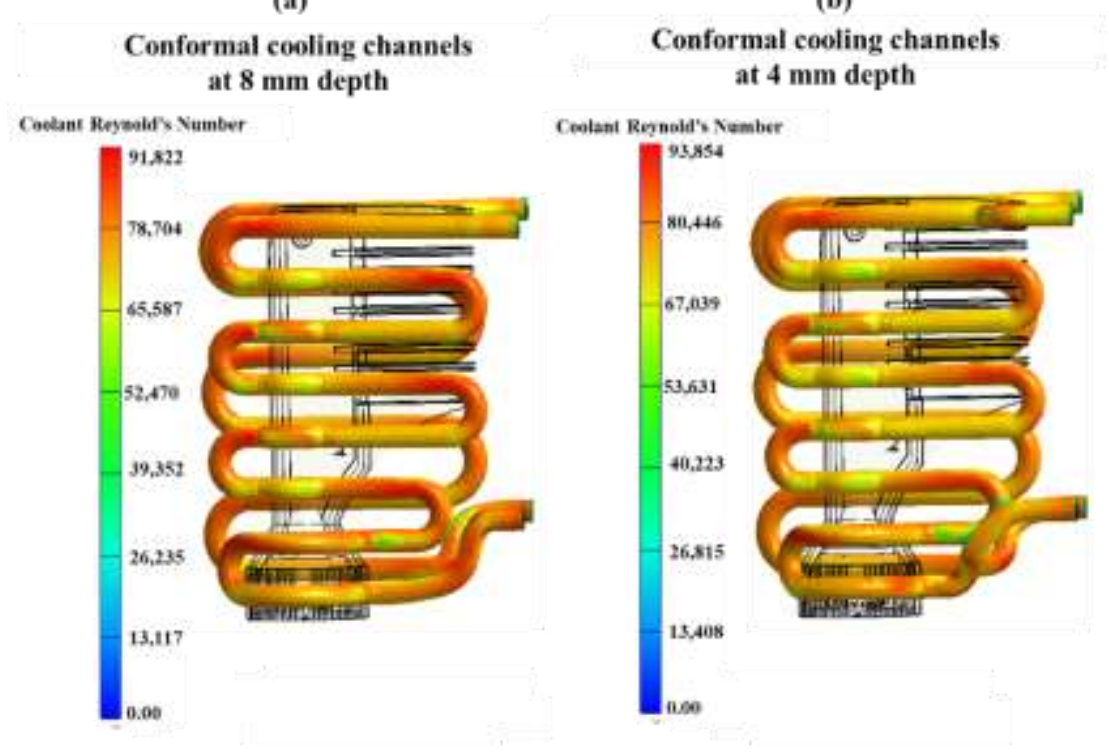

Figure H. 10 Simulations with coolant Reynolds number results at run 1 using (a) Conformal cooling channels at $8 \mathrm{~mm}$ from the mold cavity, (b) Conformal cooling channels at $4 \mathrm{~mm}$ from the mold cavity 


\title{
CURRICULUM VITAE
}

\author{
Mohith Buxani \\ 2501 S. $4^{\text {th }}$ st. The Arch Apartments apt. 8304-B Louisville, KY 40208 \\ Phone:(502)295-9275; email: mohithbuxani1 @gmail.com
}

\section{SUMMARY}

- Industrial engineer specializing in supply chain and lean manufacturing with comprehensive knowledge and experience in tooling applications and molding simulations.

- Highly motivated and driven nature for continuous improvement.

\section{SKILLS}

- Moldex3D molding simulation

- AutoCAD

- Solidworks

- $\quad$ LINGO

- Simio

- MS Office

- VBA 
- Minitab

\section{EDUCATION}

M. Eng. Industrial Engineering

3.5/4.0 August 2013-May 2018

University of Louisville, Louisville, KY

B.S. Industrial Engineering

3.7/4.0 January 2018-May 2018

University of Louisville, Louisville, KY

\section{RESEARCH EXPERIENCE}

\section{Fabrication \& Evaluation of a Plastic Injection Mold with Conformal Cooling}

Channels

Dec 2017-Jul 2018

Project Lead

Louisville, KY

- Evaluated the effect of conformal cooling channels and its distance from the mold cavity using L-PBF fabricated molds, with the purpose of decreasing cycle time and improving part quality.

- Utilized Moldex 3D Software to run simulations and compare results to injection molding trials.

- Presented at the MIM2018 Conference (International Conference on Injection Molding of Metals, Ceramics and Carbides 
- Worked on the evaluation of a 3D-printed mold, with the purpose of decreasing lead time.

- Utilized Moldex 3D Software to run simulations and compare part quality to injection molding trials following a design of experiments.

- Presented at the MIM2017 Conference (International Conference on Injection Molding of Metals, Ceramics and Carbides, and POWDERMET2017.

\section{PROFESSIONAL EXPERIENCE}

\section{UPS Supply Chain Solutions}

\section{Louisville, KY}

IE Co-op

Jan. 04, 2016-May 06,2016

- Evaluated cost-saving ideas for different areas of the warehouse, focusing on inbound and outbound.

- Built Work-Measurement Tools (WMT) for the processes in the warehouse.

- Assisted in a project involving the incorporations of a new type of box.

- Involved in various projects concerning productivity of the conveyors, MHE in the warehouse, issues backtracking the boxes. 


\section{Arvato, Bertelsmann}

\section{Louisville, KY}

IE Intern

May 08, 2017-August 15,2017

- Built Work Measurement Tools for various processes to update the MAR and evaluate cost-saving ideas.

- Assisted on building a staffing tool by identifying volume trends to optimize warehouse staffing.

- Examined alternative processes for the removal of an unused conveyor by evaluating financial profit and time reduction.

- Played a role in various projects concerning productivity tracking, demand forecasting, and Material-Handling Equipment, and employee overtime.

\section{Nucleus LaunchIt Entrepreneur Training Program}

Louisville, KY

Startup Member

April 20 ${ }^{\text {th }}, 2017$

- Worked with team members to discuss innovative ideas and evaluate them through the program.

- Acquired business and marking strategies that are commonly used in the industries.

- Networked with various people of the program and shared ideas and opinions. 
- English: fluent writing \& speaking.

- Spanish: fluent writing \& speaking.

- Hindi: fluent speaking.

ACTIVITIES \& AWARDS

- Six Sigma Green Belt Certified

- Received "Dean's Academic Honor List"

- Received Speed School Outstanding Academic Achievement award for 3.5-3.74 GPA

- Founding President of the American Society of Engineers of Indian Origin UofL Chapter (Jan 2016-May 2017) holding 20 active members

- Received 2016 Undergraduate Scholarship Award by ASEI

- Sigma Beta Rho Fraternity, Inc., Vice President \& Fundraising Chair (June 2015-present) 